Comparação de métodos de estimação em pequenas áreas para proporções: o caso da TIC Educação

\author{
IsABela Bertolini COELho
}

\author{
DISSERTAÇÃO APRESENTADA \\ $\mathrm{AO}$ \\ Instituto de Matemática e Estatística \\ DA \\ Universidade DE SÃo PAUlo \\ PARA \\ OBTENÇÃO DO TÍTULO \\ $\mathrm{DE}$ \\ Mestre EM CiÊNCIAS \\ Programa: Estatística \\ Orientadora: Prof ${ }^{\mathrm{a}}$. Dr ${ }^{\mathrm{a}}$. Lúcia Pereira Barroso
}

São Paulo, abril de 2016 



\section{Comparação de métodos de estimação em pequenas áreas para proporções: o caso da TIC Educação}

Esta versão da dissertação contém as correções e alterações sugeridas pela Comissão Julgadora durante a defesa da versão original do trabalho, realizada em 28/04/2016. Uma cópia da versão original está disponível no Instituto de Matemática e Estatística da Universidade de São Paulo.

Comissão Julgadora:

- Prof ${ }^{a}$. Dra ${ }^{\mathrm{a}}$. Lúcia Pereira Barroso (orientadora) - IME-USP

- Prof ${ }^{a}$. Dr ${ }^{a}$. Mônica Carneiro Sandoval - IME-USP

- Prof $^{\mathrm{a}}$. Dra ${ }^{\mathrm{a}}$. Denise Britz do Nascimento Silva - ENCE 



\section{Agradecimentos}

Inicio agradecendo à Professora $\mathrm{Dr}^{\mathrm{a}}$ Lúcia Pereira Barroso por aceitar esse desafio junto comigo, pela orientação, disponibilidade, dedicação, confiança e todas as palavras de otimismo ao longo desta árdua jornada.

Às professoras que compuseram a banca, Professora $\operatorname{Dr}^{\mathrm{a}}$ Denise Britz do Nascimento Silva e Professora Dra Mônica Carneiro Sandoval, por aceitarem o convite, por todas as críticas, sugestões e comentários feitos para o aprimoramento deste trabalho.

Agradeço a Deus pelo dom da vida e por iluminar meu caminho, superando todas as dificuldades.

Agradeço a minha mãe Eni por ser aquela que me orgulha, me inspira, que está sempre ao meu lado, dá excelentes conselhos e me motiva a aprender sempre mais. Obrigada por acreditar em mim e ter me proporcionado uma educação de qualidade. Agradeço ao meu irmão João Gabriel por todo seu carinho e apoio incondicional. À toda família, que compreendeu minha ausência durante esse período.

Gostaria de agradecer aos amigos do CETIC.br que se transformaram na minha família em São Paulo e que me acompanharam durante todo esse processo, em especial: Ali, Luana, Lu, Maíra, Manu, Maria, Rapha, Tati e Wins. Agradeço ao Alexandre Barbosa, Marcelo Pitta e Emerson Santos por acreditarem em mim, no meu trabalho, pelo incentivo e, também, pela disponibilização da base de dados para a execução desta pesquisa.

Agradeço, também, a todos os meus amigos e amigas queridas que entenderam minhas recusas para os happy hours, aniversários, viagens e afins. À Guada, Lyse e Maíra que estiveram ao meu lado em todos os momentos e não me deixaram desistir.

Por último, mas não menos importante, agradeço ao meu namorado Guaraci por todo companheirismo e compreensão. Faltam palavras para agradece-lo por ter sido meu braço direito em todos os momentos da construção desta dissertação, desde a programação em $\mathrm{R}$ a paciência em revisar este texto inúmeras vezes. 



\section{Resumo}

A sociedade atual é também conhecida como Sociedade da Informação, pois o acesso às informações e ao conhecimento está disponível de maneira rápida através das Tecnologias de Informação e Comunicação (TIC), como computador, Internet e telefone celular. Assim, tem sido necessário elaborar novas maneiras de pensar e conviver com essas tecnologias. Para o desenvolvimento sócioeconômico das nações é importante formar uma sociedade crítica, reflexo do processo educacional adotado; dessa maneira, é preciso se apropriar das TIC para obter práticas de ensino mais criativas e flexíveis. Para que essa integração gere resultados satisfatórios é preciso a união de diversos fatores como a infraestrutura disponível na escola, o domínio dos professores sobre a utilização nas atividades de ensino-aprendizagem, a integração no projeto político-pedagógico, a implementação de políticas públicas na área educacional pelo governo etc. Dessa forma, o levantamento de dados estatísticos sobre a adoção das TIC nos processos educacionais se faz necessário. Pesquisas amostrais são muito utilizadas com o intuito de conhecer determinada característica sobre uma população. O tamanho das amostras costuma ser planejado para a obtenção de dados para grandes áreas, no entanto, vem crescendo o desejo de se obter informações em níveis mais desagregados, onde o tamanho da amostra é pequeno para a produção de estimativas com precisão aceitável, sem aumentar o tamanho amostral. Em vista disso, a metodologia de estimação em pequenas áreas tem sido desenvolvida de forma a produzir estimativas com precisão adequada para as características de interesse, considerando a distribuição de probabilidade trazida no desenho amostral ou a utilização de modelos que "emprestam" informações para áreas semelhantes. O objetivo desta dissertação é a obtenção dessas estimativas para a proporção de escolas em que os professores usam a Internet em atividades de ensino-aprendizagem com os alunos para cada Unidade Federativa do Brasil, utilizando dados reais provenientes da pesquisa TIC Educação, produzida pelo CGI.br, e do Censo Escolar, produzido pelo INEP. Obtemos as estimativas por diferentes abordagens, tanto direto da amostra quanto através da construção de modelos de regressão logística, e as comparamos através da estimativa do erro quadrático médio e da proporção de acertos, através da matriz de confusão por validação leave-one-out. Para a consolidação dos resultados obtidos nos dados reais, fazemos um estudo de simulação de dados. O modelo de efeitos aleatórios é considerado como o que apresentou os melhores resultados.

Palavras-chave: estimação em pequenas áreas, Tecnologia da Informação e Comunicação, educação, TIC Educação. 



\section{Abstract}

The current society is also known as the Information Society because access to information and knowledge is available through Information and Communication Technologies (ICT) such as computer, Internet and mobile phone. Thus, new ways of thinking and living with these technologies have become necessary. For the socio-economic development of nations it is important to create a critical society, reflection of adopted educational process; In that way, appropriating ICT should be necessary to obtain more creative and flexible teaching practices. To obtain satisfactory performance it needs the union of several factors such as the infrastructure available in schools, the teacher's knowledge about how to adopt ICT on practical activities, the ICT integration on the political pedagogical project, the implementation of public policies on the educational sector etc. In this manner, collect statistical data about ICT adoption on teaching practices is necessary. Sample surveys are widely used in order to understand certain characteristics of a population. The sample sizes is often designed to obtain results for large areas, nevertheless, the desire to obtain these results for more disaggregated areas, where the sample size is small to produce reliable estimates, are increasing without increasing the sample size. Small area estimation methodology has been developed to produce reliable estimates about some desired characteristics considering the probability distribution introduced on the sample design or considering models to "lend" information to resembling domains. Our purpose is to obtain estimates to the proportion of schools wherein teachers use the Internet to teaching-learning activities with their students for each Federative Unit of Brazil using real data from ICT in Education Survey, conducted by CGI.br, and Scholar Census, conducted by INEP. We obtain these estimates from different aproaches both by direct estimator and by logistic regression models and we compare them under the mean squared error and the proportion of success using confusion matrix by leave-one-out cross-validation. To consolidate these results we do a simulation study. The logistic random effects model is considered the best approach.

Keywords: small area estimation, Information and Communication Technology, education, ICT Education. 



\section{Sumário}

$\begin{array}{ll}\text { Lista de Figuras } & \text { iii }\end{array}$

$\begin{array}{ll}\text { Lista de Tabelas } & \text { v }\end{array}$

Lista de Abreviaturas $\quad$ vii

1 Introdução $\quad \mathbf{1}$

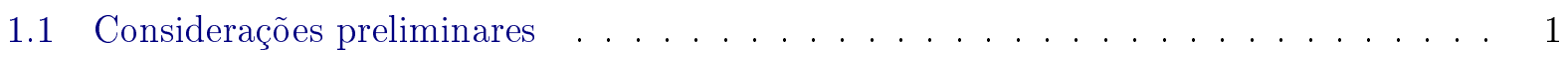

1.2 Motivação . . . . . . . . . . . . . . . . . . . . . . 3

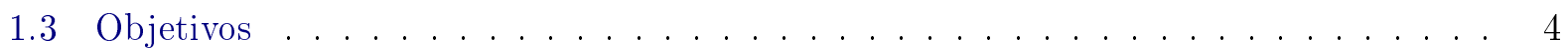

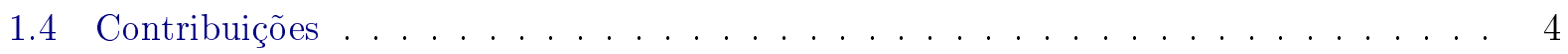

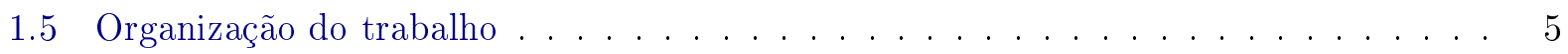

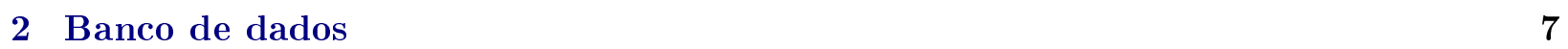

2.1 Censo Escolar . . . . . . . . . . . . . . . . . . . . . . . 7

2.2 Pesquisa TIC Educação . . . . . . . . . . . . . . . . . . 8

2.3 Construção do banco de dados final . . . . . . . . . . . . . . . . . 9

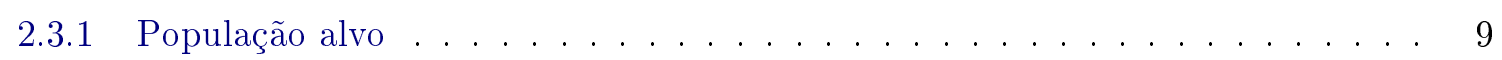

2.3.2 Variáveis do banco de dados final . . . . . . . . . . . . . . . . 10

2.3 .3 Críticas e imputações . . . . . . . . . . . . . . . . . . . . 11

2.3 .4 Reponderação dos resultados da pesquisa TIC Educação . . . . . . . . . . . 13

2.4 Cálculo do peso amostral para toda listagem . . . . . . . . . . . . . . . . . 13

3 Metodologias $\quad 15$

3.1 Estimador direto . . . . . . . . . . . . . . . . . . . 17

3.2 Abordagens baseadas em modelos . . . . . . . . . . . . . . . 17

3.2 .1 Modelo de regressão logística com efeitos aleatórios . . . . . . . . . . . 18

3.2 .2 Modelo de regressão logística . . . . . . . . . . . . . . . 20

3.2.3 Modelo de regressão logística com efeito do plano amostral . . . . . . . . . . . 21

3.3 Erro Quadrático Médio . . . . . . . . . . . . . . . . . . . . . . . . . . . . . . 22

3.3.1 Amostragem Sequencial de Poisson . . . . . . . . . . . . . . . 23

4 Comparação utilizando dados reais $\quad 25$

4.1 Estimador direto . . . . . . . . . . . . . . . . . . . . . 25

4.2 Modelo geral . . . . . . . . . . . . . . . . . . . . . . . 28

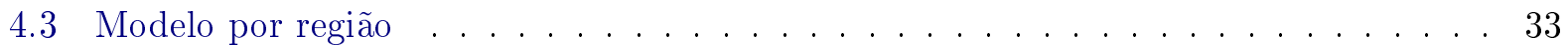


4.4 Modelo por cluster . . . . . . . . . . . . . . . . . . 38

4.4 .1 Análise de agrupamentos . . . . . . . . . . . . . . . . . . . . . . . . . . . . 38

4.4 .2 Descrição dos agrupamentos . . . . . . . . . . . . . . . 39

4.4 Modelagem . . . . . . . . . . . . . . . . . . . 42

4.5 Modelo com efeitos aleatórios . . . . . . . . . . . . . . . . . 46

4.6 Modelo com efeitos aleatórios e efeito do plano amostral . . . . . . . . . . . 50

4.7 Comparação das estimativas . . . . . . . . . . . . . . . 53

5 Simulação $\quad 61$

5.1 População obtida segundo modelo geral . . . . . . . . . . . . . . . . 61

5.2 População obtida segundo modelo de intercepto aleatório . . . . . . . . . . . . . . 64

5.3 População obtida segundo modelo de intercepto e inclinação aleatórios . . . . . . . . 68

5.4 Comparação das estimativas . . . . . . . . . . . . . . . . . 72

6 Conclusões $\quad 75$

6.1 Considerações finais . . . . . . . . . . . . . . . . . . . . . 75

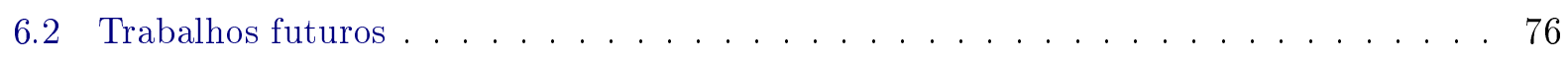

$\begin{array}{ll}\text { A Tabelas adicionais } & 77\end{array}$

$\begin{array}{ll}\text { Referências Bibliográficas } & 87\end{array}$ 


\section{Lista de Figuras}

4.1 Mapa com as estimativas das proporções de escolas em que os professores usam a Internet com os alunos para atividades de ensino-aprendizagem obtidas pelo estimador

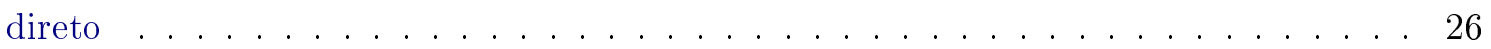

4.2 Curva ROC para o modelo geral . . . . . . . . . . . . . . . . . 30

4.3 Mapa com as estimativas das proporções de escolas em que os professores usam a Internet com os alunos para atividades de ensino-aprendizagem obtidas pelo modelo

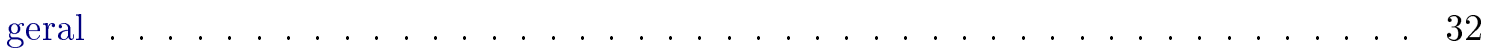

4.4 Curva ROC para o modelo por região . . . . . . . . . . . . . . . . . . 35

4.5 Mapa com as estimativas das proporções de escolas em que os professores usam a Internet com os alunos para atividades de ensino-aprendizagem obtidas pelo modelo

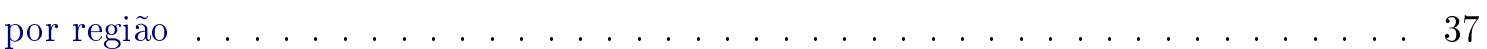

4.6 Curva ROC para o modelo por cluster . . . . . . . . . . . . . . . . . . 44

4.7 Mapa com as estimativas das proporções de escolas em que os professores usam a Internet com os alunos para atividades de ensino-aprendizagem obtidas pelo modelo

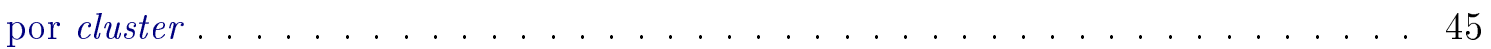

4.8 Curva ROC para o modelo de efeitos aleatórios . . . . . . . . . . . . . . . 48

4.9 Mapa com as estimativas das proporções de escolas em que os professores usam a Internet com os alunos para atividades de ensino-aprendizagem obtidas pelo modelo de efeitos aleatórios . . . . . . . . . . . . . . . . . . . 49

4.10 Curva ROC para o modelo de efeitos aleatórios considerando o plano amostral . . . . 51

4.11 Mapa com as estimativas das proporções de escolas em que os professores usam a Internet com os alunos para atividades de ensino-aprendizagem obtidas pelo modelo de efeitos aleatórios considerando o plano amostral . . . . . . . . . . . . . . 53

4.12 Estimativas do EQM sob as abordagens de estimador direto e modelo geral . . . . . 55

4.13 Estimativas do EQM sob as abordagens de modelos misto, região e cluster . . . . . . 56

4.14 Estimativas do EQM sob as abordagens de efeitos aleatórios e por cluster . . . . . . 57

4.15 Razão da raiz quadrada da estimativa do EQM pela estimativa da proporção, segundo o estimador direto e o modelo de efeitos aleatórios $(\%) \ldots \ldots \ldots \ldots$

5.1 EQM obtidos na simulação com a população determinada pelo modelo geral . . . . 65

5.2 EQM obtidos na simulação com a população determinada pelo modelo de efeitos

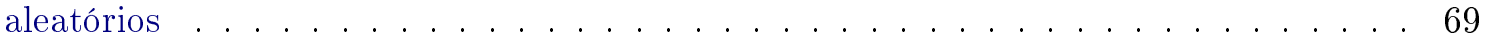

5.3 EQM obtidos na simulação com a população determinada pelo modelo de intercepto e inclinação aleatórios . . . . . . . . . . . . . . . . . . . . 73 


\section{Lista de Tabelas}

4.1 Classificação das estimativas quanto à precisão em uso . . . . . . . . . . . . 27

4.2 Estimativas da proporção de escolas em que os professores usam a Internet com os alunos para atividades de ensino-aprendizagem, EQM e CV, por UF, segundo o estimador direto . . . . . . . . . . . . . . . . . . . . . . 28

4.3 Representação geral de uma matriz de confusão . . . . . . . . . . . . . . . . . . . 31

4.4 Matriz de confusão, segundo o modelo geral . . . . . . . . . . . . . . . . . . 31

4.5 Estimativas da proporção de escolas em que os professores usam a Internet com os alunos para atividades de ensino-aprendizagem e do erro quadrático médio, por UF, segundo o modelo geral f . . . . . . . . . . . . . . . . . . . . 33

4.6 Matriz de confusão, segundo o modelo por região ～. . . . . . . . . . . . . . 36

4.7 Estimativas da proporção de escolas em que os professores usam a Internet com os alunos para atividades de ensino-aprendizagem e do erro quadrático médio, por UF, segundo o modelo por região . . . . . . . . . . . . . . . . . . . . . . . 37

4.8 Quantidade de escolas, por grupo . . . . . . . . . . . . . . . . . . . . 39

4.9 Quantidade de escolas, por grupo, segundo dependência administrativa . . . . . . . . 40

4.10 Quantidade de escolas, por grupo, segundo existência do laboratório de informática . 40

4.11 Proporção de escolas, por grupo, segundo o acesso à Internet . . . . . . . . . . . . . 40

4.12 Média do número de equipamentos disponíveis, segundo grupo . . . . . . . . . . . . . 41

4.13 Proporção de escolas, por grupo, segundo região . . . . . . . . . . . . . . . . . . . 41

4.14 Proporção de escolas, por grupo, segundo UF . . . . . . . . . . . . . . . . . . . 41

4.15 Proporção de escolas em que os professores utilizam Internet com os alunos, por grupo 42

4.16 Matriz de confusão, segundo o modelo por cluster . . . . . . . . . . . . . . . . . . 44

4.17 Estimativas da proporção de escolas em que os professores usam a Internet com os alunos para atividades de ensino-aprendizagem e do erro quadrático médio, por UF, segundo o modelo por cluster . . . . . . . . . . . . . . . . . . . . . 46

4.18 Valores dos interceptos obtidos pelo modelo de efeitos aleatórios . . . . . . . . . . . 47

4.19 Matriz de confusão, segundo o modelo de efeitos aleatórios . . . . . . . . . . . . . . 48

4.20 Estimativas da proporção de escolas em que os professores usam a Internet com os alunos para atividades de ensino-aprendizagem e do erro quadrático médio, por UF, segundo o modelo de efeitos aleatórios . . . . . . . . . . . . . . . . . 49

4.21 Valores dos interceptos obtidos pelo modelo de efeitos aleatórios considerando o plano

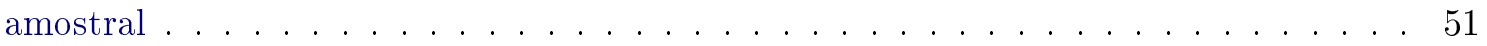

4.22 Matriz de confusão, segundo o modelo de efeitos aleatórios considerando o plano

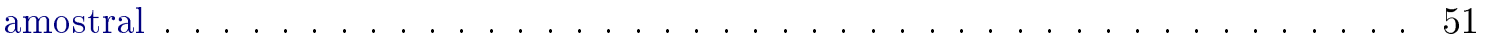


4.23 Estimativas da proporção de escolas em que os professores usam a Internet com os alunos para atividades de ensino-aprendizagem e do erro quadrático médio, por UF, segundo o modelo de efeitos aleatórios e efeito do plano amostral . . . . . . . . . . 52

4.24 Razão da raiz quadrada do EQM sobre a estimativa da proporção, segundo o modelo

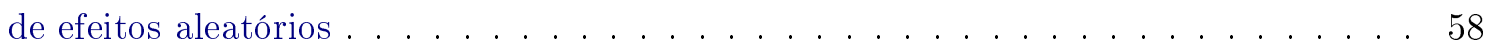

5.1 Verdadeira proporção das pequenas áreas, por área, segundo a simulação pelo modelo

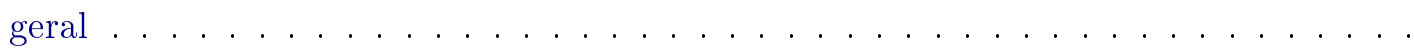

5.2 Estimativas da proporção e erro quadrático médio, por área, segundo cada abordagem a partir da população gerada através do modelo geral . . . . . . . . . . . . . . . . . 64

5.3 Verdadeira proporção das pequenas áreas, por área, segundo a simulação pelo modelo

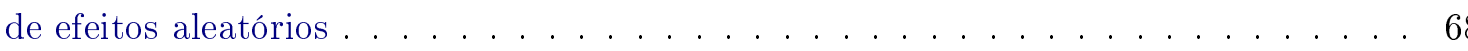

5.4 Estimativas da proporção e erro quadrático médio, por área, segundo cada abordagem a partir da população gerada através do modelo de efeitos aleatórios . . . . . . . . 68

5.5 Verdadeira proporção das pequenas áreas, por área, segundo a simulação pelo modelo de intercepto e inclinação aleatórios . . . . . . . . . . . . . . . . 71

5.6 Estimativas da proporção e erro quadrático médio, por área, segundo cada abordagem a partir da população gerada através do modelo de intercepto e inclinação aleatórios

A.1 Tamanho da população e tamanho da amostra, por UF . . . . . . . . . . . . . 77

A.2 Proporção da variável de interesse P44_TOTAL, por UF, para as observações da amostra da pesquisa TIC Educação . . . . . . . . . . . . . . . . . . 78

A.3 Estimativas, erros-padrão, estatísticas $t$ e valores-p do modelo geral . . . . . . . . . 79

A.4 Estimativas, erros-padrão, estatísticas $t$ e valores-p do modelo para a região Norte . . 79

A.5 Estimativas, erros-padrão, estatísticas $t$ e valores-p do modelo para a região Nordeste 79

A.6 Estimativas, erros-padrão, estatísticas $t$ e valores-p do modelo para a região Sudeste 80

A.7 Estimativas, erros-padrão, estatísticas $t$ e valores-p do modelo para a região Sul . . . 80

A.8 Estimativas, erros-padrão, estatísticas $t$ e valores-p do modelo para a região Centro-

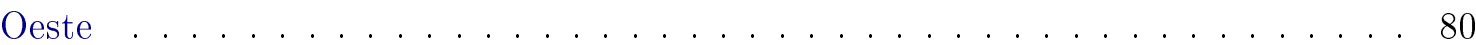

A.9 Estimativas, erros-padrão, estatísticas $t$ e valores-p do modelo para o grupo $1 \ldots$. . 81

A.10 Estimativas, erros-padrão, estatísticas $t$ e valores-p do modelo para o grupo 2 . . . 81

A.11 Estimativas, erros-padrão, estatísticas $t$ e valores-p do modelo para o grupo 3 . . . 81

A.12 Estimativas, erros-padrão, estatísticas $t$ e valores-p do modelo para o grupo 4 . . . 82

A.13 Estimativas, erros-padrão, estatísticas $t$ e valores-p do modelo para o grupo 5 . . . 82

A.14 Estimativas, erros-padrão, estatísticas $t$ e valores-p do modelo de efeitos aleatórios . 82

A.15 Estimativas, erros-padrão, estatísticas $t$ e valores-p do modelo de efeitos aleatórios e efeito do plano amostral . . . . . . . . . . . . . . . . . . 82

A.16 Medidas descritivas para as populações bootstrap, segundo o modelo geral . . . . . 83

A.17 Medidas descritivas para as populações bootstrap, segundo o modelo por região . . 84

A.18 Medidas descritivas para as populações bootstrap, segundo o modelo por cluster . . . 85

A.19 Medidas descritivas para as populações bootstrap, segundo o modelo de efeitos aleatórios 86 


\section{Lista de Abreviaturas}

ANOVA Análise de variância

AUC Área sob a curva ROC

CETIC.br Centro Regional de Estudos para o Desenvolvimento da Sociedade da Informação sob os auspícios da UNESCO

CGI.br Comitê Gestor da Internet no Brasil

CV Coeficiente de variação

EQM Erro Quadrático Médio

IBGE Instituto Brasileiro de Geografia e Estatística

ICT Information and Communication Technologies

INEP Instituto Nacional de Estudos e Pesquisas Educacionais Anísio Teixeira

MEC Ministério da Educação

NIC.br Núcleo de Informação e Coordenação do Ponto BR

PPT Probabilidade Proporcional ao Tamanho

PQL Penalized Quasi-Likelihood

ROC Receiver Operating Characteristics

SAE Estimação em pequenas áreas

TIC Tecnologias de Informação e Comunicação

UF Unidade Federativa do Brasil

UNESCO Organização das Nações Unidas para a Educação, a Ciência e a Cultura 


\section{Capítulo 1}

\section{Introdução}

\subsection{Considerações preliminares}

As Tecnologias de Informação e Comunicação (TIC) provocaram mudanças na sociedade atual em tão pouco tempo que novas maneiras de pensar e conviver precisam ser elaboradas. Segundo Belloni (2001) apud Albino (2015), o termo TIC abrange o conjunto de recursos tecnológicos que propiciam agilidade no processo de comunicação, transmissão e distribuição de informações, notícias e conhecimentos. A sociedade atual muitas vezes é denominada por "Sociedade da Informação", pois o acesso às informações e ao conhecimento estão disponíveis de maneira rápida e acessível através do computador, da Internet e de telefone celular, por exemplo. No entanto, a escola se mantém como a principal instituição organizadora e sistematizadora do conhecimento.

As tecnologias têm mudado nosso meio de pensar, agir e a nossa percepção da realidade, mas, em geral, as estruturas da escola ainda orientam-se pelo modelo em que o acesso à informação do cidadão é demorado e de difícil obtenção. Sabe-se que o desenvolvimento sócio-econômico de uma nação está diretamente relacionado à educação que acompanha e impulsiona as mudanças, e ao mesmo tempo, se apropria das tecnologias disponíveis (Albino, 2015). Assim, é necessário um processo educacional criativo e flexível, incorporando as TIC que vise formar uma sociedade mais crítica. Estudos apontam que apenas inserir as TIC no ambiente escolar sem alterar as práticas de ensino não trazem resultados satisfatórios, logo, as tecnologias devem atuar de modo complementar, mas não substituir os métodos já utilizados.

A sociedade da informação deve ter um viés inclusivo onde todas as pessoas possam ter a liberdade e as condições para criar, receber, compartilhar e utilizar informações e conhecimentos através da educação (Barbosa et al., 2004). Para que a integração das TIC nas escolas gere resultados positivos é preciso a união de diversos fatores, como a infraestrutura disponível na escola, que possibilite o uso das mesmas durante as aulas; o domínio do professor sobre a utilização das TIC para atividades de ensino-aprendizagem; a integração das TIC no projeto político-pedagógico das escolas; o investimento do governo para motivação e formação continuada do professor, dentre outros. Dessa forma, as TIC atuam como auxiliadoras para a melhoria da educação básica e consequentemente a diminuição da exclusão digital.

Sobre a infraestrutura disponível nas escolas, o instituto de estatística da UNESCO (UIS, 2009) coloca a disponibilidade de hardware, medida através dos tipos de computador, conexão de acesso à Internet, presença de rede etc., e a disponibilidade de software, medida a partir de tipos de aplicativos, ferramentas de gestão etc., como medidas para avaliação da infraestrutura da organi- 
zação. Todavia, diversos autores apontam que o problema das escolas não está na disponibilidade de infraestrutura, mas em como articular os atores escolares no processo de inclusão na prática pedagógica.

Diversas pesquisas são desenvolvidas para medir o uso das TIC nas escolas. Destacamos as pesquisas do Comitê Gestor da Internet no Brasil (CGI.br) que, não apenas na área educacional, contribuem com estatísticas a respeito das TIC para servir como insumo para o debate de inclusão digital e impactos das tecnologias. A pesquisa TIC Educação (CGI.br, 2014) traz dados a respeito da posse, uso, adoção e apropriação das TIC nas escolas brasileiras. A partir de seus resultados, temos que $99 \%$ das escolas possuem computador e, destas, $97 \%$ possuem acesso à Internet, o que corrobora que a infraestrutura não é o problema mais grave para a adoção das TIC. Porém, a pesquisa também traz que a proporção de alunos por computador disponível e em funcionamento é muito alto, ou seja, os alunos têm que compartilhar o computador, pois o número de alunos na escola é maior que o número de computadores, além disso, a baixa velocidade de conexão também é um problema recorrente, logo, ainda são obstáculos a serem superados.

Para que mudanças ocorram na prática pedagógica deve existir o uso inteligente das TIC nas escolas, para isso, as escolas precisam de líderes que facilitem esse processo e apoiem a comunidade para a integração tecnológica. Os professores exercem uma atividade extremamente importante para esse processo, sendo necessária a compreensão que não são apenas responsáveis pela transferência do conhecimento, mas facilitadores do processo de ensino-aprendizagem, sendo promotores do aprendizado, uma vez que são os atores capazes de ampliar e ter uma relação mais fluída entre os alunos e o conhecimento. Dessa maneira, o uso das TIC necessita de um professor preparado e em constante aprendizado.

Fu (2013) apud Albino (2015) realiza uma extensa revisão da bibliografia disponível para retratar as mais recentes discussões sobre o uso das TIC no ambiente escolar, que discorrem a respeito dos benefícios, barreiras, desafios e fatores que influenciam o uso. Cita ainda que a tecnologia é um suporte na abordagem de ensino centrada no estudante, uma vez que ofertada pelos docentes o aluno passa a desenvolver um pensamento crítico e assume o papel de autoria na produção do conhecimento, o que traz uma melhoria da qualidade da aprendizagem e do ensino.

De Albino (2015) temos que, "Dentro do contexto brasileiro, Lopes et al. (2010) realizaram um estudo em 400 escolas públicas de Ensino Fundamental e Médio das capitais brasileiras com o objetivo de investigar o uso do computador e da Internet. Os autores concluíram que:

- a tecnologia deve ser integrada ao projeto pedagógico da escola, no seu monitoramento e avaliação e ao planejamento de atividades do professor;

- apesar dos dados levantados sobre recursos e infraestrutura serem favoráveis, infraestrutura, formação de professores e problemas com acesso à Internet são apontados como os principais problemas para uso pedagógico do computador;

- a formação oferecida não é percebida como suficiente e adequada, pois falta preparo para o uso da tecnologia centrado em ensino-aprendizagem dos conteúdos escolares;

- o número de professores que usam a tecnologia com seus alunos é ainda pequeno e este uso se dá no laboratório de informática; 
- na maioria das escolas, as atividades que utilizam tecnologia e são realizadas com os alunos têm pouca complexidade ou usam recursos simples."

Dessa forma, o uso das TIC dentro das escolas não depende exclusivamente do conhecimento e habilidade dos alunos e professores, mas também depende da gestão escolar e dos recursos disponíveis. Assim, as tecnologias podem promover a criação de comunidades de aprendizagem, privilegiando o processo de construção coletiva e gestão integrada entre as frentes administrativas, pedagógicas e informacional da escola. Nesse intuito, a percepção e atuação do diretor da escola -responsável pela gestão escolar- é fundamental para a adoção dessas novas práticas de ensino, seja estimulando os professores, adotando projetos político-pedagógicos que visem as tecnologias, quanto equipando a escola. A união entre gestores e professores é a fórmula para o sucesso nessa nova etapa vivida pelo ambiente educacional na sociedade da informação.

Esta dissertação visa aprimorar os dados já disponíveis na pesquisa TIC Educação de forma que, a partir de uma estimativa confiável para áreas onde há pouca informação, possam servir como insumo para a construção de novas políticas públicas, e que incentive os atores escolares a uma maior adoção e apropriação das novas metodologias em suas abordagens de ensino, uma vez que para o crescimento econômico de uma nação é mais importante a qualidade do que a quantidade de educação.

\subsection{Motivação}

O ensino público de qualidade é um dever do Estado através da Constituição Federal do Brasil de 1988. O Estado deveria assegurar que todos os alunos frequentassem a escola até a conclusão dos estudos. No entanto, o que a realidade nos mostra é uma baixa qualidade da educação pública no Brasil, o que agrava os problemas como desigualdade de renda, alto índice de pobreza, escassez de mão de obra especializada etc. A qualidade da educação ofertada é um empecilho para a solução de problemas econômicos e sociais existentes.

As TIC possibilitam novas formas de distribuir o conhecimento, e por esse motivo têm sido colocadas como grandes aliadas no desenvolvimento sócio-econômico de todas as nações. A primeira ideia que surge no contexto educacional é aumentar o acesso dos alunos às TIC, desse modo, foram elaborados diversos programas governamentais para impulsionar o uso das tecnologias, levando equipamentos, como computadores e tablets, e acesso à Internet para aumentar a infraestrutura disponível na escola. Esses programas surgiram com o intuito de diminuir a diferença entre o acesso dos estudantes de escolas públicas em relação aos estudantes de escolas particulares, que em sua maioria já são informatizadas. No entanto, apenas levar a infraestrutura não garante e não é suficiente para adoção e apropriação no processo de ensino-aprendizagem. Além disso, em algumas pesquisas qualitativas, são diagnosticados problemas a respeito de infraestrutura anteriores ao recebimento de computadores, como falta de local para instalação, falta de cabeamento ou até mesmo a não existência de energia elétrica. Também são mencionadas a falta de suporte e manutenção desses equipamentos.

Nos casos em que não há envolvimento dos professores ou não lhes são fornecidos formação específica e tempo necessário para a sua inserção no processo de informatização da escola, observa-se como resultado que os professores não aprendem a lidar com tais tecnologias e muito menos como fazer uso pedagógico delas em sua rotina escolar na sala de aula ou no laboratório de informática 
(Unesco Brasil (2008a); Unesco Brasil (2008b) apud Albino (2015)). Nesse contexto, as Secretarias de Educação, tanto municipais quanto estaduais, e o Ministério da Educação (MEC) têm investido na formação do professor para utilização pedagógica das TIC. Alguns autores alegam que, apesar dos investimentos realizados, não houve uma melhoria significativa na qualidade da educação pública no Brasil em muitas vezes relacionada à falta de interesse do professor.

Os diretores de escola têm um papel muito importante para a integração das TIC no processo de ensino-aprendizagem. Eles são responsáveis por criar condições para o uso e proporcionar uma abertura entre os atores escolares, principalmente alunos e docentes, para que sejam avaliadas as potencialidades de adoção dessas tecnologias. Assim, a visão do diretor sobre todo esse processo de mudança educacional é fundamental para a compreensão da realidade da adoção das TIC nas escolas brasileiras. Com isso, a produção de dados estatísticos que auxiliem os gestores públicos, responsáveis pelas tomadas de decisão, para a construção e implementação de políticas públicas visando a área educacional se faz necessária.

\subsection{Objetivos}

O objetivo principal desta dissertação é obter estimativas confiáveis para a proporção de escolas em que os professores usam a Internet em atividades de ensino-aprendizagem com os alunos para cada Unidade Federativa do Brasil (UF). Dessa maneira, a partir da pesquisa TIC Educação (CGI.br, 2014), e dados do Censo Escolar (INEP, 2014a), são desenvolvidos modelos que permitam estimar essa proporção em níveis não permitidos pelo plano amostral, como é o caso das UF para a pesquisa TIC Educação.

Esses modelos são construídos a partir da teoria estatística que será detalhada no Capítulo 3 a fim de obter melhores resultados. Dessa forma, comparamos as estimativas geradas por diferentes técnicas, para que, diagnosticando a técnica mais adequada, possamos gerar resultados como esses para outros indicadores. A disponibilização de resultados com maior nível de detalhamento, como por exemplo para as UF, pode servir como insumo para a tomada de decisão de gestores públicos a fim de fomentar e implementar novas políticas de inclusão e adoção das TIC no contexto educacional como ferramenta pedagógica, a fim de melhorar a qualidade da educação no Brasil.

\subsection{Contribuições}

Ao cumprirmos os objetivos desta dissertação, obtemos as seguintes contribuições:

- Fornecer estimativas confiáveis, isto é, com precisão adequada, para a proporção de escolas em que os professores usam a Internet em atividades de ensino-aprendizagem com os alunos para cada UF, que podem ser utilizadas para fundamentar a formulação de políticas públicas na área educacional pelas Secretarias Estaduais de Educação e pelo Ministério da Educação;

- Além de fomentar novas políticas, os resultados podem ser utilizados para a avaliação do impacto de políticas públicas já implementadas, como, por exemplo, o programa Banda Larga nas Escolas ${ }^{1}$;

\footnotetext{
${ }^{1}$ Para maiores informações, consulte: http://www.fnde.gov.br/programas/programa-nacional-de-tecnologiaeducacional-proinfo/proinfo-programa-banda-larga-nas-escolas-pble. Acesso em: 14/01/2016.
} 
- A metodologia de estimação em pequenas áreas não é ainda um campo de estudo muito difundido no Brasil, assim esperamos que este trabalho sirva como motivação para demais pesquisadores;

- Com a apropriação da metodologia utilizada na estimação em pequenas áreas, fornecer ao CETIC.br a motivação para divulgar os resultados obtidos nas pesquisas ${ }^{2}$ por eles conduzidas para pequenos domínios.

\subsection{Organização do trabalho}

O Capítulo 2 traz as definições dos cadastros utilizados nesta dissertação, bem como todas as etapas para a construção do arquivo de banco de dados final utilizado nesta dissertação. O Capítulo 3 traz um resumo sobre a metodologia de estimação em pequenas áreas, além de enunciar as técnicas que serão utilizadas, servindo como referencial teórico para a construção dos modelos. Também traz o algoritmo utilizado para a estimação do erro quadrático médio que será utilizado como medida de qualidade do ajuste, bem como uma introdução a respeito da Amostragem Sequencial de Poisson, metodologia adotada na pesquisa TIC Educação.

Os resultados obtidos utilizando os dados reais fornecidos pela pesquisa TIC Educação 2013 (CGI.br, 2014) e o Censo Escolar 2013 (INEP, 2014a) são apresentados no Capítulo 4. Já o Capítulo 5 traz os resultados obtidos através da simulação de dados.

O último capítulo, o Capítulo 6, traz as conclusões obtidas através da análise das estimativas obtidas pelo conjunto de dados reais e simulados. Disponibilizamos algumas tabelas adicionais para consulta no Apêndice A. Por fim, apresentamos as referências bibliográficas utilizadas para a fundamentação teórica desta dissertação.

\footnotetext{
${ }^{2}$ As pesquisas produzidas pelo CETIC.br podem ser obtidas em: http://cetic.br/pesquisas/. Acesso em: $14 / 01 / 2016$.
} 


\section{Capítulo 2}

\section{Banco de dados}

Neste capítulo apresentamos algumas informações a respeito do Censo Escolar (INEP, 2014a) e da pesquisa TIC Educação (CGI.br, 2014) que são os cadastros de referência amplamente utilizados nesta dissertação. Todavia, a descrição não é exaustiva de modo que recomenda-se a leitura dos resumos técnicos (INEP (2014b), CGI.br (2014), páginas 111-131) para maior detalhamento.

Além disso, uma vez que o objetivo da amostragem é fazer inferências sobre uma população baseada no resultado de uma amostra, precisamos conhecer a população a qual estamos abordando. Assim trazemos uma descrição sobre a população alvo do nosso estudo e todos os procedimentos adotados até obtermos o banco de dados final.

\subsection{Censo Escolar}

O Censo Escolar conduzido anualmente pelo Instituto Nacional de Estudos e Pesquisas Educacionais Anísio Teixeira (INEP) é o principal levantamento estatístico a respeito das escolas de educação básica no Brasil. A partir dessas informações são construídas diversas políticas públicas no âmbito educacional, além disso, essas informações também são utilizadas para o repasse de verbas para as escolas públicas.

É designado como Censo Escolar, pois conta com a participação de todas as escolas públicas (municipais, estaduais e federais) e particulares de diferentes etapas de ensino, ou seja, educação infantil, ensino fundamental e ensino médio; e de diferentes modalidades, isto é, escolas do ensino regular, de educação especial, de educação de jovens e adultos e de educação profissional. Levantam-se informações a respeito dos estabelecimentos de ensino, das turmas oferecidas, dos alunos, dos profissionais escolares e do rendimento escolar. Essas informações são atribuídas a quatro grupos: Escolas, Alunos, Profissionais e Turmas. Segundo o INEP 1, "para cada dimensão existem informações que buscam caracterizar esses grupos, a saber:

- Escolas: infraestrutura disponível (local de funcionamento, salas, tipo de abastecimento de água e de energia elétrica, destinação de lixo e esgoto sanitário), dependências existentes (diretoria, secretaria, cozinha, tipo de banheiro, laboratórios, acessibilidade, quadra de esporte, parque infantil), equipamentos (computadores, acesso à Internet, aparelhos de TV e DVD, antena parabólica), etapas e modalidades de escolarização oferecidas; organização do ensino

\footnotetext{
${ }^{1}$ http://portal.inep.gov.br/web/educacenso/censo-escolar. Acesso em: 25/11/2015.
} 
fundamental; localização, dependência administrativa, mantenedora e tipo de escola privada, escolas privadas conveniadas com o poder público.

- Alunos: sexo, cor/raça, idade, nacionalidade, local de nascimento, turma que frequenta, etapa e modalidade de ensino que frequenta, utilização de transporte escolar, tipo de deficiência.

- Profissionais escolares: são coletadas informações dos professores/as, auxiliares/assistentes educacionais, profissionais/monitores de atividade complementar e tradutores/intérprete de Libras. Das informações coletadas, podemos ressaltar: sexo, cor/raça, idade, escolaridade (formação: nível e curso, instituição formadora), etapa e modalidade de ensino de exercício, turma de exercício, disciplinas que ministra, nacionalidade e função que exerce.

- Turmas: tipo de atendimento (escolarização, atividade complementar, classe hospitalar, unidade de atendimento socioeducativo, unidade prisional, atendimento educacional especializado - AEE), horários de início e de término, modalidade, etapa, disciplinas, dentre outras."

\subsection{Pesquisa TIC Educação}

O Centro Regional de Estudos para o Desenvolvimento da Sociedade da Informação sob os auspícios da UNESCO (CETIC.br) é um departamento do Núcleo de Informação e Coordenação do Ponto BR (NIC.br), braço executivo do Comitê Gestor da Internet no Brasil (CGI.br), que produz, desde 2010, estatísticas a respeito da posse, do uso, da adoção e da apropriação das Tecnologias de Informação e Comunicação (TIC) em escolas públicas e privadas de áreas urbanas no Brasil. A Pesquisa sobre o uso das tecnologias de informação e comunicação nas escolas brasileiras - TIC Educação ${ }^{2}$, levanta dados a respeito da infraestrutura das TIC, como computador e Internet, da apropriação delas nos processos educacionais, bem como as habilidades no uso nas atividades de ensino-aprendizagem. As estatísticas produzidas pelo CGI.br auxiliam os gestores públicos na formulação e avaliação de políticas relacionadas ao uso das TIC pelas escolas de educação básica brasileiras, visando melhorias na qualidade da educação.

A população alvo da pesquisa é constituída pelas escolas públicas estaduais, públicas municipais e particulares de áreas urbanas, em atividade, que oferecem ensino regular em pelo menos uma das séries de interesse, a saber: $4^{\mathrm{a}}$ série $/ 5^{\circ}$ ano do Ensino Fundamental, $8^{\mathrm{a}}$ série $/ 9^{\circ}$ ano do Ensino Fundamental e $2^{\circ}$ ano do Ensino Médio. Alunos, diretores, coordenadores pedagógicos e professores de português e matemática também fazem parte da população alvo da pesquisa. Segundo o CGI.br, de forma a cumprir o objetivo da pesquisa, as seguintes dimensões são investigadas para cada uma das unidades de análise:

- "Escolas: perfil em termos de infraestrutura e práticas envolvendo TIC;

- Diretores: perfil de uso do computador e Internet; uso de TIC nas atividades administrativas e de gestão; interação com a comunidade e percepção sobre as limitações para a integração das TIC à educação;

- Coordenadores pedagógicos: perfil de uso do computador e Internet; uso de TIC nas atividades administrativas e de coordenação pedagógica e percepção sobre as limitações para integração das TIC à educação;

\footnotetext{
${ }^{2}$ Para maiores informações acesse http://cetic.br/pesquisa/educacao/. Acesso em: 25/11/2015.
} 
- Professores: perfil profissional e de uso de computador e Internet; habilidades e capacitação para o uso de TIC; uso de TIC nas atividades gerais e de ensino-aprendizagem; uso de conteúdos educacionais e percepção sobre as limitações para a integração das TIC à educação;

- Alunos: perfil de uso de computador e Internet; habilidades para o uso de TIC; capacitação para o uso de TIC; atividades realizadas com o uso de Internet na escola."

Para a realização deste trabalho, utilizamos a publicação mais recente disponível no momento, a edição 2013 da pesquisa TIC Educação (CGI.br, 2014). A amostra de escolas foi selecionada através do cadastro do Censo Escolar 2012 do INEP. Para maiores detalhes a respeito do plano amostral empregado, o desenho e a seleção da amostra da pesquisa, recomendamos consultar a Seção Relatório Metodológico da pesquisa TIC Educação 2013 (CGI.br (2014), páginas 111-131).

Nesta dissertação, nossa variável de interesse é a proporção de escolas em que os professores usam a Internet em atividades de ensino-aprendizagem com os alunos. Essa variável faz parte do conjunto de indicadores disponibilizados pelo CETIC.br para a unidade de análise Escolas. Uma vez que os diretores são os informantes para as informações coletadas para a unidade de análise Escolas, utilizamos apenas os microdados referentes a este público, de tal modo que foram realizadas 939 entrevistas com diretores na edição 2013 da Pesquisa TIC Educação.

\subsection{Construção do banco de dados final}

\subsubsection{População alvo}

A pesquisa TIC Educação 2013 teve como base para a seleção da amostra o Censo Escolar 2012, no entanto o período de coleta dos dados ocorreu de setembro a dezembro de 2013. As condições de elegibilidade da pesquisa foram aplicadas conforme a situação da escola no ano de 2013, isto significa que as respostas fornecidas são referentes às condições escolares no ano de 2013. Dessa forma, para utilizar os cadastros com o mesmo período de referência, se fez necessário o uso do cadastro do Censo Escolar 2013 para a estimação dos modelos desta dissertação. Assim, foi preciso transformar o Censo Escolar 2013 (INEP, 2014a) para a mesma população alvo considerada na pesquisa TIC Educação 2013.

O cadastro de escolas do Censo Escolar 2013 é composto por 272.049 escolas, das quais mantivemos 195.656 que estão em funcionamento. As escolas federais não estão no âmbito da pesquisa TIC Educação por apresentarem um comportamento singular, assim as escolas da rede pública (municipal e estadual) e as da rede privada totalizam 195.139 escolas, sendo 124.233 de áreas urbanas. Não são consideradas escolas de ensino profissionalizante, educação infantil, educação especial, educação de jovens e adultos, de tal forma que o ensino regular está presente em 80.774 escolas.

O cadastro de turmas do Censo Escolar 2013 é composto por 2.486.525 turmas, 2.015.272 são da modalidade de ensino regular. São mantidas apenas as 327.271 turmas das etapas de ensino de interesse e que não sejam classes hospitalares, de unidades de internação socioeducativa, de unidade prisional, de atendimento complementar ou de atendimento educacional especializado. Para formar o banco de dados final, juntamos as informações obtidas sobre as turmas existentes nas séries de interesse as mais de 80 mil escolas regulares. Como algumas escolas não possuem nenhuma turma sendo oferecida para as etapas de ensino pesquisadas na modalidade de ensino regular, ou seja, turmas que não satisfazem as condições de elegibilidade, temos que o cadastro final com a população 
alvo conta com 73.564 escolas. Em resumo, temos que a população alvo do estudo corresponde às escolas com as seguintes características:

- Situação de funcionamento: em atividade;

- Rede: municipal, estadual ou privada;

- Área: urbana;

- Modalidade de ensino: regular;

- Etapas de ensino:

- $4^{\mathrm{a}}$ série do Ensino Fundamental;

$-5^{\circ}$ ano do Ensino Fundamental;

- $8^{\mathrm{a}}$ série do Ensino Fundamental;

$-9^{\circ}$ ano do Ensino Fundamental;

- $2^{\mathrm{o}}$ ano do Ensino Médio;

- $2^{\circ}$ ano do Ensino Médio Integrado;

- $2^{0}$ ano do Ensino Médio - Normal/Magistério;

- Tipo de atendimento: turmas que não estejam alocadas em hospitais, em unidades de internação socioeducativa, em prisões, que sejam de atendimento complementar ou de atendimento educacional especializado.

\subsubsection{Variáveis do banco de dados final}

Após os procedimentos de construção da base de dados, excluímos diversas variáveis existentes nos cadastros utilizados do Censo Escolar e da pesquisa TIC Educação, formando o banco de dados final, que é utilizado ao longo desta dissertação. As variáveis que serão utilizadas foram consideradas como relevantes no contexto educacional e relacionadas com a variável de interesse utilização da Internet em atividades de ensino-aprendizagem com os alunos na escola. O banco de dados é composto por 73.564 escolas distintas, com observações para as seguintes variáveis:

- PK_COD_ENTIDADE: código INEP de identificação da escola;

- REGIAO: código de identificação da macrorregião à qual a escola pertence;

- FK_COD_ESTADO: código de identificação da UF à qual a escola pertence;

- SIGLA: sigla da UF à qual a escola pertence;

- ID_DEPENDENCIA_ADM: dependência administrativa;

- ESTRATO_FINAL: estrato de seleção da escola;

- ID_LABORATORIO_INFORMATICA: existência de laboratório de informática nas dependências da escola; 
- NUM_SALAS_UTILIZADAS: número de salas utilizadas como salas de aula (dentro e fora do prédio);

- NUM_EQUIP_MULTIMIDIA: quantidade de projetores multimídia datashow;

- NUM_COMPUTADORES: quantidade de computadores na escola;

- NUM_COMP_ALUNOS: quantidade de computadores para uso dos alunos;

- ID_INTERNET: existência do acesso à Internet;

- ID_BANDA_LARGA: existência do acesso à Internet banda larga;

- ID_PROF_INF: existência de professor de informática no quadro de docentes da escola;

- $Q T \_D O C E N T E S:$ quantidade de docentes existentes na escola;

- MED_IDADE: média da idade dos docentes da escola;

- P44_tOTAL: utilização da Internet pelos professores em atividades de ensino-aprendizagem com os alunos na escola (variável resposta);

- TIC: variável que identifica se a escola pertenceu à pesquisa TIC Educação 2013;

- $N_{-} A M O$ : tamanho da amostra dentro de cada estrato de seleção;

- PROB_FINAL: probabilidade de seleção da escola;

- PESO_FINAL: peso amostral da escola.

\subsubsection{Críticas e imputações}

Com o intuito de aumentar a acurácia dos modelos e dispondo de dados para todas as escolas a respeito das funções docentes, a partir do cadastro de docentes do Censo Escolar 2013, construímos três variáveis que serão utilizadas como independentes na estimação dos modelos, uma vez que pretendemos avaliar o uso dos docentes nas escolas. A primeira delas, $Q T$ _DOCENTES, é a quantidade de funções docentes dentro das escolas presentes no cadastro já trabalhado, isto é, consideramos apenas os docentes das modalidades e etapas de ensino já mencionadas. A segunda é a média da idade desses docentes, $M E D_{-} I D A D E$. E a terceira é uma variável que indica se a escola possui, ou não possui, pelo menos um professor de informática ou computação em seu quadro de docentes, $I D_{-} P R O F_{-} I N F$.

Os cadastros de escolas, turmas e docentes do Censo Escolar e o cadastro da pesquisa TIC Educação foram agrupados em um arquivo único, nele estão disponíveis apenas as escolas que correspondem à população alvo do estudo para as variáveis descritas na Subseção 2.3.2. De posse desse arquivo, realizamos alguns testes de consistência nos dados, e a partir deles realizamos algumas imputações:

- Se a escola não tem computador, atribuímos que também não há computadores para uso dos alunos;

- Se a escola não tem Internet, atribuímos que também não tem Internet banda larga; 
- Se a escola tem Internet banda larga, atribuímos que também tem acesso à Internet.

A variável do número de computadores disponíveis para uso dos alunos vinda do cadastro de escolas do Censo Escolar, NUM_COMP_ALUNOS, mesmo após a imputação realizada, possui dados faltantes para $15 \%$ das escolas. Todavia, não foi detectado um padrão de ocorrência dessas variáveis, uma vez que há casos em que o total de computadores declarado é o mesmo para os disponíveis para o uso dos alunos e os disponíveis para o uso administrativo; em outros a soma do número de computadores para uso administrativo e para uso dos alunos é menor que o total de computadores; e ainda há casos nos quais o número de computadores para o uso dos alunos é a diferença entre o total de computadores e o os de uso administrativo, portanto, não realizamos nenhum tipo de imputação e optamos por manter essas informações ausentes, isto é, caso essa variável seja incluída no modelo final, as escolas que não declararam essa variável, não será possível realizar a estimação e, logo, não entraram no cálculo da proporção que desejamos estimar nesta dissertação.

O cadastro do Censo Escolar não disponibiliza a variável região da escola, isto é, a macrorregião brasileira onde a escola está. No entanto, as variáveis de UF, município e distrito estão disponíveis. Dessa forma, construímos a variável REGIAO a partir do primeiro código da UF em que ela está inserida, tal que contemplasse as 5 regiões, segundo critérios do Instituto Brasileiro de Geografia e Estatística (IBGE): Norte, Nordeste, Sul, Sudeste e Centro-Oeste.

Desconsiderando os efeitos de amostragem complexa, isto é, não levando em consideração os pesos amostrais, podemos fazer a análise descritiva das variáveis apresentadas na Subseção 2.3.2 para as 73.564 escolas. No cadastro final temos que $32 \%$ das escolas pertencem à rede estadual de ensino, $41 \%$ à rede municipal e $27 \%$ à rede privada. Observando para a região geográfica, $39 \%$ são da região Sudeste, $31 \%$ da região Nordeste, $15 \%$ da região Sul, $8 \%$ da região Norte e $7 \%$ da região Centro-Oeste do Brasil.

Com relação à infraestrutura de TIC, as escolas têm em média 21 computadores, já a média de computadores para uso dos alunos é de 18 computadores, lembrando que essa variável não tem informações para 15\% das escolas e que não foram consideradas apenas para o cálculo dessa média, nas demais variáveis essas escolas foram contabilizadas. Um total de 1082 escolas declararam não ter computadores, ou seja o NUM_COMPUTADORES é igual a zero. Em relação ao acesso à Internet, $93 \%$ das escolas o possuem, como também, $81 \%$ são de conexões banda larga. Dentre as escolas que possuem equipamentos multimídias, estão disponíveis em média 2,5 equipamentos, mas é importante destacar que mais de 17 mil escolas não possuem nenhum desses equipamentos.

Em 78\% das escolas, o laboratório de informática existe em suas dependências e as escolas possuem em média 11,6 salas de aula. Apenas 13\% das escolas possuem em seus quadros professor de informática, sendo que em média as escolas possuem 27 docentes e com média de idade de 39 anos.

Da pesquisa TIC Educação 2013, utilizamos apenas a variável para a qual queremos obter os resultados para todas as UF, a proporção de escolas em que os professores usam a Internet em atividades de ensino aprendizagem com os alunos, P44_TOTAL. As escolas que não possuem acesso à Internet, não responderam à essa pergunta, assim, consideramos que se a escola não tem acesso à Internet, ela não pode ser utilizada pelos professores para as atividades de ensino-aprendizagem com os alunos atribuindo a resposta não para a variável de interesse. Por outro lado, escolas que não possuem computador não responderam a pergunta sobre acesso à Internet que, por sua vez, era a pergunta que atuou como filtro para a investigação sobre uso da Internet pelos professores em 
atividades com os alunos. Dessa maneira, optamos por não considerar essas escolas na análise, pois não é possível supor que a ausência de computador extinga a existência de acesso a Internet e o consequente uso pelo professor com os alunos. Além da exclusão desses casos, ao final trabalhamos com 927 respostas obtidas, pois outras escolas não são encontradas através do seu código no cadastro de turmas do Censo Escolar. Portanto, dentre as 927 escolas presentes na amostra da pesquisa, 85\% declararam que os professores utilizam a Internet em atividades de ensino-aprendizagem.

\subsubsection{Reponderação dos resultados da pesquisa TIC Educação}

A Pesquisa TIC Educação é uma pesquisa com amostra probabilística, tal que as escolas presentes na amostra representam todas as unidades que fazem parte da população alvo, inclusive as que não foram selecionadas. A alocação da amostra utiliza métodos de estratificação e uso de probabilidades desiguais para inclusão na amostra, de tal forma que se fez necessário calcular a probabilidade de seleção de cada unidade selecionada para que fosse possível generalizar os resultados da pesquisa para toda população.

De acordo com o CGI.br (2014), o cálculo do peso da escola considerou a seleção da amostra com probabilidade proporcional ao número de turmas existentes na população alvo de cada escola em relação à quantidade de turmas disponíveis em cada um dos 15 estratos formados pelo cruzamento das macrorregiões brasileiras e dependências administrativas para cada uma das séries de interesse da pesquisa. A correção de não resposta foi realizada dentro de cada estrato, de tal forma que o peso das escolas foi redistribuído somente entre as escolas em que houve pelo menos uma entrevista. Para escolas com mais de uma série selecionada para participar da pesquisa, foi extraída a média dos pesos para a obtenção do peso final da escola.

Esses pesos amostrais estavam disponíveis no banco de dados disponibilizado pelo CETIC.br para a execução desta dissertação. No entanto, como já mencionado, o total da amostra de escolas da pesquisa é de 939, mas utilizamos apenas 927 casos em que temos respostas obtidas na variável de interesse. Dessa forma, realizamos a mesma correção de não resposta que o CETIC.br para o peso final de cada uma das 927 escolas. Isto é, nós redistribuímos o peso das 939 escolas apenas para as 927 que responderam, multiplicando o peso fornecido pela razão entre a soma dos pesos das escolas por estrato e a soma dos pesos das escolas que aceitaram participar da pesquisa e declararam alguma resposta para a nossa variável de interesse, por estrato. Dessa forma, obtivemos o peso final considerado nos modelos que levam em conta o efeito do plano amostral que serão discutidos adiante.

\subsection{Cálculo do peso amostral para toda listagem}

No Capítulo 3, Seção 3.3 introduzimos o cálculo da estimativa do erro quadrático médio segundo o algoritmo bootstrap proposto por González-Manteiga et al. (2007), que será utilizado, ao longo desta dissertação. Para a execução desse algoritmo era preciso conhecer a probabilidade de seleção para todas as escolas presentes no banco de dados final, no entanto, essa informação não estava disponível para todas as unidades, só estava disponível a informação dos pesos amostrais fornecidos pela pesquisa TIC Educação e reponderados de acordo com a Seção 2.3.4. Dessa forma, foi preciso calcular a probabilidade de seleção para todas as escolas presentes no banco de dados final. Essa seção visa apenas descrever como foi esse procedimento, uma vez que foi realizado em todo o 
conjunto de dados.

A variável ESTRATO_FINAL é formada por uma combinação de série, macrorregião e dependência administrativa. Para as escolas que não estavam na amostra da pesquisa TIC Educação, não temos as informações da variável estrato, pois uma escola pode conter mais de uma série de interesse. Dessa forma, precisamos atribuir uma série para cada uma dessas escolas a fim de construir a variável ESTRATO_FINAL para todas as escolas da listagem. Assim, selecionamos aleatoriamente uma série para cada uma dessas escolas de maneira proporcional ao número de turmas existentes para as séries de interesse nessas escolas.

Seguindo o proposto em Ohlsson (1998), que será descrito na Seção 3.3.1, obtemos a medida de tamanho que será utilizada para a seleção de escolas com probabilidade proporcional ao tamanho (PPT) para todas as escolas do banco de dados final. Essa medida é a razão entre a quantidade de turmas na série da escola $i$ no estrato $h$ em relação a quantidade de turmas na série em todo o estrato $h$.

Ainda, temos que $n_{h}$ é o tamanho da amostra desejada dentro do estrato $h$. Consideramos que o tamanho da amostra desejado dentro de cada estrato é o tamanho observado na amostra da pesquisa TIC Educação. Assim, calculamos a probabilidade de que a escola $i$ seja incluída na amostra $s$.

Com base no inverso da probabilidade de seleção calculada, obtivemos o peso amostral para cada unidade que não estava presente na amostra da pesquisa TIC Educação, uma vez que estas já possuíam seu peso atribuído e não encontramos justificativas para não considerá-los como peso final. Dessa maneira, todas as unidades da listagem possuem um peso amostral e sua respectiva probabilidade de seleção, disponibilizado através das variáveis PESO_FINAL e PROB_FINAL, respectivamente. Cabe ressaltar que os pesos amostrais para as escolas presentes na amostra já são os reponderados conforme Subseção 2.3.4. 


\section{Capítulo 3}

\section{Metodologias}

Atualmente as pesquisas amostrais são amplamente difundidas e utilizadas por institutos de pesquisas com o intuito de conhecer determinada característica acerca de uma população. De maneira geral, o tamanho das amostras costuma ser planejado para produzir dados confiáveis para grandes áreas, como para a população como um todo. No entanto, o desejo de obter essas informações em níveis mais desagregados, sem aumentar o tamanho da amostra, vem crescendo nos setores públicos e privados. Ocorre que o tamanho das amostras dentro desses domínios desagregados não é suficientemente grande para a produção de estimativas com precisão aceitável.

A metodologia de estimação em pequenas áreas - do inglês, Small Area Estimation (SAE)-, ou pequenos domínios, começa a ser desenvolvida para que seja possível a produção de estimativas confiáveis para as características de interesse, como total populacional, médias, proporções, contagens etc., para essas áreas onde a amostra é muito pequena ou até mesmo onde não se tenha amostra disponível. De acordo com Rao (2003), domínios podem ser definidos por áreas geográficas, grupos sócio-demográficos ou outra subpopulação, ou seja, o termo pequena área não se refere necessariamente a uma área geográfica, mas sim a um domínio de interesse em que o tamanho da amostra é pequeno. Nesta dissertação, utilizamos os termos pequenas áreas e pequenos domínios de maneira indiscriminada.

Os métodos de SAE podem ser divididos em: baseados no desenho amostral - do inglês designbased - ou baseados em modelos - do inglês model-based. Os estimadores baseados no desenho amostral utilizam as ponderações aplicadas nas pesquisas amostrais, assim, as inferências estão diretamente baseadas na distribuição de probabilidade trazida no desenho amostral. Já os estimadores baseados em modelos, como o próprio nome diz, utilizam um modelo, construído com os dados provenientes da amostra e variáveis auxiliares de outras fontes de dados, como por exemplo de censos e registros administrativos, para "emprestar" informações para as demais áreas semelhantes, com isso, as inferências são realizadas de acordo com o modelo assumido.

Classificamos os modelos de SAE em dois grandes tipos: o modelo de área - do inglês area-level - e o modelo de unidade - do inglês unit-level. O modelo de área relaciona as estimativas diretas da variável de interesse de cada pequena área com as variáveis auxiliares também em nível agregado. Grande parte dos modelos de área utilizados na prática, seja para a obtenção de estimativas em pequenas áreas para a renda ou grau de escolaridade de uma determinada população quanto para o mapeamento de doenças, dentre outros possíveis exemplos, são inspirados no modelo proposto por Fay e Herriot (1979), que estimaram a renda per capita em pequenos domínios nos EUA com população menor que 1000 habitantes, usando como variável resposta a média amostral. Já o modelo 
de unidade relaciona a característica de interesse e as informações auxiliares em nível desagregado, ou seja, em unidades específicas do estudo. Esse modelo requer que os dados para cada elemento, ou seja de nível de unidade, estejam disponíveis. O modelo de unidade foi inicialmente proposto por Battese et al. (1988) para estimar a área plantada com milho e soja por segmento para 12 pequenas áreas utilizando dados obtidos por satélite e amostrais. Uma ideia geral sobre a utilização dos modelos para SAE é dada a seguir.

Seja $P$ uma população finita de tamanho $N, P=\{1, \cdots, N\}$. Essa população pode ser subdividida em $D$ pequenos domínios, tal que denotamos por $P_{d}$ a subpopulação de $P$ no pequeno domínio $d, P_{d} \subset P, d=1, \cdots, D$. O tamanho de cada subpopulação $P_{d}$ é denotado por $N_{d}$, $d=1, \cdots, D$, onde $N=\sum_{d=1}^{D} N_{d}$. Considere $\boldsymbol{X}$ a matriz com dimensão $N \times p$, em que cada linha $\boldsymbol{x}_{d j}^{\prime}, j=1, \cdots, N_{d}$, contém as informações das variáveis auxiliares, e $\boldsymbol{y}$ o vetor de dimensão $N \times 1$ da variável de interesse.

Considere que $s$ é uma amostra de tamanho $n<N$ extraída de $P$; e $r=P-s$ as unidades complementares. Denotamos por $s_{d}=s \cap P_{d}$ as unidades pertencentes a amostra da área $d$, de tamanho $n_{d}$, tal que $n=\sum_{d=1}^{D} n_{d}$. Do mesmo modo, $r_{d}=r \cap P_{d}$ são as unidades de $P_{d}$ não amostradas com cardinalidade $N_{d}-n_{d}, d=1, \cdots, D$. Com base nessa notação podemos reescrever as partições de $\boldsymbol{X}$ e $\boldsymbol{y}$ como:

$$
\boldsymbol{X}=\left[\begin{array}{l}
\boldsymbol{X}_{s} \\
\boldsymbol{X}_{r}
\end{array}\right], \quad \boldsymbol{y}=\left[\begin{array}{l}
\boldsymbol{y}_{s} \\
\boldsymbol{y}_{r}
\end{array}\right],
$$

tal que, $\boldsymbol{X}_{s}$ e $\boldsymbol{y}_{s}$ são as partições para as unidades presentes na amostra $s$ e $\boldsymbol{X}_{r}$ e $\boldsymbol{y}_{r}$ para as unidades fora da amostra. Consideramos que a única parte desconhecida é $\boldsymbol{y}_{r}$. Dessa forma, o modelo é construído com as informações de $\boldsymbol{X}_{s}$ e $\boldsymbol{y}_{s}$, e é realizada a predição para as unidades fora da amostra a partir das informações de $\boldsymbol{X}_{r}$.

Para um maior detalhamento a respeito da metodologia empregada na técnica de SAE, recomendamos a leitura de Pfeffermann (2013), Moura (2008), Rao (2003) ou o recém lançado Rao e Molina (2015). Estas referências não constituem uma bibliografia extensiva sobre o assunto, mas servem para apresentar os pontos gerais.

Em nosso caso de estudo, as pequenas áreas são as UF, pois a pesquisa TIC Educação produz resultados confiáveis apenas para o total de escolas e para as regiões geográficas do Brasil, pois o tamanho da amostra para cada UF é pequeno (ver Tabela A.1). Apesar da amostra da pesquisa TIC Educação ser realizada dentro de cada região, o que não garante a seleção de unidades em todas as UF, na edição 2013 da pesquisa todas as UF possuem pelo menos uma escola amostrada, o que nos permite obter o estimador direto da amostra, que será mais detalhado na Seção 3.1.

Além disso, como o objetivo desta dissertação é estimar a proporção de escolas onde os professores usam a Internet em atividades de ensino-aprendizagem para cada UF e nossa variável resposta é binária, assumindo os valores 0 e 1 - para as respostas não e sim, respectivamente-, podemos utilizar a teoria já existente sobre modelos de regressão logística para a construção de modelos que expliquem essa utilização nas escolas (Seção 3.2). Como medida de qualidade do ajuste, utilizamos o algoritmo proposto por González-Manteiga et al. (2007) para a estimação do Erro Quadrático Médio (Seção 3.3). Por fim, era preciso conhecer o desenho amostral empregado na pesquisa TIC Educação e trazemos um resumo a respeito da Amostragem Sequencial de Poisson na Subseção 3.3.1. 


\subsection{Estimador direto}

O método de obtenção das estimativas da característica de interesse com base apenas nas observações amostradas é denominado de estimador direto. Considere que $\overline{Y_{d}}$ é a proporção, ou média, da característica de interesse dentro da pequena área $d=1, \cdots, D$. O estimador direto é a forma mais simples de se obter uma estimativa para $\overline{Y_{d}}$, pois considera apenas os elementos da amostra e as informações do desenho amostral.

Seja $\pi_{d j}$ a probabilidade de inclusão da escola $j$ da área $d$ na amostra $s_{d}$ e $w_{d j}$ o correspondente peso amostral da escola, tal que $w_{d j}=\pi_{d j}{ }^{-1}$. De acordo com Cochran (1977) e Molina e Marhuenda (2015), dentre outros, o estimador direto não viesado de $\overline{Y_{d}}$ é o estimador de Horvitz-Thompson dado por:

$$
{\widehat{\bar{Y}_{d}}}^{D I R}=N_{d}^{-1} \sum_{j \in s_{d}} w_{d j} y_{d j}, j=1, \cdots, n_{d}, d=1, \cdots, D .
$$

Molina e Marhuenda (2015) mostram que o estimador não viesado da variância do estimador (3.1) é dado por:

$$
\widehat{V_{\pi}}\left({\widehat{\overline{Y_{d}}}}^{D I R}\right)=\frac{1}{N_{d}^{2}} \sum_{j \in s_{d}} w_{d j}\left(w_{d j}-1\right) y_{d j}^{2}, \quad j=1, \cdots, n_{d}, d=1, \cdots, D .
$$

O Erro Quadrático Médio (EQM) é dado pela soma da variância e o quadrado do viés. Como o estimador dado pela Equação (3.2) é não viesado, temos que o estimador do EQM é igual ao estimador da variância,

$$
\widehat{E Q M}\left({\widehat{\overline{Y_{d}}}}^{D I R}\right)=\widehat{V_{\pi}}\left({\widehat{\overline{Y_{d}}}}^{D I R}\right) j=1, \cdots, n_{d}, d=1, \cdots, D .
$$

Cabe ressaltar, que apesar da facilidade de cálculo do estimador de Horvitz-Thompson, ele não permite a estimação de domínios fora da amostra, isto é, ele só existe para áreas em que há amostra disponível.

\subsection{Abordagens baseadas em modelos}

Uma vez que o principal objetivo desta dissertação é obtenção de estimativas confiáveis para a proporção de escolas em que os professores usam a Internet em atividades de ensino-aprendizagem com os alunos para cada UF, julgamos necessária a construção de modelos por abordagens distintas de modo a comparar as estimativas produzidas entre os modelos e também em relação às estimativas diretas da amostra. Nesse sentido, são propostas cinco abordagens ${ }^{1}$ diferentes para avaliar se algum método se sobressai aos demais. Denominamos as abordagens por:

1. Modelo geral: modelo que considera todas as informações sem nenhuma subdivisão dos dados;

2. Modelo por região: construído um modelo para cada região geográfica;

3. Modelo por cluster: após uma análise de agrupamentos das escolas, é construído um modelo para cada agrupamento formado;

\footnotetext{
${ }^{1} \mathrm{O}$ detalhamento da construção de cada abordagem será feita no Capítulo 4 .
} 
4. Modelo com efeitos aleatórios: modelo que leva em consideração os efeitos aleatórios;

5. Modelo com efeitos aleatórios e efeito do plano amostral: modelo que leva em consideração tanto os efeitos aleatórios quanto o plano amostral.

As abordagens 4 e 5 assumem a presença de efeitos aleatórios, isto é, consideram que as UF assumem distribuições de probabilidades distintas, assim, utilizam a teoria apresentada na Subseção 3.2.1. Por outro lado, as abordagens 1, 2 e 3, não consideram a presença do efeito aleatório, pois é feita a suposição que os efeitos são todos fixos, conforme será descrito na Subseção 3.2.2.

A utilização do efeito do plano amostral ainda não é amplamente difundida na metodologia de estimação em pequenas áreas. No entanto, julgamos necessária a incorporação desse efeito na construção de modelos, de tal forma que as abordagens 1, 2 e 5 o incoporam, enquanto as abordagens 3 e 4 não o levam em consideração. A incorporação do plano amostral complexo é discutida na Subseção 3.2.3.

\subsubsection{Modelo de regressão logística com efeitos aleatórios}

O cálculo de estimativas diretas para domínios em que o tamanho da amostra é pequeno pode não ser de muita confiabilidade. Dessa forma, procedimentos baseados em modelos foram utilizados para construir melhores estimativas para as pequenas áreas, explorando informações auxiliares, que por muitas vezes possuem boa correlação com a variável de interesse. A estimação em pequenas áreas para respostas binárias utiliza a teoria de modelos lineares mistos generalizados, considerando as variáveis auxiliares com informação no nível de unidade. Esse método já foi utilizado por um grande número de autores, por exemplo, Jiang (1998), Jiang (2007), Liu (2009), Rahman et al. (2010).

De modo geral, a inclusão de efeitos aleatórios são utilizados a fim de capturar a relação entre a variável resposta e as variáveis auxiliares para dados agrupados por algum fator de classificação, que não é explicada pelos efeitos fixos. Não discutiremos em profundidade a teoria de modelos lineares mistos generalizados, para isso recomendamos a leitura de McCullagh e Nelder (1989). Trazemos apenas um resumo da teoria que será utilizada na construção do modelo para o estudo.

Como já mencionado, seja $P=\{1, \cdots, N\}$ uma população finita de tamanho $N$ subdividida em $D$ pequenos domínios, $P_{d} \subset P$, cada qual de tamanho $N_{d}, d=1, \cdots, D$, tal que $N=\sum_{d=1}^{D} N_{d}$. Em nosso caso, $P$ é a população alvo de escolas conforme definido na Subseção 2.3.1. Além disso, denotamos por $y_{d j}$ o valor da variável de interesse para a escola $j$ da pequena área $d, j=1, \cdots, N_{d}$, e $\boldsymbol{x}_{d j}^{\prime}$ o vetor contendo as variáveis auxiliares provenientes do Censo Escolar na mesma escola.

Seja $u_{d}$ o efeito aleatório normalmente distribuído com média zero e variância $\varphi$ para a pequena área $d$. Assumimos que $u_{1}, \cdots, u_{D}$ são independentes, de modo que $y_{d j} \mid u_{d} \sim \operatorname{Bin}\left(m_{d j}, p_{d j}\right)$, ou seja, dado $u_{d}$, as observações $y_{d j}$ são independentes e com distribuição binomial de tamanho $m_{d j} \mathrm{e}$ probabilidade $p_{d j}$. Neste caso, temos que $y_{d j}$ é uma variável binária, assumindo os valores de 0 ou 1 , assim, $m_{d j}=1$. Como a distribuição condicional de $y_{d j}$ pertence à família exponencial, a função de ligação utilizada é o logito,

$$
\log \left(\frac{p_{d j}}{1-p_{d j}}\right), j=1, \cdots, N_{d}, d=1, \cdots, D
$$

Fazendo a relação com as variáveis descritas na Seção 2.3.2, temos que $y_{d j}=$ P44_TOTAL e 
a variável que define os pequenos domínios nos quais a população é particionada é sigLA. Já o vetor $\boldsymbol{x}_{d j}^{\prime}$ contém as demais variáveis disponíveis, com exceção das variáveis PK_COD_ENTIDADE, ESTRATO_FINAL, TIC, N_AMO, PROB_FINAL e PESO_FINAL.

Assumindo que $\boldsymbol{\beta}$ é o vetor de coeficientes dos efeitos fixos do modelo e que o preditor linear seja dado por $\eta_{d j}=\boldsymbol{x}_{d j}^{\prime} \boldsymbol{\beta}+u_{d}$, consideramos que o modelo válido para toda a população $P$ é dado por:

$$
\log \left(\frac{p_{d j}}{1-p_{d j}}\right)=\boldsymbol{x}_{d j}^{\prime} \boldsymbol{\beta}+u_{d}, \quad j=1, \cdots, N_{d}, d=1, \cdots, D
$$

Podemos reescrever a Equação (3.4), como:

$$
p_{d j}=\frac{\exp \left\{\boldsymbol{x}_{d j}^{\prime} \boldsymbol{\beta}+u_{d}\right\}}{1+\exp \left\{\boldsymbol{x}_{d j}^{\prime} \boldsymbol{\beta}+u_{d}\right\}}, j=1, \cdots, N_{d}, d=1, \cdots, D .
$$

Como o objetivo desta dissertação é obter a proporção de escolas em que os professores usam a Internet em atividades de ensino-aprendizagem para cada UF, isso significa dizer que nossa quantidade de interesse é o vetor $\overline{\boldsymbol{Y}}^{\prime}=\left(\overline{Y_{1}}, \cdots, \overline{Y_{D}}\right)$. Denotamos por $\overline{Y_{d}}$ a proporção, ou média, da característica de interesse dentro de cada pequena área $d$, tal que

$$
\overline{Y_{d}}=N_{d}^{-1} \sum_{j=1}^{N_{d}} y_{d j}, \quad d=1, \cdots, D
$$

Vale lembrar que $s$ é uma amostra de tamanho $n<N, s \subset P$. Denotamos por $s_{d}=s \cap P_{d}$ as unidades pertencentes à amostra da área $d$ de tamanho $n_{d}$, tal que $n=\sum_{d=1}^{D} n_{d}$. Temos ainda $r=P-s$ o conjunto das unidades que não estão incluídas na amostra $s$. Do mesmo modo, $r_{d}=r \cap P_{d}$ é o conjunto das unidades de $P_{d}$ não amostradas com cardinalidade $N_{d}-n_{d}, d=1, \cdots, D$. Dessa forma, podemos reescrever $\overline{Y_{d}}$ da seguinte maneira:

$$
\overline{Y_{d}}=N_{d}^{-1}\left(\sum_{j \in s_{d}} y_{d j}+\sum_{j \in r_{d}} y_{d j}\right), d=1, \cdots, D .
$$

A única parcela envolvida no cálculo de $\overline{Y_{d}}$ que é desconhecida é $\sum_{j \in r_{d}} y_{d j}, d=1, \cdots, D$. O valor esperado de cada elemento $y_{d j}$ de $j \in r_{d}$ pode ser calculado utilizando o preditor linear $\hat{\eta}_{d j}=\boldsymbol{x}_{d j}^{\prime} \hat{\boldsymbol{\beta}}+\hat{u}_{d}$, que foi obtido através do ajuste do modelo para as unidades presentes na amostra. Como já mencionado, temos que $y_{d j} \mid u_{d} \sim \operatorname{Bin}\left(1, p_{d j}\right)$, assim, a estimativa da probabilidade de sucesso de cada $y_{d j}$ é dada por:

$$
\hat{\mu}_{d j}=\hat{p}_{d j}=\frac{\exp \left\{\boldsymbol{x}_{d j}^{\prime} \hat{\boldsymbol{\beta}}+\hat{u}_{d}\right\}}{1+\exp \left\{\boldsymbol{x}_{d j}^{\prime} \hat{\boldsymbol{\beta}}+\hat{u}_{d}\right\}} j=1, \cdots, N_{d}, d=1, \cdots, D,
$$


de tal forma que podemos escrever o preditor para $\overline{Y_{d}}$ da seguinte maneira:

$$
\widehat{\overline{Y_{d}}}=N_{d}^{-1}\left(\sum_{j \in s_{d}} y_{d j}+\sum_{j \in r_{d}} \hat{p}_{d j}\right), d=1, \cdots, D .
$$

Por fim, temos que a expressão final do preditor do modelo misto logístico para $\widehat{\overline{Y_{d}}}$ que desejamos obter é dada por:

$$
\widehat{\overline{Y_{d}}}=\frac{1}{N_{d}}\left(\sum_{j \in s_{d}} y_{d j}+\sum_{j \in r_{d}} \frac{\exp \left\{\boldsymbol{x}_{d j}^{\prime} \hat{\boldsymbol{\beta}}+\hat{u}_{d}\right\}}{1+\exp \left\{\boldsymbol{x}_{d j}^{\prime} \hat{\boldsymbol{\beta}}+\hat{u}_{d}\right\}}\right), d=1, \cdots, D .
$$

\subsubsection{Modelo de regressão logística}

Os modelos de efeitos mistos, ou modelos com efeitos aleatórios, são principalmente usados para descrever relações entre a variável resposta e as variáveis independentes para dados que são agrupados de acordo com algum fator de classificação. Se não é razoável supor que os níveis desse fator de classificação tenham uma distribuição de probabilidade, como é o caso dos efeitos aleatórios, opta-se por considerar apenas os efeitos fixos.

Nesse sentido, quando não há a presença do efeito aleatório, $u_{d}$, assumimos que a variável resposta $y_{d j} \sim \operatorname{Bin}\left(m_{d j}, p_{d j}\right)$, ou seja, as observações da variável resposta $y_{d j}$ são independentes com distribuição binomial de tamanho $m_{d j}$ e probabilidade de sucesso $p_{d j}$. Como estamos trabalhando com uma variável resposta binária, temos que $m_{d j}=1$. Assim, o preditor linear assume a forma $\eta_{d j}=\boldsymbol{x}_{d j}^{\prime} \boldsymbol{\beta}$, possibilitando que o modelo para toda a população $P$ seja escrito como:

$$
\log \left(\frac{p_{d j}}{1-p_{d j}}\right)=\boldsymbol{x}_{d j}^{\prime} \boldsymbol{\beta}, \quad j=1, \cdots, N_{d}, d=1, \cdots, D
$$

Ou ainda, que a probabilidade de sucesso é dada por:

$$
p_{d j}=\frac{\exp \left\{\boldsymbol{x}_{d j}^{\prime} \boldsymbol{\beta}\right\}}{1+\exp \left\{\boldsymbol{x}_{d j}^{\prime} \boldsymbol{\beta}\right\}}, j=1, \cdots, N_{d}, d=1, \cdots, D .
$$

Seguindo com a mesma notação da Subseção 3.2.1, o objetivo é fazer inferência sobre o vetor $\overline{\boldsymbol{Y}}^{\prime}=\left(\overline{Y_{1}}, \cdots, \overline{Y_{D}}\right)$, ou seja, a proporção de escolas em que os professores usam a Internet em atividades de ensino-aprendizagem por UF. Consideramos que $\overline{Y_{d}}$ é a proporção, ou a média, da característica de interesse dentro de cada pequena área $d$, tal que

$$
\overline{Y_{d}}=N_{d}^{-1} \sum_{j=1}^{N_{d}} y_{d j}=N_{d}^{-1}\left(\sum_{j \in s_{d}} y_{d j}+\sum_{j \in r_{d}} y_{d j}\right), d=1, \cdots, D
$$

onde $s_{d}$ são as unidades presentes na amostra $s$ de tamanho $n=\sum_{d=1}^{D} n_{d}$ e $r_{d}$ o complementar dessas unidades que compõe a subpopulação $P_{d}, P_{d} \in P$, tal que a cardinalidade de $r_{d}$ é de $N_{d}-n_{d}$, $d=1, \cdots, D$. 
A única parcela envolvida no cálculo de $\overline{Y_{d}}$, dado pela Equação (3.8), que é desconhecida é $\sum_{j \in r_{d}} y_{d j}, d=1, \cdots, D$. O valor esperado de cada elemento $y_{d j}$ de $j \in r_{d}$ pode ser calculado utilizando o preditor linear $\hat{\eta}_{d j}=\boldsymbol{x}_{d j}^{\prime} \hat{\boldsymbol{\beta}}$, que foi obtido através do ajuste do modelo para as unidades presentes na amostra. Como já mencionado, temos que $y_{d j} \sim \operatorname{Bin}\left(1, p_{d j}\right)$, assim, a estimativa da probabilidade de sucesso de cada $y_{d j}$ é dada por:

$$
\hat{\mu}_{d j}=\hat{p}_{d j}=\frac{\exp \left\{\boldsymbol{x}_{d j}^{\prime} \hat{\boldsymbol{\beta}}\right\}}{1+\exp \left\{\boldsymbol{x}_{d j}^{\prime} \hat{\boldsymbol{\beta}}\right\}} j=1, \cdots, N_{d}, d=1, \cdots, D .
$$

Para que tenhamos as proporções $\widehat{\overline{Y_{d}}}$ para cada pequena área $d=1, \cdots, D$, utilizamos a seguinte expressão:

$$
\widehat{\overline{Y_{d}}}=\frac{1}{N_{d}}\left(\sum_{j \in s_{d}} y_{d j}+\sum_{j \in r_{d}} \frac{\exp \left\{\boldsymbol{x}_{d j}^{\prime} \hat{\boldsymbol{\beta}}\right\}}{1+\exp \left\{\boldsymbol{x}_{d j}^{\prime} \hat{\boldsymbol{\beta}}\right\}}\right) .
$$

\subsubsection{Modelo de regressão logística com efeito do plano amostral}

Apesar da ponderação na análise de dados amostrais ser incorporada com muita frequência na estimação direta de parâmetros, não é consenso o uso na inferência baseada em modelos. Discute-se a relevância da incorporação dos pesos amostrais, porém há estudos que mostram que a utilização protege os modelos de má especificação e de planos amostrais não-ignoráveis que poderiam introduzir ou causar vícios nas estimativas. Pessoa e Silva (1998) revelam que ignorar o plano amostral pode levar a decisões erradas e avaliações inadequadas da precisão das estimativas amostrais.

Nesse sentido, e com o intuito de comparar as predições obtidas pelo modelo de regressão logística com efeitos aleatórios, pelo modelo obtido posteriormente à análise de cluster e pelo estimador direto, propomos a utilização de modelos de regressão logística considerando o efeito do plano amostral, isto é, os pesos amostrais. Neste caso, as abordagens utilizadas foram a do modelo geral, do modelo por região e do modelo com efeitos aleatórios e efeito do plano amostral.

Ao compararmos a inclusão dos planos amostrais complexos na construção de modelos de regressão logística, como os propostos nas Equações (3.6) e (3.9), e modelos que não o levam em consideração, notamos que a diferença está na forma de obtenção do $\hat{\boldsymbol{\beta}}$, pois os dados provenientes de amostragem complexa violam a suposição de independência das observações, o que pode tornar inviável a estimação por máxima verossimilhança. Binder (1983) propôs o método da máxima pseudo-verossimilhança - do inglês, pseudo-maximum likelihood estimation- como uma técnica para estimar os parâmetros do modelo (Heeringa et al., 2010). Esse método foi revisto e aprimorado por diversos autores, mas atualmente é o método adotado para a estimação de modelos de regressão logística para amostras complexas na maioria dos softwares. Dessa forma, a obtenção do estimador $\hat{\boldsymbol{\beta}}$ por máxima pseudo-verossimilhança de $\boldsymbol{\beta}$ é a solução do sistema de equações dado por (3.11), tal que pode ser maximizado por método iterativos, como o método de Newton-Rapshon,

$$
\sum_{d=1}^{D} \sum_{j=1}^{n_{d}} w_{d j}\left[y_{d j}-\frac{\exp \left\{\boldsymbol{x}_{d j}^{\prime} \boldsymbol{\beta}\right\}}{1+\exp \left\{\boldsymbol{x}_{d j}^{\prime} \boldsymbol{\beta}\right\}}\right] \boldsymbol{x}_{d j}=\mathbf{0}
$$


onde $w_{d j}$ é o peso amostral da escola $j$ da área $d$, tal que $w_{d j}=\pi_{d j}{ }^{-1}$.

Nesta dissertação, para as abordagens 1 e 2 utilizamos o pacote survey do R, uma explicação sobre sua utilização é encontrada em Lumley (2011). Para a abordagem número 5, não encontramos nenhum pacote no $\mathrm{R}$ que ajustasse modelos mistos de regressão logística para amostras complexas, assim utilizamos o software STATA ${ }^{\circledR}$, através da função svy: melogit, e maiores informações sobre sua aplicação podem ser encontradas em Heeringa et al. (2010).

\subsection{Erro Quadrático Médio}

Como medida de qualidade do ajuste do modelo é utilizado o Erro Quadrático Médio (EQM), pois segundo Casella e Berger (2002) o EQM tem vantagens de interpretação frente a outras medidas de distâncias, além de incorporar uma medida de variabilidade do estimador (precisão) e outra de viés (acurácia). Adicionalmente, um estimador que tem boas propriedades de EQM tem uma combinação controlada de variância e viés. No entanto, de acordo com González-Manteiga et al. (2007) para estimadores em pequenas áreas a forma analítica não é adequada para ser calculada explicitamente. $\mathrm{O}$ artigo traz ainda uma lista extensa de autores que se dedicaram a aprimorar o cálculo do EQM para esses casos, muitos deles utilizando métodos de linearização e outros utilizando estimadores via bootstrap, mas destacam que para o modelo logístico misto ainda há uma escassez nos estudos.

Nesta dissertação adotamos o método de bootstrap proposto em González-Manteiga et al. (2007), por este ser mais vantajoso para populações binomiais com tamanho de amostra pequeno e que apesar do custo computacional, permite estimar qualquer característica da população até mesmo quando a expressão analítica é desconhecida. Nosso caso é um caso específico da distribuição Binomial, tal que o parâmetro de tamanho é igual a um, ou seja, conforme declarado anteriormente, $y_{d j} \sim \operatorname{Bin}\left(1, p_{d j}\right)$, e desejamos estimar a proporção da população com a característica de interesse.

O método de reamostragem proposto é uma combinação entre o wild bootstrap, inicialmente proposto por Wu (1986), e o bootstrap para populações finitas, que a partir de um população artificial finita, que imite a população real, consiga obter os estimadores. Os passos do método de bootstrap para obter o EQM são resumidos no seguinte algoritmo:

1. Ajuste o modelo com os dados obtidos na amostra de modo a obter as estimativas $\hat{\beta}$ e $\hat{\varphi}$, para $\beta$ e $\varphi$ respectivamente;

2. Para $b=1,2, \cdots, B$ faça:

a. Gere o vetor $\mathbf{T}_{\mathbf{1}}$ de tamanho $D$, com variáveis independentes tal que $E\left[T_{1}\right]=0$ e $\operatorname{Var}\left[T_{1}\right]=1$;

b. Construa o vetor $u^{*}=\left(u_{1}^{*}, \cdots, u_{D}^{*}\right)^{\prime}=\hat{\varphi} \mathbf{T}_{\mathbf{1}}$;

c. Construa a população $P^{*(b)}$ de tamanho $N=\sum_{d=1}^{D} N_{d}$, gerando valores de uma distribuição de Bernoulli com probabilidades $p_{d j}^{*}$ de acordo com o modelo de superpopulação

$$
p_{d j}^{*}=\frac{\exp \left\{\boldsymbol{x}_{d j}^{\prime} \hat{\boldsymbol{\beta}}+u_{d}^{*}\right\}}{1+\exp \left\{\boldsymbol{x}_{d j}^{\prime} \hat{\boldsymbol{\beta}}+u_{d}^{*}\right\}}, j=1, \cdots, N_{d}, d=1, \cdots, D .
$$

Ou seja, $y_{d j}^{*} \sim \operatorname{Bernoulli}\left(p_{d j}^{*}\right), j=1, \cdots, N_{d}$ e $d=1, \cdots, D$; 
d. Determine ${\overline{Y_{d}^{*}}}^{(b)}, d=1, \cdots, D$ (Equação $\left.(3.5)\right)$;

e. Extraia uma amostra $s^{*}$ com as mesmas características da amostra original (ver Subseção 3.3.1);

f. A partir da amostra $s^{*}$, calcule o preditor ${\widehat{Y_{d}^{*}}}^{(b)}, d=1, \cdots, D$ (Equação $(3.7)$ );

3. A aproximação do $\operatorname{EQM}\left(\widehat{\overline{Y_{d}}}\right)$ é dada por:

$$
\widehat{E Q M}\left(\widehat{\overline{Y_{d}}}\right)=B^{-1} \sum_{b=1}^{B}\left({\widehat{Y_{d}^{*}}}^{(b)}-{\overline{Y_{d}^{*}}}^{(b)}\right)^{2}, d=1, \cdots, D .
$$

Fizemos uma adaptação do algoritmo acima para os modelos que não levam em consideração os efeitos aleatórios. Mantivemos todos os passos, com exceção dos itens a, b do passo 2, uma vez que estes se referem aos efeitos aleatórios. Dessa maneira, no item c ao invés da Equação (3.12) temos que a população $P^{*(b)}$ é construída a partir de valores de uma distribuição de Bernoulli com probabilidades $p_{d j}^{*}$, tal que:

$$
p_{d j}^{*}=\frac{\exp \left\{\boldsymbol{x}_{d j}^{\prime} \hat{\boldsymbol{\beta}}\right\}}{1+\exp \left\{\boldsymbol{x}_{d j}^{\prime} \hat{\boldsymbol{\beta}}\right\}}, j=1, \cdots, N_{d} .
$$

Logo, no item d do passo 2 utilizamos a Equação (3.8) no lugar da Equação (3.5) e no item f, também do passo 2, empregamos a Equação (3.10) ao invés da Equação (3.7).

\subsubsection{Amostragem Sequencial de Poisson}

O primeiro estágio de seleção da amostra da pesquisa TIC Educação é feito utilizando o método de Amostragem Sequencial de Poisson. Como esse primeiro estágio é o de seleção das escolas que compõem a unidade de análise de nosso interesse, utilizamos o mesmo método para o procedimento de reamostragem, uma vez que é necessário extrair uma nova amostra, a cada iteração, com as mesmas características da amostra utilizada na pesquisa.

Uma das vantagens do método de Amostragem Sequencial de Poisson é que se trata de uma forma simples de se desenhar uma amostra de uma população finita com probabilidade proporcional ao tamanho (PPT). Neste trabalho, utilizamos o processo proposto por Ohlsson (1998).

Dado que a população $P=\{1, \cdots, N\}$ é finita, podemos calcular o vetor $\boldsymbol{\tau}=\left(\tau_{1}, \cdots, \tau_{N}\right)$ que é a medida de tamanho utilizada no procedimento PPT para todas as unidades da população. Em nosso caso, $\tau_{i}$ é a razão entre a quantidade de turmas da escola $i$ no estrato $h$ em relação ao número total de turmas no mesmo estrato, $i=1, \cdots, N$ e $h=1, \cdots, H$. Relembramos que, para os dados reais utilizados neste trabalho, os estratos são formados a partir da combinação das variáveis região, dependência administrativa e série; dessa forma, temos que $h=1, \cdots, 45$. Sendo assim, $\tau_{i}$ é dado por:

$$
\tau_{i}=\frac{m_{h i}}{\sum_{i=1}^{N_{h}} m_{h i}},
$$

em que $m_{h i}$ é o número de turmas da escola $i$ no estrato $h$ e $N_{h}$ é o número de escolas no estrato $h$. 
Dentro de cada estrato $h$, temos que $\tau_{i}>0$, para todo $i$, de tal forma que $\sum_{i=1}^{N_{h}} \tau_{i}=1$, uma vez que queremos amostrar unidades com probabilidades proporcionais a $\tau_{i}$.

Assumimos que $n_{h}$ é o tamanho da amostra dentro do estrato $h$ e $n$ o tamanho total da amostra desejada, tal que $n=\sum_{h=1}^{H} n_{h}$. Tal como já mencionado, no conjunto de dados reais utilizado neste trabalho, $h=1, \cdots, 45$ e que neste caso $n=927$ e os valores de $n_{h}$ estão disponíveis na variável $N_{-} A M O$ do banco de dados final.

Atribui-se para cada unidade $i$ da listagem um número aleatório independente uniformemente distribuído no intervalo [0,1], aqui denotado por $R_{i}$. Para a Amostragem Sequencial de Poisson, a partir desses valores, são formados os números aleatórios modificados, dados por:

$$
\xi_{i}=\frac{R_{i}}{\tau_{i}}
$$

Assim, temos que a inclusão de uma unidade $i$, dentro do estrato $h$, na amostra $s$ é de tal maneira que $\xi_{i} \leq n_{h}$. Segundo Ohlsson (1998), uma amostra é dita desenhada por Amostragem Sequencial de Poisson de tamanho $n$ se ela consiste nas $n$ unidades com os menores números aleatórios modificados $\xi_{i}$. Entretanto, na prática, ordena-se a listagem na ordem descrescente dos $\xi_{i}$ e, para cada estrato $h$, as $n_{h}$ primeiras unidades constituem a amostra $s$. 


\section{Capítulo 4}

\section{Comparação utilizando dados reais}

Neste capítulo, os métodos apresentados no Capítulo 3 serão aplicados a dados reais a fim de obter estimativas para a proporção de escolas em que os professores usam a Internet em atividade de ensino-aprendizagem com os alunos para cada Unidade Federativa do Brasil (UF). Assim, a partir dos dados provenientes da pesquisa TIC Educação 2013 produzida pelo CGI.br e o Censo Escolar 2013 disponibilizado pelo INEP aplicamos as abordagens: estimador direto; modelo geral; modelo por região; modelo por cluster; modelo com efeitos aleatórios; e modelo com efeitos aleatórios e efeito do plano amostral.

Dessa forma, apresentamos o modo de obtenção e as estimativas alcançadas para cada UF. Dispomos esses valores em mapas, pois uma vez que as UF são áreas geográficas, o intuito é tornar a visualização e a interpretação mais fácil. Além disso, apresentamos a estimativa do erro quadrático médio (EQM) que é utilizada como medida de qualidade do ajuste. Por fim, apresentamos uma comparação entre as estimativas obtidas.

\subsection{Estimador direto}

Dados de pesquisas amostrais são muito utilizados para obter estimativas diretamente da amostra para toda a população. Um estimador direto utiliza apenas a informação proveniente da amostra para a variável resposta, assim só é possível obter resultados para domínios onde há amostra. No entanto, há pesquisas em que é impossível selecionar amostras para todas as áreas de interesse. Livros de amostragem, como, por exemplo, Cochran (1977) e Bolfarine e Bussab (2005) descrevem técnicas para desenho da amostra para obter resultados para os totais ou regiões, porém, como detalhado no Capítulo 3, obter resultados para áreas onde o tamanho da amostra disponível é pequeno vêm sendo muito requisitado por pesquisadores e gestores de políticas públicas ao redor do mundo.

O estimador direto da amostra é o estimador de Horvitz-Thompson, dado na Equação (3.1), que é a forma mais simples de se obter um resultado, pois só considera a variável resposta declarada pelos elementos amostrados e o respectivo peso amostral, que leva em consideração todo o desenho da amostra e correções de não resposta. Vale lembrar que os pesos amostrais também são interpretados como o número de elementos na população representado pela unidade amostrada. Dessa forma, as estimativas obtidas através do estimador direto da amostra para a variável de interesse proporção de escolas em que os professores usam a Internet com os alunos para atividades de ensinoaprendizagem - para cada UF foram calculadas para o conjunto de dados provenientes da pesquisa 
TIC Educação (Tabela 4.2) e serão utilizadas na comparação com as estimativas encontradas via as diferentes abordagens baseadas em modelos.

Optamos por incluir as proporções obtidas para cada UF em uma representação cartográfica, pois a visualização torna-se mais rápida e intuitiva. Notamos que os estados do Espírito Santo e Rio Grande do Norte possuem as menores estimativas, pois estão representadas na coloração azul mais clara, para os estados de Tocantins e Mato Grosso do Sul, que tiveram uma estimava de 100\% das escolas em que os professores utilizam a Internet com os alunos, estão com a coloração azul mais escura, indicando proporções maiores.

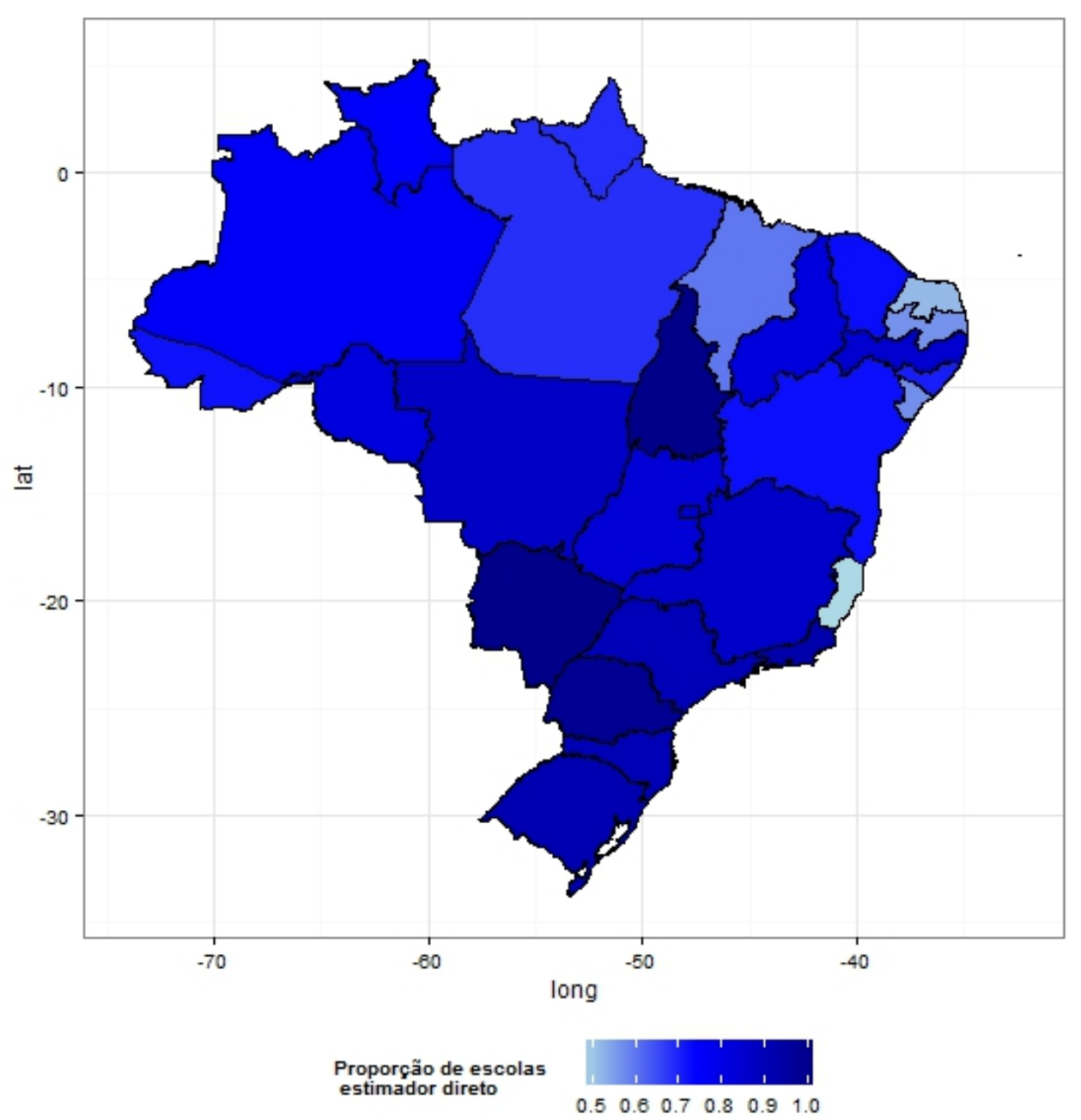

Figura 4.1: Mapa com as estimativas das proporções de escolas em que os professores usam a Internet com os alunos para atividades de ensino-aprendizagem obtidas pelo estimador direto

De acordo com as Equações (3.2) e (3.3), a estimativa do Erro Quadrático Médio (EQM) para cada UF é igual a sua variância, pois trata-se de um estimador não viesado. Podemos interpretar essa estimativa como o quão distante, em média, as estimativas estão do valor real. Através das informações disponíveis na Tabela 4.2, temos que as menores estimativas do EQM são para os estados de Tocantins e Mato Grosso do Sul, de tal modo que o resultado é exatamente igual a zero, o que significa que a estimativa para a proporção é o verdadeiro valor. No entanto, esses casos estão superestimados, pois o estimador direto considera apenas as informações existentes na amostra, e para esses casos específicos, todas as escolas presentes na amostra declararam que seus 
professores utilizam a Internet em atividades de ensino-aprendizagem com os alunos. Para o estado do Paraná temos o mesmo tipo de ocorrência, a estimativa do EQM é aproximadamente zero e 1\% das escolas da amostra declaram que os professores não utilizam a Internet em atividades de ensinoaprendizagem com os alunos. Já para o estado de São Paulo, 10\% das escolas presentes na amostra declararam que os professores não utilizam a Internet em atividades de ensino-aprendizagem com os alunos e a estimativa do EQM foi pequena, 0,001. Disponibilizamos para consulta no Apêndice A, a Tabela A.2 com as proporções da variável de interesse P44_TOTAL para as observações da amostra, sem considerar os efeitos do plano amostral, para cada UF.

Também disponibilizamos para consulta no Apêndice A, a Tabela A.1 contendo o tamanho populacional $\left(N_{d}\right)$ e o tamanho da amostra proveniente da pesquisa TIC Educação $\left(n_{d}\right)$. Desta maneira, podemos compreender os valores obtidos nas estimativas do EQM para os estados de Roraima, Sergipe e Espírito Santo, pois são os maiores valores encontrados, mas são as UF com os menores tamanho de amostra de escolas.

Na Tabela 4.2 também dispomos as estimativas do Coeficiente de Variação (CV), expresso em porcentagem, que é uma medida de dispersão calculada pela razão entre o desvio-padrão da estimativa e a média. Pela Equação (3.3), temos que o estimador do EQM é igual ao estimador da variância, assim, o estimador do CV para o estimador direto é dado por:

$$
\widehat{C V}\left(\widehat{\bar{Y}}^{D I R}\right)=\frac{\sqrt{\widehat{E Q M}\left(\widehat{\bar{Y}}^{D I R}\right)}}{{\widehat{\bar{Y}_{d}}}^{D I R}}
$$

Essa medida é empregada para estimar a precisão das estimativas, de tal forma que quanto menor for o CV mais homogêneo é o dado. Albieri (2006) afirma que o Instituto Brasileiro de Geografia e Estatística (IBGE) adota o critério apresentado na Tabela 4.1 para a classificação das estimativas do CV quanto à precisão.

Tabela 4.1: Classificação das estimativas quanto à precisão em uso

\begin{tabular}{c|c|c}
\hline Indicador & Intervalo de CV (\%) & Conceito \\
\hline Z & Zero & "Exata" \\
A & Mais de 0 a 5 & Ótima \\
B & Mais de 5 a 15 & Boa \\
C & Mais de 15 a 30 & Razoável \\
D & Mais de 30 a 50 & Pouco precisa \\
E & Mais de 50 & Imprecisa \\
\hline
\end{tabular}

Fonte: Albieri (2006)

Assim, além do tamanho pequeno da amostra para os estados de Roraima, Sergipe e Espírito Santo, o CV dessas estimativas são altos, de 31\%, $46 \%$ e $64 \%$, respectivamente, o que caracteriza estimativas pouco precisas ou imprecisa, no caso do Espírito Santo. O estado do Rio Grande do Norte também possui um CV pouco preciso, de 34\%. Os estados do Maranhão, Amapá, Paraiba, Alagoas, Acre e Rondônia também possuem estimativas do CV classificadas como razoável. O CV dos estados de Mato Grosso do Sul e de Tocantins são "exatos", pois como mencionado anteriormente, todas as escolas presentes na amostra da pesquisa TIC Educação declararam que pelo menos um professor utiliza a Internet com os alunos para atividades de ensino-aprendizagem. As demais UF possuem 
estimativas do CV ótimas e boas.

Tabela 4.2: Estimativas da proporção de escolas em que os professores usam a Internet com os alunos para atividades de ensino-aprendizagem, EQM e CV, por UF, segundo o estimador direto

\begin{tabular}{cccc|cccc|cccc}
\hline $\mathrm{UF}$ & $\widehat{\overline{Y_{d}}}(\%)$ & $\mathrm{EQM}$ & $\mathrm{CV}(\%)$ & $\mathrm{UF}$ & $\widehat{\overline{Y_{d}}}(\%)$ & $\mathrm{EQM}$ & $\mathrm{CV}(\%)$ & $\mathrm{UF}$ & $\widehat{\overline{Y_{d}}}(\%)$ & $\mathrm{EQM}$ & $\mathrm{CV}(\%)$ \\
\hline $\mathrm{AC}$ & 72 & 0,0235 & 21 & $\mathrm{MA}$ & 60 & 0,0253 & 27 & $\mathrm{RJ}$ & 92 & 0,0021 & 5 \\
$\mathrm{AL}$ & 70 & 0,0243 & 22 & $\mathrm{MG}$ & 86 & 0,0038 & 7 & $\mathrm{RN}$ & 52 & 0,0310 & 34 \\
$\mathrm{AM}$ & 75 & 0,0061 & 10 & $\mathrm{MS}$ & 100 & 0,0000 & 0 & $\mathrm{RO}$ & 81 & 0,0178 & 16 \\
$\mathrm{AP}$ & 69 & 0,0329 & 26 & $\mathrm{MT}$ & 87 & 0,0054 & 9 & $\mathrm{RR}$ & 75 & 0,0551 & 31 \\
$\mathrm{BA}$ & 72 & 0,0086 & 13 & $\mathrm{PA}$ & 68 & 0,0060 & 11 & $\mathrm{RS}$ & 91 & 0,0016 & 4 \\
$\mathrm{CE}$ & 73 & 0,0095 & 13 & $\mathrm{~PB}$ & 57 & 0,0196 & 25 & $\mathrm{SC}$ & 90 & 0,0081 & 10 \\
$\mathrm{DF}$ & 86 & 0,0051 & 8 & $\mathrm{PE}$ & 85 & 0,0068 & 10 & $\mathrm{SE}$ & 57 & 0,0698 & 46 \\
$\mathrm{ES}$ & 48 & 0,0965 & 64 & $\mathrm{PI}$ & 81 & 0,0101 & 12 & $\mathrm{SP}$ & 90 & 0,0012 & 4 \\
$\mathrm{GO}$ & 83 & 0,0033 & 7 & $\mathrm{PR}$ & 98 & 0,0003 & 2 & $\mathrm{TO}$ & 100 & 0,0000 & 0 \\
\hline
\end{tabular}

Albieri (2006) afirma que a decisão de publicar estimativas com baixa precisão ainda é muito discutida. De um lado estão os favoráveis à divulgação que preferem deixar a decisão de usar a estimativa ou não a cargo do usuário do dado e do outro lado, os contrários à divulgação que alegam que suprimindo as estimativas de pior qualidade mantém-se a credibilidade da instituição promotora da informação. Nesse intuito, observamos que a nossa característica de interesse oriunda da pesquisa TIC Educação apresenta alguns resultados de baixa qualidade para as UF. No Capítulo 3 apresentamos os conceitos da metodologia de SAE que visa obter estimativas confiáveis para níveis desagregados, onde o tamanho da amostra é pequeno. Pela Tabela A.1 podemos ver que o tamanho amostral para as áreas de interesse é pequeno e através da Tabela 4.2 mediante as estimativas do EQM e do CV notamos que, de fato, precisamos melhorar a qualidade das estimativas da proporção. Dessa forma, utilizaremos nas próximas seções a metodologia de SAE, a fim de obter estimativas da proporção com maior nível de precisão para as UF, através das abordagens baseadas em modelos.

\subsection{Modelo geral}

Uma vez que o objetivo deste trabalho é obter estimativas em um nível de precisão que o plano amostral da pesquisa TIC Educação não fornece, utilizamos a construção de modelos para que os dados "emprestem" informações para unidades similares. Logo, o primeiro modelo que nos vem em mente é utilizar todas as informações de uma única vez para analisar o comportamento geral dos dados. Dessa forma, essa seção traz os resultados obtidos na construção do modelo logístico considerando os efeitos do plano amostral construído para todas as observações, sem efeitos aleatórios ou subpopulações. Destacamos que não há subpopulações na construção dos modelos, mas que desejamos obter as proporções de escolas em que os professores utilizam a Internet com os alunos para atividades de ensino-aprendizagem para cada pequeno domínio, que neste caso são as UF.

Para a construção do modelo, empregamos as variáveis dispostas na Subseção 2.3.2, que foram selecionadas utilizando informações fornecidas por alguns especialistas na área de educação. Dessa forma, as variáveis incluídas inicialmente no modelo foram: ID_DEPENDENCIA_ADM, ID_LABORATORIO_INFORMATICA, REGIAO, NUM_SALAS_UTILIZADAS, NUM_EQUIP_MULTIMIDIA, MED_ _IDADE, QT_DOCENTES, ID_PROF_INF, NUM_COMPUTADORES, NUM_COMP_ALUNOS, ID_INTERNET e ID_BANDA_LARGA. 
Para a seleção das variáveis para a obtenção do modelo final, utilizamos o método stepwise. Além disso, realizamos o teste de Wald de múltiplos parâmetros para as variáveis tais que os valores-p eram maiores que 0,3 , a fim de obter o modelo com o menor número de parâmetros a serem estimados e que explique bem o comportamento da variável resposta (P44_TOTAL). O modelo foi ajustado utilizando a função svyglm do pacote survey do R, tal que a equação do modelo final é dada por ${ }^{1}$ :

$$
\begin{aligned}
\log \left(\frac{\hat{p}_{d j}}{1-\hat{p}_{d j}}\right)= & 4,16-1,13 \times I D_{-} D E P E N D E N C I A_{-} A D M_{\text {Municipais }} \\
& +0,33 \times I D_{-} \text {DEPENDENCIA_ADM Particulares } \\
& -0,06 \times N M_{-} M_{-} E Q U I P_{-} \text {MULTIMIDIA } \\
& +0,05 \times N U_{-} C O M_{-} A L U N O S \\
& +1,74 \times I D_{-} \text {INTERNET } \\
& +0,66 \times I D_{-} \text {BANDA_LARGA } \\
& -0,11 \times M E D_{-} \text {IDADE } \\
& +1,84 \times I D_{-} \text {PROF_INF } \\
& -0,80 \times R E G I A O_{\text {Nordeste }} \\
& -0,46 \times R E G I A O_{\text {Sudeste }} \\
& +0,24 \times R E G I A O_{\text {Sul }} \\
& -0,44 \times R E G I A O_{\text {Centro-Oeste }},
\end{aligned}
$$

Para a validação do modelo seguimos o método de validação cruzada por leave-one-out, pois como desejamos realizar uma predição para os elementos que não estão na amostra, necessitamos saber o quão preciso é esse modelo e qual a sua capacidade de generalização. Apesar do alto custo computacional, julgamos esse método como mais eficiente, pois a cada iteração retiramos uma observação amostrada, reajustamos o modelo e fazemos a predição para essa observação retirada. Dessa forma, podemos avaliar todos os casos observados e preditos. Contudo, o modelo de regressão logística fornece a probabilidade do evento ocorrer, $p_{i}^{*}$ :

$$
p_{i}^{*}=\frac{\exp \left\{\boldsymbol{x}_{i}^{\prime} \hat{\boldsymbol{\beta}}\right\}}{1+\exp \left\{\boldsymbol{x}_{i}^{\prime} \hat{\boldsymbol{\beta}}\right\}}, i=1, \cdots, n,
$$

onde $\boldsymbol{x}_{i}$ é o vetor contendo as variáveis auxiliares provenientes do Censo Escolar e $\hat{\boldsymbol{\beta}}$ o vetor estimado dos coeficientes dos efeitos fixos para os elementos da amostra $i=1, \cdots, n$.

Para a classificação das observações em sucesso ou fracasso com relação à variável de interesse, utilizamos o gráfico da curva ROC - do inglês Receiver Operating Characteristics - que é uma técnica de visualização, organização e seleção de classificadores com base em seu desempenho (Fawcett, 2006). Denominamos por sensibilidade a probabilidade de o teste fornecer os verdadeiros positivos, isto é, o resultado do modelo fornecer o mesmo resultado que o valor observado quando igual a

\footnotetext{
${ }^{1}$ A tabela contendo as estimativas, os erros-padrão, os valores das estatísticas $t$ e os valores-p está disposta no Apêndice A, Tabela A.3.
} 
1, e por especificidade a probabilidade dos verdadeiros negativos, isto é, a resposta do modelo ser negativa enquanto o valor observado também é negativo. Como desejamos maximizar tanto a especificidade quanto a sensibilidade, a curva ROC traz no seu eixo vertical a sensibilidade e no seu eixo horizontal 1-especificidade, de modo que encontrando um ponto na curva que minimize a distância do ponto $(0,1)$, este será considerado o ponto de corte para efeito de classificação das ocorrências, de tal modo que, se a probabilidade calculada pelo modelo, $p_{i}^{*}$, for menor ou igual ao ponto de corte são classificadas como fracasso, e por simetria, as probabilidades, $p_{i}^{*}$, maiores que o ponto de corte são classificadas como sucesso. Em nosso caso, sucesso é a escola ter professores que utilizam a Internet com os alunos para atividades de ensino-aprendizagem e fracasso é a escola não ter professores que fazem esse uso. A curva ROC obtida para esse modelo através dos dados calculados na validação leave-one-out está na Figura 4.2. O ponto de corte é o valor de 0,87 destacado na curva da Figura 4.2, ou seja, se a probabilidade da escola era maior que 0,87, a escola é classificada como sucesso e, caso contrário, é classificada como fracasso.

\section{Curva ROC}

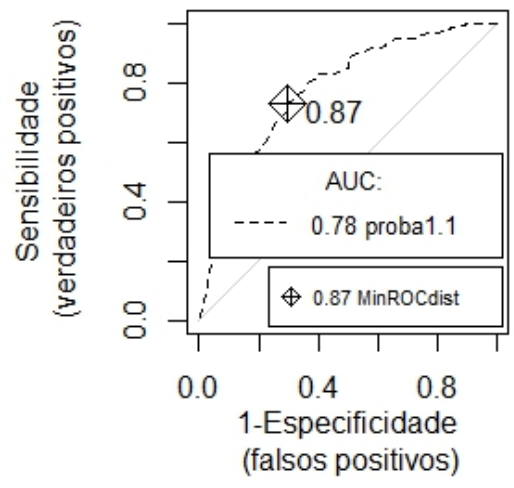

Figura 4.2: Curva ROC para o modelo geral

A área sob a curva ROC (AUC) é uma medida de acurácia e desempenho do teste, pois um teste cujo valor da AUC é de 0,5 é um teste totalmente incapaz de discriminar as unidades em sucesso e fracasso, enquanto o valor da AUC igual a 1 representa um teste perfeito, assim, quanto maior a capacidade do teste em classificar as unidades, mais a curva se aproxima do canto superior esquerdo, de tal forma que a área seria o mais próxima de 1. Na Figura 4.2, o valor da AUC está em destaque e o valor para o modelo geral é de 0,78 .

A partir das observações e dado um classificador, exitem quatro resultados possíveis. Se a ocorrência da observação é positiva e ela é classificada como positiva, é contado como verdadeiro positivo; caso seja classificada como negativo, é contado como um falso negativo. Se o valor da observação é negativo e é classificado como negativo, é contado como verdadeiro negativo; caso seja classificada como positivo, é contado como falso positivo. Dado um classificador (ponto de corte) e um conjunto de observações, uma matriz de confusão dois-por-dois pode ser construída representando as disposições dos resultados que podem ser obtidos, Tabela 4.3.

A sensibilidade e especificidade não são calculadas sobre os mesmos indivíduos, de tal forma que podemos assumir que são medidas independentes. A sensibilidade é calculada apenas entre as observações que são consideradas como sucesso (ou positivos), também é chamada de verdadeira 
Tabela 4.3: Representação geral de uma matriz de confusão

\begin{tabular}{ccc}
\hline Resultado do teste & \multicolumn{2}{c}{ Valor observado nos dados reais } \\
\cline { 2 - 3 } sob investigação & Negativo (0) & Positivo (1) \\
\hline Negativo (0) & verdadeiros negativos (VN) & falsos negativos (FN) \\
Positivo $(1)$ & falsos positivos $(\mathrm{FP})$ & verdadeiros positivos $(\mathrm{VP})$ \\
\hline Total & total de negativos $(\mathrm{FP}+\mathrm{VN})$ & total de positivos $(\mathrm{VP}+\mathrm{FN})$ \\
\hline
\end{tabular}

Fonte: Elaborado pela autora, adaptado de Martinez et al. (2003)

taxa positiva, uma vez que é a razão entre os verdadeiros positivos e o total de observações positivas. Já por sua vez, a especificidade é calculada apenas entre os indivíduos que são considerados como fracasso (ou negativos), sendo considerada a verdadeira taxa negativa, pois é a razão entre os verdadeiros negativos e o total de observações negativas. Dessa forma, podemos definir sensibilidade e especificidade como:

$$
\text { sensibilidade }=\frac{V P}{V P+F N} \quad \text { especificidade }=\frac{V N}{F P+V N}
$$

Com os dados obtidos através do processo de validação leave-one-out e com o ponte de corte definido na Figura 4.2, classificamos todas as escolas presentes na amostra da pesquisa TIC Educação em sucesso ou fracasso de acordo com o modelo. Para essas unidades, temos as observações do valor verdadeiro, pois foi declarado pela escola no momento da entrevista. Assim, construímos a matriz de confusão para esses dados, a fim de obter a proporção de acerto do modelo, que neste caso é de $72,7 \%$, vide Tabela 4.4. Ainda com auxílio da Tabela 4.4, obtemos que a sensibilidade é de $70 \%$, ou seja, de todas as escolas participantes da pesquisa TIC Educação que têm pelo menos um professor que usa a Internet com os alunos para as atividades de ensino-aprendizagem, o modelo prevê corretamente $70 \%$ desses casos. A especificidade para este modelo é de $73 \%$, isto é, o quanto o modelo prevê corretamente as escolas que não tem nenhum professor utilizando a Internet com os alunos de ensino-aprendizagem.

Tabela 4.4: Matriz de confusão, segundo o modelo geral

\begin{tabular}{c|cc}
\hline $\begin{array}{c}\text { valores preditos } \\
\text { pelo modelo }\end{array}$ & valores observados na pesquisa TIC Educação \\
0 & 73 & 1 \\
\hline 0 & 31 & 203 \\
1 & 550 \\
\hline
\end{tabular}

Como mencionado na Seção 3.2.3, não temos os valores da variável resposta para as unidades não amostradas que estão presentes no cadastro, dessa forma, realizamos a predição do seu valor médio a partir do modelo obtido. Com o intuito de obter a proporção de escolas em que os professores usam a Internet com os alunos em atividades de ensino-aprendizagem para cada uma das UF utilizamos a Equação (3.10), tal que é uma média ponderada entre a soma das respostas fornecidas pelas unidades amostradas e a soma dos valores preditos para as unidades fora da amostra.

Dispomos as proporções obtidas para cada UF em um mapa do Brasil, Figura 4.3, para podermos visualizar de maneira mais intuitiva as possíveis diferenças encontradas. As menores proporções estão representadas no mapa por um azul mais claro e aumentam gradativamente até o azul mais 
escuro. Notamos que o Maranhão possui a menor proporção de escolas em que os professores usam a Internet com os alunos em atividades de ensino-aprendizagem, seguido por alguns estados da região Nordeste, enquanto os estados da região Sul e o estado de Mato Grosso do Sul possuem as maiores proporções obtidas.

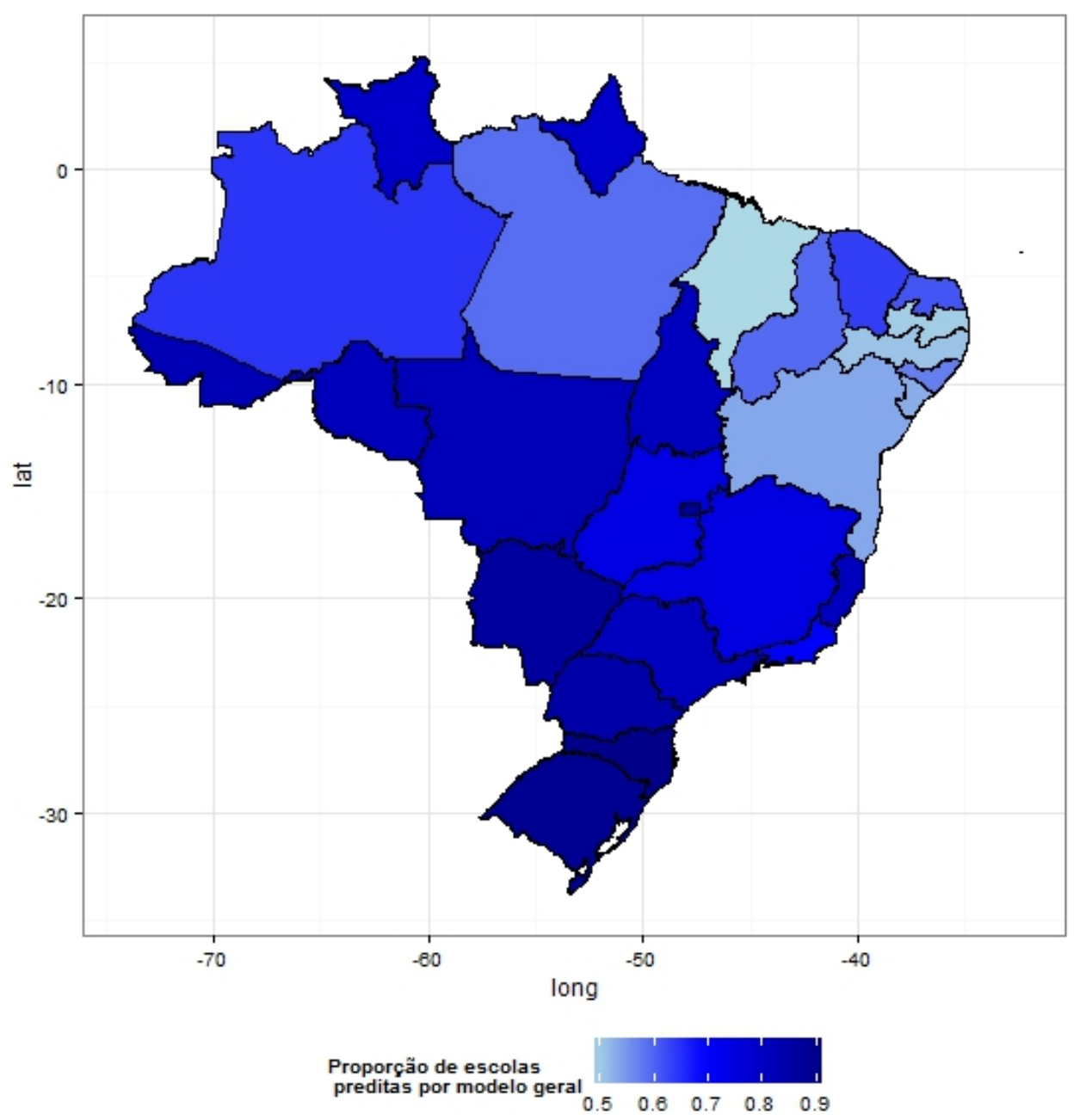

Figura 4.3: Mapa com as estimativas das proporções de escolas em que os professores usam a Internet com os alunos para atividades de ensino-aprendizagem obtidas pelo modelo geral

Como medida de qualidade do ajuste, utilizamos a estimativa obtida para o EQM, uma vez que incorpora as medidas de variabilidade e viés. Dessa forma, utilizamos o algoritmo bootstrap proposto em González-Manteiga et al. (2007), enunciado na Seção 3.3, de tal maneira que geramos 1000 populações bootstrap para a obtenção dos resultados. Assim, as proporções e seus respectivos EQM obtidos por essa abordagem estão dispostos na Tabela 4.5. Destacamos que os estados do Rio Grande do Sul, Santa Catarina e Mato Grosso do Sul possuem as menores estimativas do EQM, indicando o quão distante, em média, as proporções estão do valor real. Por outro lado, os estados do Pará e de Sergipe possuem as estimativas do EQM mais altas. Destacamos também o estado de Tocantins onde, como já mencionado na Seção 4.1, todas as escolas da amostra declararam que os professores não utilizam à Internet em atividades de ensino-aprendizagem com os alunos, mas a estimativa do EQM sob esta abordagem foi de 0,009 . 
Tabela 4.5: Estimativas da proporção de escolas em que os professores usam a Internet com os alunos para atividades de ensino-aprendizagem e do erro quadrático médio, por UF, segundo o modelo geral

\begin{tabular}{ccc|ccc|ccc}
\hline UF & Proporção (\%) & EQM & UF & Proporção (\%) & EQM & UF & Proporção (\%) & EQM \\
\hline AC & 82 & 0,0047 & MA & 48 & 0,0338 & RJ & 70 & 0,0133 \\
AL & 57 & 0,0280 & MG & 74 & 0,0110 & RN & 61 & 0,0196 \\
AM & 64 & 0,0272 & MS & 86 & 0,0027 & RO & 81 & 0,0112 \\
AP & 78 & 0,0107 & MT & 82 & 0,0042 & RR & 79 & 0,0064 \\
BA & 53 & 0,0314 & PA & 59 & 0,0533 & RS & 89 & 0,0013 \\
CE & 63 & 0,0156 & PB & 50 & 0,0444 & SC & 90 & 0,0018 \\
DF & 88 & 0,0045 & PE & 51 & 0,0453 & SE & 53 & 0,0584 \\
ES & 80 & 0,0048 & PI & 59 & 0,0299 & SP & 81 & 0,0038 \\
GO & 74 & 0,0149 & PR & 85 & 0,0055 & TO & 80 & 0,0093 \\
\hline
\end{tabular}

\subsection{Modelo por região}

Os dados da pesquisa TIC Educação (CGI.br, 2014) possuem leitura garantida para as 5 regiões geográficas do Brasil através da alocação igual da amostra. Como o objetivo deste trabalho é obter a proporção de escolas em que os professores usam Internet para atividades de ensino-aprendizagem para cada uma das UF tentamos melhorar a qualidade das nossas estimativas através da construção de um modelo para cada uma das regiões, uma vez que as características regionais podem ser mais "similares" entre os estados de uma mesma região geográfica.

Para a construção destes modelos, o conjunto de dados foi dividido em cinco, um por região, e o procedimento adotado em cada um deles foi o mesmo. Como o peso das observações da amostra consideram a região, mantivemos o peso já calculado, conforme a reponderação aplicada e detalhada na Seção 2.3.4. Dessa forma, ajustamos o modelo logístico através do pacote survey do R pela função svyglm.

Inicialmente foram incluídas as mesmas variáveis em todos os modelos: ID_DEPENDENCIA_ADM, ID_LABORATORIO_INFORMATICA, REGIAO, NUM_SALAS_UTILIZADAS, NUM_EQUIP_MULTIMIDIA, MED_ _IDADE, QT_DOCENTES, ID_PROF_INF, NUM_COMPUTADORES, NUM_COMP_ALUNOS, ID_INTERNET e ID_BANDA_LARGA, para a seleção das variáveis que compõem o modelo final utilizamos o método stepwise. Além disso, realizamos o teste de Wald de múltiplos parâmetros para as variáveis cujos valores-p eram maiores que 0,3 . Dessa forma, se o resultado do teste fosse um valor alto, maior que o nível de significância considerado de $5 \%$, então ajustamos um novo modelo sem as variáveis que testamos no passo anterior. Para a comparação desse modelos realizamos uma ANOVA e escolhemos o modelo mais parcimonioso, assim, as equações dos modelos finais são dadas por ${ }^{2}$ :

\footnotetext{
${ }^{2}$ As tabelas contendo as estimativas, os erros-padrão, os valores das estatísticas $t$ e os valores-p estão dispostas no Apêndice A, Tabelas A.4, A.5, A.6, A.7 e A.8.
} 


\section{Região Norte}

$$
\begin{aligned}
\log \left(\frac{\hat{p}_{d j}}{1-\hat{p}_{d j}}\right)= & -0,4-0,06 \times N U M_{-} S A L A S_{-} \text {UTILIZADAS } \\
& +1,71 \times I D_{-} \text {INTERNET } \\
& +0,21 \times N U_{-} \text {COMPUTADORES } \\
& -0,21 \times N U M_{-} C O M P_{-} \text {ALUNOS } \\
& +0,01 \times Q T_{-} \text {DOCENTES }
\end{aligned}
$$

\section{Região Nordeste}

$$
\begin{aligned}
\log \left(\frac{\hat{p}_{d j}}{1-\hat{p}_{d j}}\right)= & -1,77-0,2 \times I D_{-} \text {DEPENDENCIA_ADM Municipais } \\
& +1,83 \times I D_{-} \text {DEPENDENCIA_ADM Particulares } \\
& +0,07 \times N M_{-} M_{-} \text {COMPUTADORES } \\
& +1,44 \times I D_{-} \text {INTERNET }
\end{aligned}
$$

\section{Região Sudeste}

$$
\begin{aligned}
\log \left(\frac{\hat{p}_{d j}}{1-\hat{p}_{d j}}\right)= & 12,88-1,26 \times I D_{-} D E P E N D E N C I A_{-} A D M_{\text {Municipais }} \\
& +0,24 \times I D_{-} \text {DEPENDENCIA_ADM Particulares } \\
& -2,19 \times I D_{-} L A B O R A T O R I O_{-} I N F O R M A T I C A \\
& -0,19 \times N U M_{-} E Q U I P_{-} M U L T I M I D I A \\
& -0,05 \times N U M_{-} C O M P U T A D O R E S \\
& +0,12 \times N U M_{-} C O M P \_A L U N O S \\
& -0,21 \times M E D_{-} I D A D E \\
& +19,21 \times I D_{-} P R O F_{-} I N F
\end{aligned}
$$

\section{Região Sul}

$$
\begin{aligned}
\log \left(\frac{\hat{p}_{d j}}{1-\hat{p}_{d j}}\right)= & 0,19-0,28 \times N U M_{-} S A L A S_{-} U T I L I Z A D A S \\
& +1,31 \times N U M_{-} C O M P U T A D O R E S \\
& -1,22 \times N U M_{-} C O M P_{-} A L U N O S \\
& +18,37 \times I D_{-} P R O F_{-} I N F
\end{aligned}
$$




\section{Região Centro-Oeste}

$$
\begin{aligned}
& \log \left(\frac{\hat{p}_{d j}}{1-\hat{p}_{d j}}\right)=-7,23+2,13 \times I D_{-} \text {LABORATORIO_INFORMATICA } \\
& -0,28 \times N U M_{-} E Q U I P_{-} M U L T I M I D I A \\
& +0,39 \times N U M_{-} C O M P U T A D O R E S \\
& -0,42 \times N U M_{-} C O M P_{-} A L U N O S \\
& +20,84 \times I D_{-} \text {INTERNET } \\
& -1,47 \times I D_{-} B A N D A_{-} L A R G A \\
& -0,32 \times M E D \_I D A D E \\
& +0,01 \times Q T \_D O C E N T E S \\
& -1,59 \times I D \_P R O F \_I N F
\end{aligned}
$$

Realizamos a validação de cada modelo por leave-one-out, onde elimina-se uma observação do conjunto de dados, estima-se o modelo novamente e faz-se a predição para essa observação que foi eliminada. Assim, podemos comparar a resposta obtida via modelo e a declarada pela escola, tida como verdadeira. Entretanto, o modelo nos fornece a probabilidade da escola ter professores que usem Internet para atividades de ensino-aprendizagem, enquanto a resposta verdadeira é se usa ou não. Para realizarmos essa comparação, fizemos a classificação das escolas através do ponto de corte obtido pela curva ROC, assim, as probabilidades acima do ponto de corte, valor destacado na Figura 4.4, foi classificada como "sim"e os valores abaixo do ponte de corte como "não".
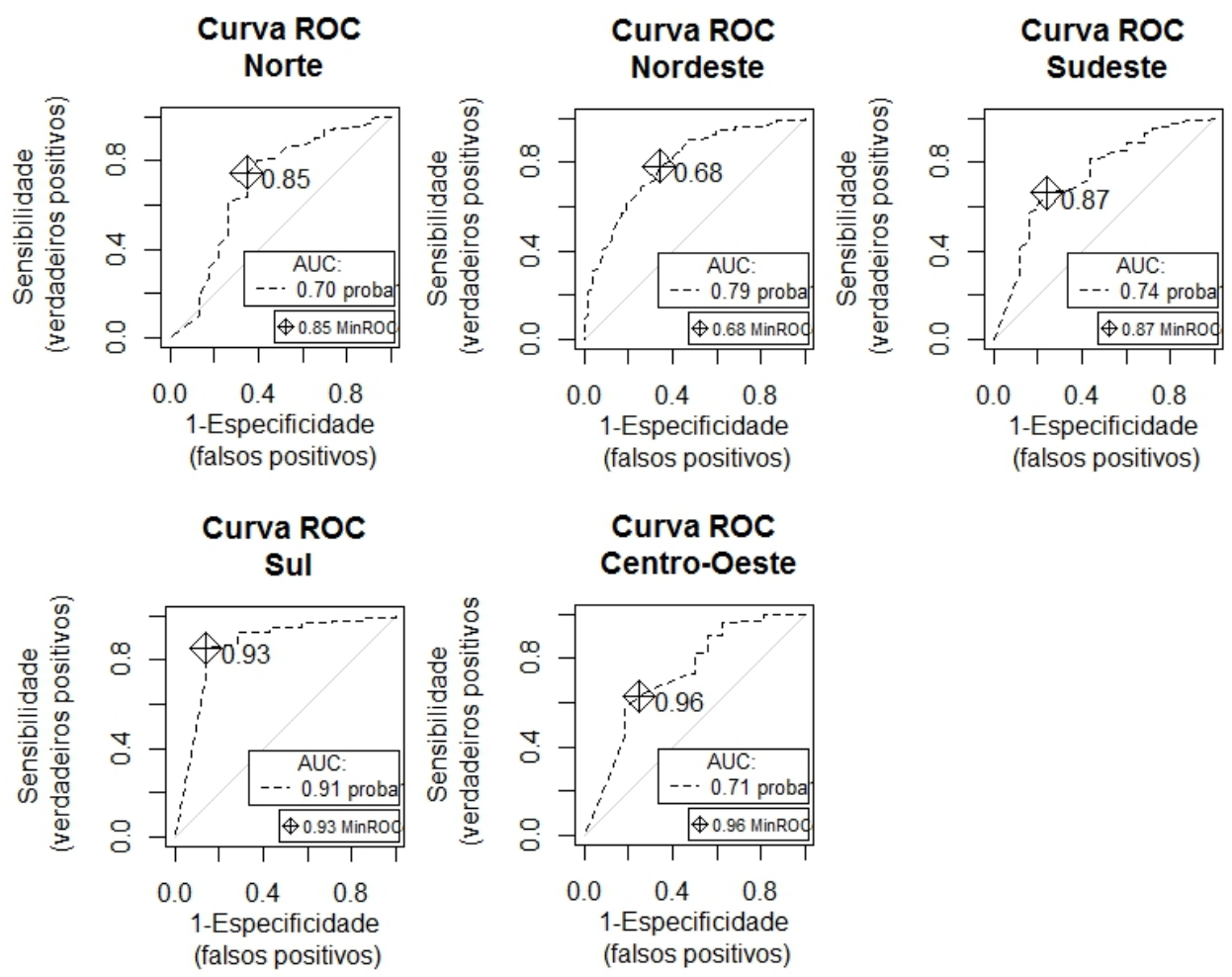

Figura 4.4: Curva ROC para o modelo por região

Para avaliarmos se o modelo estava se comportando adequadamente, observamos através da 
matriz de confusão por leave-one-out, Tabela 4.6, a proporção de valores preditos corretamente. Temos que a sensibilidade, ou seja, a taxa verdadeira de positivos da região Norte foi de $75 \%$, da região Nordeste foi de $78 \%$, da região Sudeste foi de $66 \%$, da região Sul de $85 \%$ e para a região Centro-Oeste foi de $63 \%$. Do mesmo modo, encontramos que a especificidade da região Norte foi de $65 \%$, da região Nordeste foi de $66 \%$, da região Sudeste de $76 \%$, da região Sul foi de $86 \%$ e da região Centro-Oeste foi de 75\%. Dessa forma, tivemos que o modelo para região Sul acerta corretamente $85 \%$ dos casos, para a região Nordeste $75 \%$, seguido pela região Norte com $73 \%$. No entanto, para a região Sudeste o modelo prediz corretamente $67 \%$ dos casos enquanto na região Centro-Oeste esse valor é de $64 \%$.

Tabela 4.6: Matriz de confusão, segundo o modelo por região

\begin{tabular}{c|cc||cc||cc||cc||cc}
\hline & \multicolumn{8}{c}{ Valores observados na pesquisa TIC Educação } \\
\hline Valores preditos & \multicolumn{2}{|c|}{ Norte } & \multicolumn{2}{|c||}{ Nordeste } & \multicolumn{2}{c}{ Sudeste } & \multicolumn{2}{c}{ Sul } & \multicolumn{3}{c}{ Centro-Oeste } \\
pelo modelo & 0 & 1 & 0 & 1 & 0 & 1 & 0 & 1 & 0 & 1 \\
\hline 0 & 15 & 32 & 31 & 33 & 19 & 54 & 6 & 27 & 12 & 52 \\
1 & 8 & 95 & 16 & 120 & 6 & 106 & 1 & 157 & 4 & 89 \\
\hline
\end{tabular}

Para as escolas que estão presentes no cadastro, mas não compuseram a amostra da pesquisa TIC Educação, não temos os valores observados da variável resposta, P44_TOTAL. Dessa forma, assim como mencionado na Seção 3.2.3, realizamos a predição do seu valor médio a partir das equações obtidas para os modelos. Assim, dependendo da região onde está a escola, será utilizada uma equação diferente. As proporções obtidas para cada UF, ou seja, para cada pequeno domínio, considerou a média ponderada entre a soma das respostas fornecidas pelas unidades amostradas e a soma dos valores preditos para as unidades fora da amostra, Equação (3.10), e os resultados estão dispostos na Figura 4.5.

Optamos por disponibilizar os resultados obtidos para a proporção de escolas em que os professores usam a Internet em atividades de ensino-aprendizagem com os alunos através dos modelos gerados por região para cada UF em uma representação cartográfica para que a visualização seja mais clara e que permita realizar de maneira quase que instantânea uma comparação entre as UF. As proporções mais baixas são aquelas de azul mais claro, tal como o Maranhão, seguido pelo Pará, enquanto as proporções mais altas estão marcadas em azul mais escuro, como os estados da região Sul do país: Paraná, Rio Grande do Sul e Santa Catarina.

Como medida de qualidade do ajuste, utilizamos a estimativa do EQM, pois ela incorpora medidas de variabilidade e viés. Dessa forma, utilizamos o algoritmo bootstrap abordado na Seção 3.3 para a obtenção das estimativas do EQM. Durante a execução deste processo notamos que na região Centro-Oeste, mais de $97 \%$ das escolas possuem conexão à Internet, assim, em algumas extrações de amostras, todas as escolas dessa região possuíam acesso à Internet, não sendo possível a obtenção do modelo. Dessa forma, foram geradas 1500 populações bootstrap, porém em 544 destas não foi possível obter resultados para a região Centro-Oeste. As estimativas do EQM apresentadas na Tabela 4.7 consideram os 1500 casos para as regiões Norte, Nordeste, Sudeste e Sul e os 956 casos para a região Centro-Oeste. Apresentamos, também, as proporções para cada UF na Tabela 4.7. Notamos que os estados do Rio Grande do Sul e de Santa Catarina apresentam as menores estimativas do EQM, 0,0009 e 0,0016 respectivamente, enquanto o estado do Pará apresenta o maior valor, 0,0513 . 


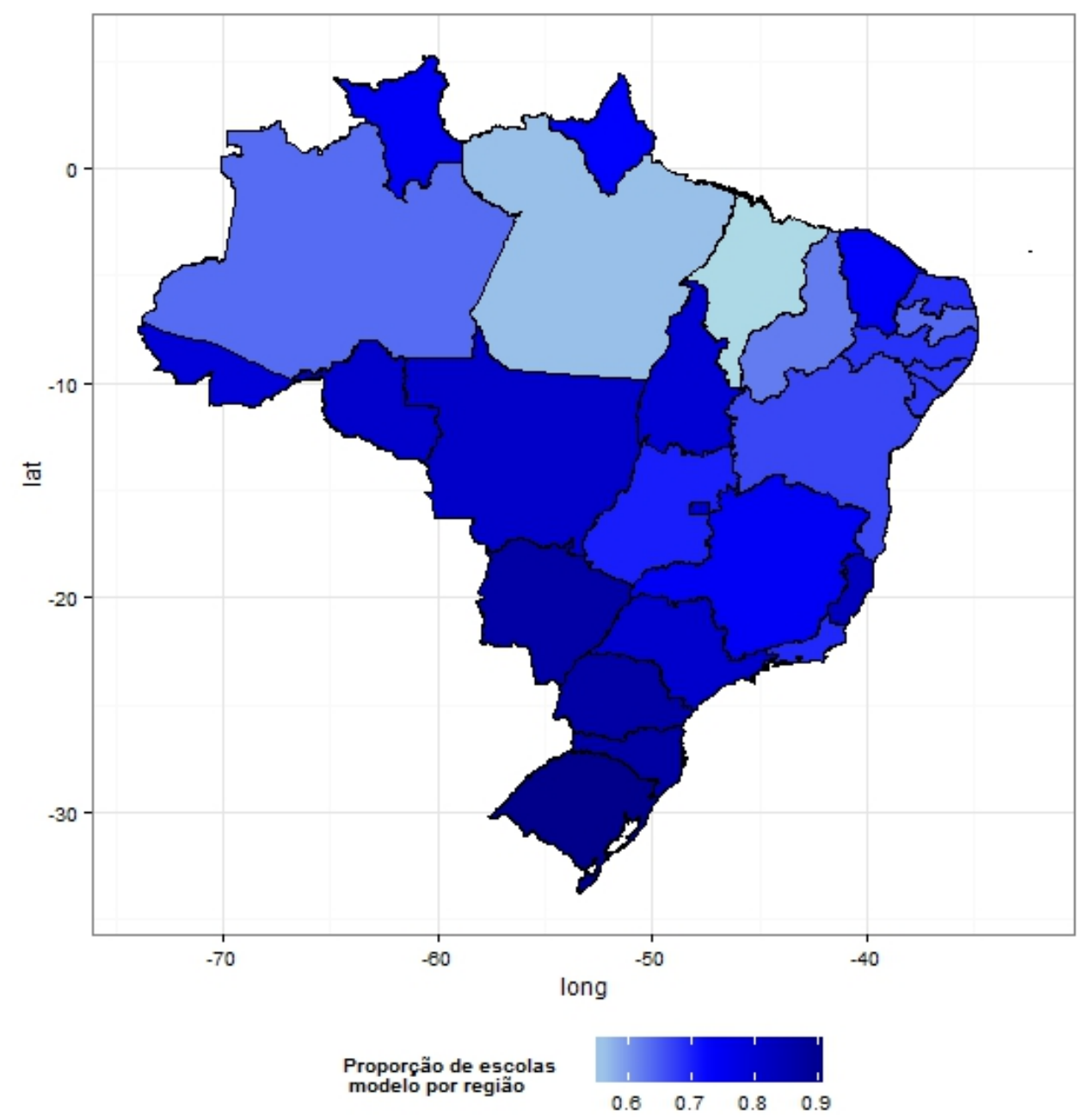

Figura 4.5: Mapa com as estimativas das proporções de escolas em que os professores usam a Internet com os alunos para atividades de ensino-aprendizagem obtidas pelo modelo por região

Tabela 4.7: Estimativas da proporção de escolas em que os professores usam a Internet com os alunos para atividades de ensino-aprendizagem e do erro quadrático médio, por UF, segundo o modelo por região

\begin{tabular}{ccc|ccc|ccc}
\hline UF & Proporção (\%) & EQM & UF & Proporção (\%) & EQM & UF & Proporção (\%) & EQM \\
\hline AC & 79 & 0,0057 & MA & 54 & 0,0054 & RJ & 69 & 0,0126 \\
AL & 68 & 0,0021 & MG & 74 & 0,0107 & RN & 69 & 0,0019 \\
AM & 63 & 0,0272 & MS & 87 & 0,0019 & RO & 81 & 0,0108 \\
AP & 73 & 0,0099 & MT & 81 & 0,0030 & RR & 74 & 0,0055 \\
BA & 67 & 0,0023 & PA & 56 & 0,0513 & RS & 91 & 0,0009 \\
CE & 74 & 0,0020 & PB & 64 & 0,0025 & SC & 87 & 0,0016 \\
DF & 81 & 0,0034 & PE & 68 & 0,0023 & SE & 68 & 0,0021 \\
ES & 83 & 0,0049 & PI & 62 & 0,0026 & SP & 81 & 0,0035 \\
GO & 70 & 0,0125 & PR & 87 & 0,0054 & TO & 80 & 0,0096 \\
\hline
\end{tabular}




\subsection{Modelo por cluster}

\subsubsection{Análise de agrupamentos}

A análise de agrupamentos ou cluster analysis faz parte de um conjunto de técnicas multivariadas que permite identificar padrões de comportamento em banco de dados por meio da formação de grupos homogêneos. Segundo Barroso e Artes (2003) as etapas da aplicação de uma análise de agrupamentos são:

1. Escolha do critério de parecença;

2. Definição do número de grupos;

3. Formação dos grupos;

4. Validação do agrupamento;

5. Interpretação dos grupos.

Ainda segundo Barroso e Artes (2003) os métodos de partição buscam encontrar a partição cujos grupos apresentem alta homogeneidade interna (observações parecidas) e que sejam diferentes entre si. O método das k-médias se baseia na partição da soma de quadrados total de uma análise de variância, de tal modo que uma boa partição seria aquela que minimizasse a soma de quadrado dentro dos grupos e maximizasse a soma de quadrados entre os grupos.

A principal vantagem desse método é que ele avalia, a cada passo do algoritmo, se os casos estão alocados da melhor forma, se não estiverem, podem ser realocados. Esse método também é indicado para grandes volumes de dados, como é o nosso caso. A principal desvantagem é a necessidade de se definir a priori o número de grupos a serem formados, de tal forma que se faz necessária a utilização do algoritmo para um número de partições diferentes e a análise da soma de quadrados dentro dos grupos para cada partição formada.

Com o objetivo de formar grupos homogêneos de escolas com relação ao uso das TIC, as variáveis selecionadas para a análise de agrupamentos foram as seguintes:

- Número de equipamentos multimídia: Padronização da variável NUM_EQUIP_MULTIMIDIA para o intervalo [0,1], obtida através da divisão de cada valor pelo maior valor observado na variável;

- Número de computadores: Padronização da variável nUm_comPutAdores para o intervalo $[0,1]$, obtida através da divisão de cada valor pelo maior valor observado na variável;

- Laboratório de informática: Variável ID_LABORATORIO_INFORMATICA, tal que 1 representa que a escola possui laboratório de informática e 0 que ela não possui;

- Internet: Variável ID_INTERNET, tal que 1 representa que a escola possui Internet e 0 que ela não possui. Essa variável tinha valores ausentes para 1081 escolas, pois apenas escolas que possuem computador respondem a essa pergunta, assim, para a análise de agrupamentos esses casos foram considerados como escolas que não tem acesso à Internet;

- Estadual: Dicotomização da variável ID_DEPENDENCIA_ADM tal que 1 representa que a dependência administrativa da escola é estadual e 0 caso contrário; 
- Municipal: Dicotomização da variável ID_DEPENDENCIA_ADM tal que 1 representa que a dependência administrativa da escola é municipal e 0 caso contrário.

As escolas particulares são obtidas através da combinação das variáveis Estadual e Municipal, uma vez que possuem o valor 0 para as duas variáveis. Assim, podemos identificar a dependência administrativa da escola da seguinte maneira:

Escolas estaduais: Estadual $=1 \&$ Municipal $=0$;

Escolas municipais: Estadual $=0 \&$ Municipal $=1$;

Escolas particulares: Estadual $=0 \&$ Municipal $=0$.

Com auxílio do software Minitab ${ }^{\circledR}$ fizemos o agrupamento das escolas através do algoritmo kmédias, que utiliza a distância euclidiana como medida de parecença. Uma das maiores dificuldades da técnica se dá na definição do número de grupos a se realizar as partições, desse modo, avaliamos a soma de quadrados da partição para diferentes números de grupos através do índice

$$
G=\frac{S Q D P(k)-S Q D P(k+1)}{S Q D P(k+1)},
$$

tal que, $S Q D P$ é a soma de quadrados dentro dos grupos e $k$ é o número de grupos. Assim, opta-se pelo menor número de grupos para o qual o valor de G se estabiliza, próximo a um número baixo, isto é, a partir do ponto que aumentar o número de grupos não é vantajoso. Desse modo, optamos por trabalhar com 5 grupos, uma vez que a contribuição na soma de quadrados com um número maior de grupos não é relevante.

\subsubsection{Descrição dos agrupamentos}

A análise descritiva dos 5 grupos formados através do método k-médias é importante para compreendermos quais são as características em comum nas escolas dentro de cada um dos grupos.

Inicialmente podemos observar através da Tabela 4.8 a quantidade de escolas dentro de cada grupo. O grupo número 4 ficou com a maior quantidade de escolas, $33 \%$ do total de escolas. Em seguida, o grupo 1 com $29 \%$ das escolas, o grupo 5 com $17 \%$, o grupo 2 com $13 \%$ e o grupo com menor número de escolas foi o grupo 3, com apenas $8 \%$ das escolas.

Tabela 4.8: Quantidade de escolas, por grupo

\begin{tabular}{cccccc}
\hline Grupo & 1 & 2 & 3 & 4 & 5 \\
\hline Quantidade de escolas & 21.604 & 9.615 & 5.886 & 24.098 & 12.361 \\
\hline
\end{tabular}

Em seguida, observamos como a dependência administrativa à qual a escola pertence se comportou na divisão em grupos. Notamos, Tabela 4.9, que os grupos 3 e 4 são formados apenas por escolas municipais e o grupo 1 apenas por escolas estaduais, enquanto o grupo 5 é formado exclusivamente por escolas particulares. O grupo 2 tem 20\% de escolas estaduais e $80 \%$ de escolas particulares.

A respeito da existência de laboratório de informática nas dependências da escola, Tabela 4.10, temos que o grupos 1, 4 e 5 são formados por escolas que possuem laboratório e os grupos 2 e 3 por escolas que não o possuem. 
Tabela 4.9: Quantidade de escolas, por grupo, segundo dependência administrativa

\begin{tabular}{cccc}
\hline Grupo & Estadual & Municipal & Particular \\
\hline 1 & 21.604 & 0 & 0 \\
2 & 1.924 & 0 & 7.691 \\
3 & 0 & 5.886 & 0 \\
4 & 0 & 24.098 & 0 \\
5 & 0 & 0 & 12.361 \\
\hline
\end{tabular}

Tabela 4.10: Quantidade de escolas, por grupo, segundo existência do laboratório de informática

\begin{tabular}{cccccc}
\hline Grupo & 1 & 2 & 3 & 4 & 5 \\
\hline Sem laboratório de informática & 0 & 9.615 & 5.886 & 0 & 0 \\
Com laboratório de informática & 21.604 & 0 & 0 & 24.098 & 12.361 \\
\hline
\end{tabular}

Observamos através da Tabela 4.11, que nos grupos 1, 4 e 5, a proporção de escolas com acesso à Internet é maior que $90 \%$, enquanto a proporção de escolas com conexão à Internet é de $88 \%$ no grupo 2. Entretanto, no grupo 3, 30\% das escolas não possuem acesso.

Tabela 4.11: Proporção de escolas, por grupo, segundo o acesso à Internet

\begin{tabular}{cccccc}
\hline Grupo & 1 & 2 & 3 & 4 & 5 \\
\hline Sem acesso à Internet & $3 \%$ & $12 \%$ & $30 \%$ & $9 \%$ & $2 \%$ \\
Com acesso à Internet & $97 \%$ & $88 \%$ & $70 \%$ & $91 \%$ & $98 \%$ \\
\hline
\end{tabular}

No universo as escolas têm em média 21 computadores e 2 equipamentos multimídia como pode ser visto na Tabela 4.12. Observamos que, por grupo, esse número pode ser bem diferente. Nos grupos 2 e 3, as escolas têm em média 6 computadores, mas são exatamente os grupos que não possuem laboratório de informática. Enquanto o grupo 5 possui em média 31 computadores e 4 equipamentos multimídia, o grupo 5 é o grupo das escolas particulares com laboratório de informática, prioritariamente da região Sudeste e com conexão à Internet.

Ao analisar a distribuição das regiões nos grupos formados, pode-se observar que $49 \%$ das escolas do grupo 3 são da região Nordeste, do grupo 5, 50\% são da região Sudeste, do grupo 2 são $49 \%$ da região Nordeste e $32 \%$ da região Sudeste, enquanto no grupo 4, 35\% são da região Sudeste e $32 \%$ do Nordeste. O grupo 1 tem que $42 \%$ de suas escolas pertencem à região Sudeste, conforme pode ser visto na Tabela 4.13.

Com relação a distribuição das escolas dentro dos grupos de acordo com as unidades da federação, a Tabela 4.14 traz o percentual de cada UF dentro de cada um dos grupos. Observamos que São Paulo, está presente em todos os grupos, de tal forma que no grupo 5 ele representa $24 \%$ do total, no grupo $1,22 \%, 15,7 \%$ no grupo 4 e $12 \%$ nos grupos 2 e 3 . Temos também que no grupo 1, 13\% das escolas são de Minas Gerais, no grupo 5, 17\% das escolas são do Rio de Janeiro e 16\% das escolas do grupo 3 são da Bahia. Já o grupo 2, de suas escolas $12 \%$ são da Bahia, $11 \%$ de Pernambuco e outros $11 \%$ do Rio de Janeiro.

A variável que será utilizada como resposta do modelo é a de uso da Internet pelos professores com os alunos. Assim, observamos (Tabela 4.15) que apenas no grupo 3, na maioria das escolas os professores não utilizam a Internet com seus alunos, 59\%. Nos grupos 2 e 4 mais de $20 \%$ também 
Tabela 4.12: Média do número de equipamentos disponíveis, segundo grupo

\begin{tabular}{ccc}
\hline Grupos & $\begin{array}{c}\text { Média do número } \\
\text { de computadores }\end{array}$ & $\begin{array}{c}\text { Média do número de } \\
\text { equipamentos multimídia }\end{array}$ \\
\hline 1 & 26 & 2 \\
2 & 6 & 1 \\
3 & 6 & 1 \\
4 & 23 & 2 \\
5 & 31 & 4 \\
\hline Total & 21 & 2 \\
\hline
\end{tabular}

Tabela 4.13: Proporção de escolas, por grupo, segundo região

\begin{tabular}{cccccc}
\hline Grupo & 1 & 2 & 3 & 4 & 5 \\
\hline Norte & $8 \%$ & $9 \%$ & $10 \%$ & $8 \%$ & $4 \%$ \\
Nordeste & $21 \%$ & $49 \%$ & $49 \%$ & $32 \%$ & $26 \%$ \\
Sudeste & $42 \%$ & $32 \%$ & $28 \%$ & $35 \%$ & $50 \%$ \\
Sul & $19 \%$ & $4 \%$ & $9 \%$ & $18 \%$ & $11 \%$ \\
Centro-Oeste & $10 \%$ & $6 \%$ & $4 \%$ & $7 \%$ & $9 \%$ \\
\hline
\end{tabular}

Tabela 4.14: Proporção de escolas, por grupo, segundo UF

\begin{tabular}{cccccc}
\hline Grupo & 1 & 2 & 3 & 4 & 5 \\
\hline AC & $0,7 \%$ & $0,1 \%$ & $0,3 \%$ & $0,3 \%$ & $0,1 \%$ \\
AL & $1,0 \%$ & $2,3 \%$ & $2,1 \%$ & $1,7 \%$ & $1,5 \%$ \\
AM & $1,9 \%$ & $1,4 \%$ & $2,1 \%$ & $1,5 \%$ & $1,0 \%$ \\
AP & $0,6 \%$ & $0,1 \%$ & $0,3 \%$ & $0,3 \%$ & $0,2 \%$ \\
BA & $4,8 \%$ & $12,3 \%$ & $16,4 \%$ & $8,5 \%$ & $5,6 \%$ \\
CE & $2,3 \%$ & $5,7 \%$ & $3,8 \%$ & $6,0 \%$ & $5,3 \%$ \\
DF & $2,0 \%$ & $0,7 \%$ & $0,0 \%$ & $0,0 \%$ & $2,0 \%$ \\
ES & $1,6 \%$ & $0,5 \%$ & $1,0 \%$ & $2,5 \%$ & $1,6 \%$ \\
GO & $4,0 \%$ & $3,6 \%$ & $3,1 \%$ & $3,9 \%$ & $4,2 \%$ \\
MA & $2,2 \%$ & $3,1 \%$ & $8,1 \%$ & $4,3 \%$ & $1,8 \%$ \\
MG & $13,2 \%$ & $8,0 \%$ & $8,3 \%$ & $8,6 \%$ & $7,4 \%$ \\
MS & $1,4 \%$ & $0,5 \%$ & $0,2 \%$ & $1,4 \%$ & $1,2 \%$ \\
MT & $2,3 \%$ & $0,9 \%$ & $0,5 \%$ & $1,5 \%$ & $1,1 \%$ \\
PA & $2,0 \%$ & $6,1 \%$ & $6,0 \%$ & $4,1 \%$ & $2,0 \%$ \\
PB & $2,2 \%$ & $6,1 \%$ & $3,7 \%$ & $2,6 \%$ & $1,5 \%$ \\
PE & $3,6 \%$ & $11,3 \%$ & $8,2 \%$ & $3,8 \%$ & $5,8 \%$ \\
PI & $2,2 \%$ & $2,5 \%$ & $4,3 \%$ & $2,0 \%$ & $1,5 \%$ \\
PR & $7,3 \%$ & $2,4 \%$ & $5,8 \%$ & $7,7 \%$ & $4,9 \%$ \\
RJ & $4,8 \%$ & $11,4 \%$ & $6,3 \%$ & $8,8 \%$ & $17,2 \%$ \\
RN & $2,1 \%$ & $3,0 \%$ & $1,6 \%$ & $1,9 \%$ & $1,9 \%$ \\
RO & $0,9 \%$ & $1,0 \%$ & $0,7 \%$ & $0,5 \%$ & $0,3 \%$ \\
RR & $0,3 \%$ & $0,1 \%$ & $0,1 \%$ & $0,2 \%$ & $0,1 \%$ \\
RS & $8,2 \%$ & $0,8 \%$ & $1,8 \%$ & $6,5 \%$ & $3,6 \%$ \\
SC & $3,9 \%$ & $0,6 \%$ & $1,3 \%$ & $4,1 \%$ & $2,7 \%$ \\
SE & $1,0 \%$ & $2,8 \%$ & $1,3 \%$ & $0,8 \%$ & $0,9 \%$ \\
SP & $22,0 \%$ & $12,3 \%$ & $12,1 \%$ & $15,7 \%$ & $24,0 \%$ \\
TO & $1,6 \%$ & $0,7 \%$ & $0,7 \%$ & $1,0 \%$ & $0,4 \%$ \\
\hline & & & & &
\end{tabular}


não utilizam, enquanto nos grupos 1 e 5, 90\% e 97\% utilizam.

Tabela 4.15: Proporção de escolas em que os professores utilizam Internet com os alunos, por grupo

\begin{tabular}{cccccc}
\hline Grupo & 1 & 2 & 3 & 4 & 5 \\
\hline Não & $10 \%$ & $27 \%$ & $59 \%$ & $22 \%$ & $3 \%$ \\
Sim & $90 \%$ & $73 \%$ & $41 \%$ & $78 \%$ & $97 \%$ \\
\hline
\end{tabular}

\subsubsection{Modelagem}

Através da análise de agrupamentos formamos 5 grupos homogêneos de escolas com relação ao uso das TIC, assim, o banco de dados foi separado para cada um dos grupos. Tal como o modelo por região, Seção 4.3, ajustamos um modelo para cada grupo, em que mantivemos apenas as variáveis significativas. Inicialmente foram testadas as variáveis ID_DEPENDENCIA_ADM, ID_LABORATORIO_INFORMATICA, REGIAO, NUM_SALAS_UTILIZADAS, NUM_EQUIP_MULTIMIDIA, MED_ _IDADE, QT_DOCENTES, ID_PROF_INF, NUM_COMPUTADORES, NUM_COMP_ALUNOS, ID_INTERNET e ID_BANDA_LARGA. Além do método stepwise para seleção das variáveis que comporiam o modelo final, utilizamos o teste de Wald de múltiplos parâmetros para as variáveis cujos valores-p eram maiores que 0,3 . Assim, escolhemos o modelo com o menor número de variáveis, mas que explique bem a variável resposta.

Diferentemente dos modelos anteriores, neste caso perdemos as informações sobre o plano amostral ao realizar a análise de agrupamentos, que é uma técnica descritiva. Desse modo, não consideramos o efeito do plano amostral para a estimação desse modelo, de tal modo que ele foi construído utilizando a função $g l m$ do software R. Através da expressão final do modelo para cada um dos agrupamentos é possível avaliar quais foram as variáveis que foram significativas para cada um deles e qual é o valor do incremento no logito. De tal modo que as equações dos modelos para cada agrupamento são dadas por $^{3}$ :

\section{Grupo 1}

$$
\begin{aligned}
& \log \left(\frac{\hat{p}_{d j}}{1-\hat{p}_{d j}}\right)=4,75+2,75 \times I D_{-} \text {INTERNET } \\
& -0,14 \times M E D \_I D A D E \\
& +0,008 \times Q T \_D O C E N T E S \\
& \text { - 0,02 } \times \text { REGIAO Nordeste } \\
& \text { - 0,20 } \times \text { REGIAO Sudeste } \\
& +2,69 \times R E G I A O_{S u l} \\
& +0,31 \times R E G I A O_{\text {Centro-Oeste }}
\end{aligned}
$$

\footnotetext{
${ }^{3}$ As tabelas contendo as estimativas, os erros-padrão, os valores das estatísticas $t$ e os valores-p estão dispostas no Apêndice A, Tabelas A.9, A.10, A.11, A.12 e A.13.
} 


\section{Grupo 2}

$$
\begin{aligned}
\log \left(\frac{\hat{p}_{d j}}{1-\hat{p}_{d j}}\right)= & 2,46+1,41 \times I D_{-} \text {DEPENDENCIA_ADM } M_{\text {Particulares }} \\
& +0,36 \times N U M_{-} \text {COMPUTADORES } \\
& -0,11 \times M E D_{-} \text {IDADE }
\end{aligned}
$$

\section{Grupo 3}

$$
\log \left(\frac{\hat{p}_{d j}}{1-\hat{p}_{d j}}\right)=-2,08+2,16 \times I D_{-} I N T E R N E T
$$

\section{Grupo 4}

$$
\begin{aligned}
\log \left(\frac{\hat{p}_{d j}}{1-\hat{p}_{d j}}\right)= & -1,39-0,09 \times N U M_{-} S A L A S_{-} U T I L I Z A D A S \\
& +0,33 \times N U M_{-} C O M P U T A D O R E S \\
& -0,28 \times N U_{-} C O M P_{-} A L U N O S \\
& +1,80 \times I D_{-} \text {BANDA_LARGA } \\
& +0,01 \times Q T_{-} \text {DOCENTES } \\
& +1,53 \times I D_{-} P R O F_{-} I N F
\end{aligned}
$$

\section{Grupo 5}

$$
\begin{aligned}
\log \left(\frac{\hat{p}_{d j}}{1-\hat{p}_{d j}}\right)= & 10,74-0,21 \times M E D_{-} I D A D E \\
& +0,03 \times Q T_{-} \text {DOCENTES }
\end{aligned}
$$

Assim como nos métodos descritos anteriormente, fizemos a validação cruzada por leave-one-out, onde a cada passo do algoritmo uma unidade é excluída do conjunto de dados, deste modo, o modelo é re-estimado e com os valores observados é feita a predição da probabilidade de que naquela escola os professores usem Internet nas atividades de ensino-aprendizagem. Assim, para construirmos a matriz de confusão para este modelo, precisamos classificar as escolas segundo o uso da Internet pelos professores nas atividades. Tendo como base as probabilidades preditas, estimamos a Curva ROC de modo a minimizar a distância entre a curva e o ponto $(0,1)$, para maximizar a especificidade e a sensibilidade. Na Figura 4.6 observamos, destacado em cada gráfico, o valor referente ao ponto de corte. Assim, se a probabilidade predita é maior que o valor do ponto de corte, essa escola é classificada como "sim", os professores utilizam Internet, e caso contrário é classificada como "não".

Com base na classificação obtida através do procedimento descrito anteriormente, foi possível construir a matriz de confusão por leave-one-out, Tabela 4.16, e avaliamos a proporção de acerto do modelo em cada grupo, onde o acerto é o modelo prever o mesmo resultado que a escola declarou no momento da entrevista. Podemos observar que o grupo 1 teve $68 \%$ de acerto, o grupo 2 foi de $69 \%$, 

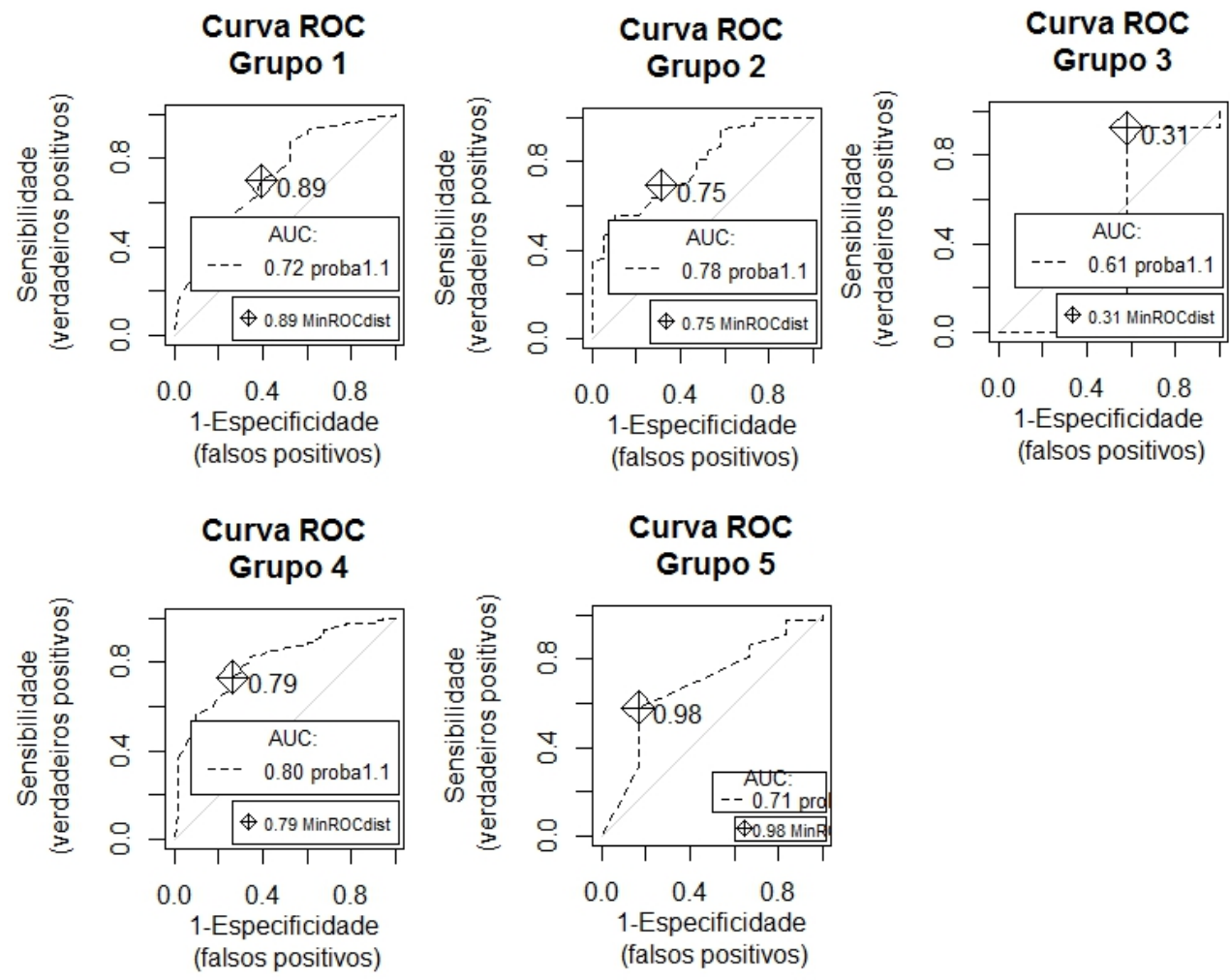

Figura 4.6: Curva ROC para o modelo por cluster

o grupo 3,63\%, o 4 obteve $73 \%$ e por fim, o grupo 5 com $59 \%$ de acerto. Também com auxílio da Tabela 4.16, podemos calcular a especificidade e a sensibilidade de cada grupo. O grupo 1 teve $61 \%$ de especificidade e $70 \%$ de sensibilidade, para o grupo 2 a especificidade foi de $68 \%$ e a sensibilidade de $69 \%$, e para o grupo 4 temos $74 \%$ de sensibilidade e $73 \%$ de especificidade. O grupo 3 obteve $42 \%$ de especificidade e $92 \%$ de sensibilidade, isso mostra que o modelo está ajustando bem os valores verdadeiramente positivos, mas precisa ser aprimorado para capturar adequadamente os verdadeiros negativos, em contrapartida o grupo 5 tem $83 \%$ de especificidade e $58 \%$ de sensibilidade.

Tabela 4.16: Matriz de confusão, segundo o modelo por cluster

\begin{tabular}{c|cc||cc||cc||cc||cc||cc}
\hline & \multicolumn{1}{c}{ Valores observados na pesquisa TIC Educação } \\
\hline Valores preditos & \multicolumn{2}{|c|}{ Grupo 1 } & \multicolumn{2}{|c|}{ Grupo 2 } & \multicolumn{2}{|c}{ Grupo 3 } & \multicolumn{2}{|c}{ Grupo 4 } & \multicolumn{2}{|c|}{ Grupo 5 } \\
pelo modelo & 0 & 1 & 0 & 1 & 0 & 1 & 0 & 1 & 0 & 1 \\
\hline 0 & 23 & 105 & 13 & 16 & 8 & 1 & 39 & 50 & 5 & 80 \\
1 & 15 & 243 & 6 & 36 & 11 & 12 & 14 & 138 & 1 & 111 \\
\hline
\end{tabular}

Com base nessas equações, realizamos a predição de todas as escolas existentes no cadastro e que não fizeram parte da amostra da pesquisa TIC Educação 2013. Assim, ao final do processo obtivemos alguma informação para todas as unidades presentes na listagem, de tal modo que foi possível calcular o vetor das proporções de escolas em que os professores usam a Internet em atividades de ensino-aprendizagem com os alunos obtidas através dos modelos gerados por agrupamento para cada uma das UF. Cada proporção foi calculada considerando a média ponderada entre a soma das respostas fornecidas pelas unidades amostradas e a soma dos valores preditos para as unidades fora da amostra. Através da Figura 4.7 podemos ver a distribuição das proporções para cada uma das 
UF. Com isso, podemos destacar que Santa Catarina, Rio Grande do Sul, Mato Grosso do Sul e Distrito Federal possuem as maiores proporções (azul mais escuro) enquanto Maranhão possui a proporção mais baixa (azul mais claro).

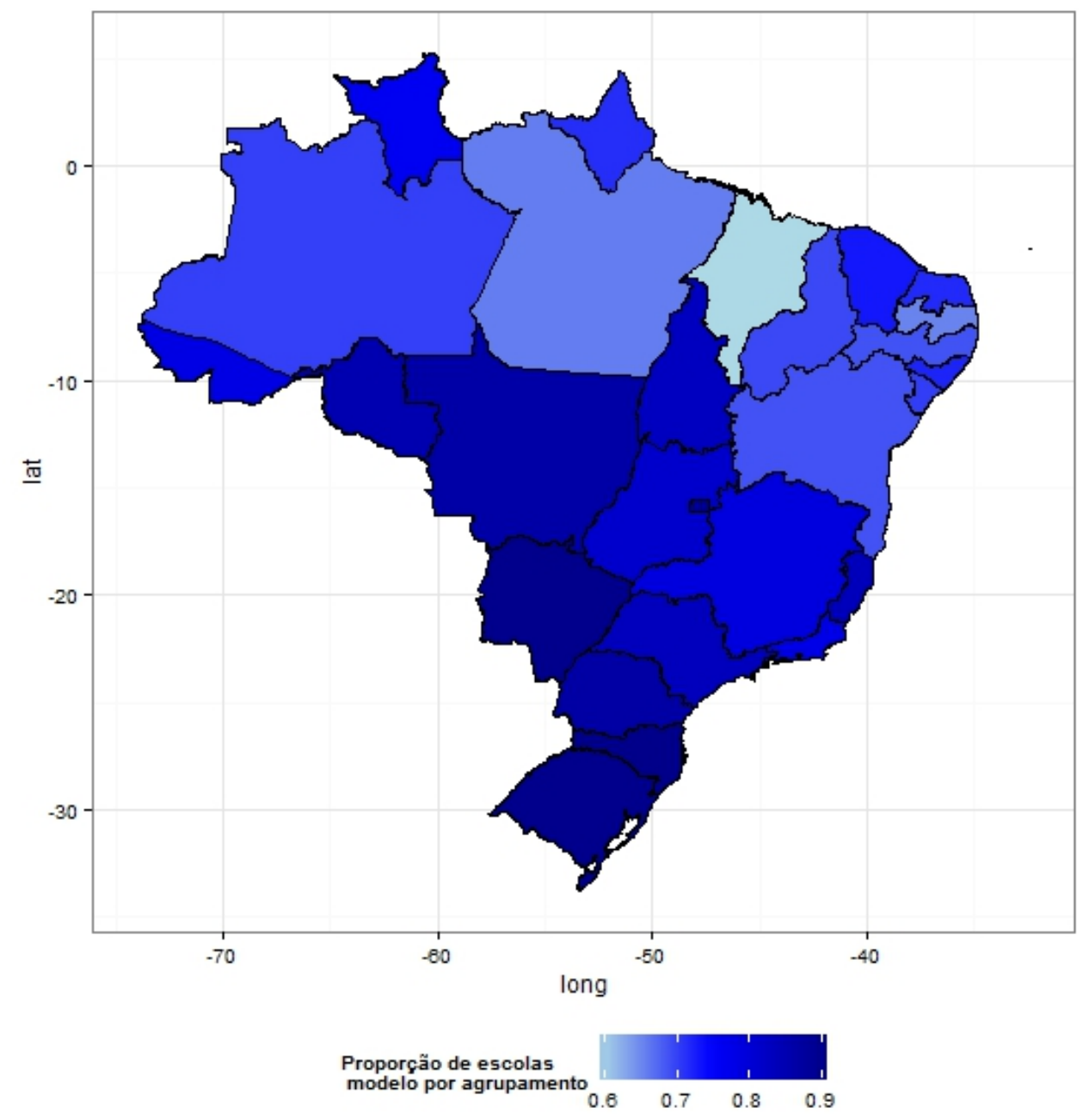

Figura 4.7: Mapa com as estimativas das proporções de escolas em que os professores usam a Internet com os alunos para atividades de ensino-aprendizagem obtidas pelo modelo por cluster

Para avaliar a qualidade do ajuste, utilizamos o algoritmo bootstrap abordado na Seção 3.3 para a obtenção da estimativa do EQM, uma vez que essa medida incorpora a variabilidade e o viés. Foram geradas 1000 populações bootstrap para a obtenção das estimativas, no entanto, obtivemos resultados para 994 dessas populações, pois em 6 iterações todas as escolas do grupo 3, presentes na amostra extraída, possuíam conexão à Internet, não sendo possível estimar o respectivo modelo. Esses casos foram desconsiderados para o cálculo do EQM. Assim sendo, estão dispostos na Tabela 4.17 as proporções e seus respectivos EQM obtidos para a abordagem de Cluster, tal que foi obtido um modelo para cada grupo formado. Dessa forma, temos que os estados do Rio Grande do Sul e Santa Catarina além de apresentarem as maiores proporções, 90\%, possuem o menor EQM, 0,0002, o que caracteriza uma estimativa bastante próxima ao valor verdadeiro. Podemos estender o resultado para o estado de Mato Grosso do Sul, pois a proporção também é de $90 \%$ e apresenta um EQM de 0,0003. O estado do Maranhão é o que apresenta o pior desempenho, pois seu EQM é de 0,0033, o mais alto obtido por esta abordagem. 
Tabela 4.17: Estimativas da proporção de escolas em que os professores usam a Internet com os alunos para atividades de ensino-aprendizagem e do erro quadrático médio, por UF, segundo o modelo por cluster

\begin{tabular}{ccc|ccc|ccc}
\hline UF & Proporção (\%) & EQM & UF & Proporção (\%) & EQM & UF & Proporção (\%) & EQM \\
\hline AC & 78 & 0,0012 & MA & 59 & 0,0033 & RJ & 78 & 0,0004 \\
AL & 72 & 0,0007 & MG & 79 & 0,0005 & RN & 71 & 0,0008 \\
AM & 70 & 0,0007 & MS & 90 & 0,0003 & RO & 85 & 0,0005 \\
AP & 71 & 0,0015 & MT & 86 & 0,0004 & RR & 76 & 0,0015 \\
BA & 69 & 0,0009 & PA & 65 & 0,0007 & RS & 90 & 0,0002 \\
CE & 73 & 0,0005 & PB & 65 & 0,0008 & SC & 90 & 0,0002 \\
DF & 89 & 0,0006 & PE & 68 & 0,0008 & SE & 70 & 0,0007 \\
ES & 84 & 0,0004 & PI & 69 & 0,0010 & SP & 83 & 0,0004 \\
GO & 81 & 0,0003 & PR & 87 & 0,0003 & TO & 83 & 0,0007 \\
\hline
\end{tabular}

\subsection{Modelo com efeitos aleatórios}

Os modelos de efeitos aleatórios, ou efeitos mistos, são utilizados a fim de descrever a relação entre a variável resposta e as covariáveis de dados agrupados de acordo com um ou mais fatores. Além disso, a introdução de efeitos aleatórios adicionam mais uma fonte de erro que tem em conta a correlação entre as unidades dentro de um mesmo grupo. A metodologia empregada para o cálculo de estimativas em pequenas áreas segue a teoria de modelos lineares mistos generalizados, conforme Subseção 3.2.1. Dessa maneira, é razoável supor que cada UF apresenta uma distribuição de probabilidade e, logo, podem ser tratadas como efeitos aleatórios.

Denotamos por $\boldsymbol{u}=\left\{u_{1}, \cdots, u_{D}\right\}$ o vetor de efeitos aleatórios. Desse modo, assumimos que $u_{d}$ é o efeito aleatório normalmente distribuído com média zero e variância $\varphi$ para cada pequena área $d=1, \cdots, D$, ou seja, o valor assumido para cada UF. Assim, desejamos obter os valores preditos, $\hat{u}_{d}$, que representam o desvio da média da população em relação a média dentro da UF.

Assim como nas seções anteriores, as variáveis que foram incluídas inicialmente no modelo são: ID_DEPENDENCIA_ADM, ID_LABORATORIO_INFORMATICA, REGIAO, NUM_SALAS_UTILIZADAS, NUM_ _EQUIP_MULTIMIDIA, MED_IDADE, QT_DOCENTES, ID_PROF_INF, NUM_COMPUTADORES, NUM_COMP_ _ALUNOS, ID_INTERNET e ID_BANDA_LARGA. No entanto, diferentemente das abordagens anteriores, para os modelos lineares mistos generalizados, os métodos de estimação baseados na função de verossimilhança ainda enfrentam desafios computacionais. Um método muito difundido é o, do inglês, Penalized Quasi-Likelihood (PQL) que apesar de introduzir vício aos estimadores é de fácil obtenção. Dessa forma, utilizamos a função $g \operatorname{lmm} P Q L$ do pacote $M A S S$ do software R para a construção desses modelos.

Para a seleção de variáveis utilizamos o método de Wald para múltiplos parâmetros com as variáveis tais que os valores-p eram maiores que 0,3. Dessa forma, as variáveis NUM_SALAS_UTILIZADAS e NUM_COMP_ALUNOS foram removidas do modelo. Comparamos o modelo inicial e o modelo obtido após a exclusão dessas variáveis através de uma ANOVA, como não havia diferença significativa entre os modelos, optamos por aquele com o menor número de variáveis, tal que a equação final do modelo é dada por ${ }^{4}$ :

\footnotetext{
${ }^{4}$ A tabela contendo as estimativas, os erros-padrão, os valores das estatísticas $t$ e os valores-p está disposta no Apêndice A, Tabela A.14.
} 


$$
\begin{aligned}
& \log \left(\frac{\hat{p}_{d j}}{1-\hat{p}_{d j}}\right)=\left(\hat{\boldsymbol{\beta}}_{0}+\hat{u}_{d}\right)-0,46 \times I D_{-} \text {DEPENDENCIA_ADM Municipais } \\
& +1,04 \times I D_{-} D E P E N D E N C I A_{-} A D M_{\text {Particulares }} \\
& +0,84 \times I D \_L A B O R A T O R I O \_I N F O R M A T I C A \\
& -0,05 \times N U M_{-} E Q U I P \_M U L T I M I D I A \\
& +0,04 \times N U M_{-} C O M P U T A D O R E S \\
& +1,48 \times I D_{-} \text {INTERNET } \\
& +0,53 \times I D_{-} B A N D A_{-} L A R G A \\
& +0,66 \times I D_{-} P R O F_{-} I N F \\
& +0,009 \times Q T_{-} \text {DOCENTES } \\
& -0,08 \times M E D \_I D A D E \text {, }
\end{aligned}
$$

onde $\hat{\boldsymbol{\beta}}_{0}$ é a estimativa do intercepto dos efeitos fixos e $\hat{u}_{d}$ é a predição dos efeitos aleatórios. Dessa forma, como cada UF possui um intercepto diferente, apresentamos o valor do intercepto aleatório para cada UF na Tabela 4.18.

Tabela 4.18: Valores dos interceptos obtidos pelo modelo de efeitos aleatórios

\begin{tabular}{cc|cc|cc}
\hline $\mathrm{UF}$ & $\hat{\boldsymbol{\beta}}_{0}+\hat{u}_{d}$ & $\mathrm{UF}$ & $\hat{\boldsymbol{\beta}}_{0}+\hat{u}_{d}$ & $\mathrm{UF}$ & $\hat{\boldsymbol{\beta}}_{0}+\hat{u}_{d}$ \\
\hline $\mathrm{AC}$ & 1,44 & $\mathrm{MA}$ & 1,51 & $\mathrm{RJ}$ & 1,55 \\
$\mathrm{AL}$ & 1,48 & $\mathrm{MG}$ & 1,35 & $\mathrm{RN}$ & 1,40 \\
$\mathrm{AM}$ & 1,49 & $\mathrm{MS}$ & 1,63 & $\mathrm{RO}$ & 1,61 \\
$\mathrm{AP}$ & 1,50 & $\mathrm{MT}$ & 1,57 & $\mathrm{RR}$ & 1,50 \\
$\mathrm{BA}$ & 1,45 & $\mathrm{PA}$ & 1,56 & $\mathrm{RS}$ & 1,66 \\
$\mathrm{CE}$ & 1,49 & $\mathrm{~PB}$ & 1,50 & $\mathrm{SC}$ & 1,62 \\
$\mathrm{DF}$ & 1,41 & $\mathrm{PE}$ & 1,54 & $\mathrm{SE}$ & 1,53 \\
$\mathrm{ES}$ & 1,49 & $\mathrm{PI}$ & 1,54 & $\mathrm{SP}$ & 1,51 \\
$\mathrm{GO}$ & 1,45 & $\mathrm{PR}$ & 1,69 & $\mathrm{TO}$ & 1,62 \\
\hline
\end{tabular}

A validação do modelo foi realizada segundo o método de validação cruzada por leave-one-out, tal como nas abordagens modelo geral, modelo por região e modelo por cluster. Nesse método retiramos uma observação do conjunto de dados, refazemos o modelo e realizamos a predição para essa unidade, de tal modo que ao final temos o valor verdadeiro e o valor obtido pelo modelo sendo possível comparar os resultados e conhecer a precisão do modelo. No entanto, como o modelo nos fornece a probabilidade de sucesso, utilizamos a Curva ROC, mais detalhada na Seção 4.2, para obter um ponto de corte que atua como classificador das escolas, ponto em destaque na Figura 4.8. Assim, se a probabilidade da escola era maior que 0,84 , a escola é classificada como sucesso e, caso contrário, é classificada como fracasso.

A partir da classificação das unidades pelo ponto de corte obtido na Curva ROC e das observações obtidas no momento da realização da entrevista, esse método é realizado apenas para as unidades presentes na amostra, podemos construir a matriz de confusão dada pela Tabela 4.19. Dessa forma, podemos avaliar as unidades que foram preditas corretamente pelo modelo, isto é, um sucesso classificado como sucesso e um fracasso classificado como fracasso. Logo, a proporção 


\section{Curva ROC}

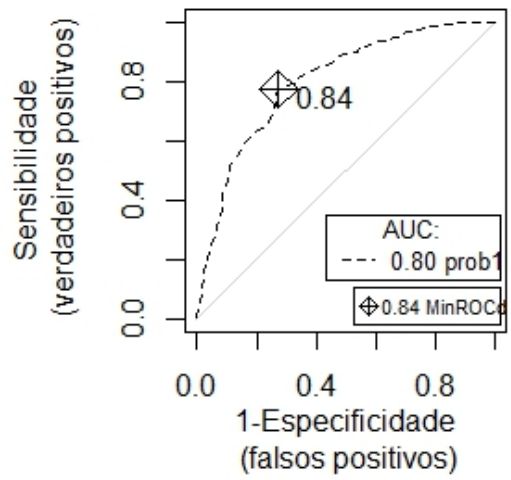

Figura 4.8: Curva ROC para o modelo de efeitos aleatórios

de acertos deste modelo é de 76,7\%. Também é possível obter a taxa de verdadeiros negativos, a especificidade, e a taxa de verdadeiros positivos, a sensibilidade. Para este modelo, a especificidade foi de $73 \%$ e a sensibilidade foi de $77 \%$.

Tabela 4.19: Matriz de confusão, segundo o modelo de efeitos aleatórios

\begin{tabular}{c|cc}
\hline $\begin{array}{c}\text { valores preditos } \\
\text { pelo modelo }\end{array}$ & valores observados na pesquisa TIC Educação \\
\hline 0 & 9 & 1 \\
\hline 1 & 37 & 179 \\
\hline
\end{tabular}

O que desejamos obter são estimativas confiáveis para a proporção de escolas em que os professores usam a Internet com os alunos em atividades de ensino-aprendizagem para cada UF, assim, para o cálculo dessas estimativas, utilizamos o valor declarado para as escolas que participaram da pesquisa TIC Educação e realizamos a predição para as demais unidades, através do modelo obtido. Dessa forma, obtivemos as estimativas, através da Equação (3.7), que estão dispostas na Tabela 4.20. Além disso, optamos por divulgar essas estimativas em uma representação gráfica através de mapas, Figura 4.9, de tal forma que as proporções mais baixas estão representadas no azul mais claro e que a medida que as proporções vão aumentando a coloração azul vai escurecendo, como disposto na legenda da Figura 4.9. Assim, podemos notar que o estado do Maranhão foi o que apresentou a menor estimativa e que as estimativas foram aumentando gradativamente até atingir o patamar mais elevado para o estado do Mato Grosso do Sul, azul mais escuro.

Para avaliar a qualidade do ajuste, e consequentemente das estimativas, utilizamos a estimativa fornecida pelo EQM e que foi obtida através do algoritmo bootstrap detalhado na Seção 3.3. Foram geradas 1000 populações bootstrap para a obtenção das estimativas do EQM. Destacamos que as amostras extraídas para a obtenção dos modelos e estimativas em cada iteração foram obtidas com as mesmas características da amostra da pesquisa TIC Educação. Os resultados estão dispostos na Tabela 4.20, e através deles podemos notar que o Distrito Federal possui a menor estimativa do EQM, mostrando que apesar da estimativa da proporção ser bastante alta esse valor desvia-se pouco do valor real. Do mesmo modo, o estado de São Paulo possui uma estimativa do EQM pequena, indicando que a proporção estimada é bastante precisa. Em contrapartida, o estado do Maranhão 


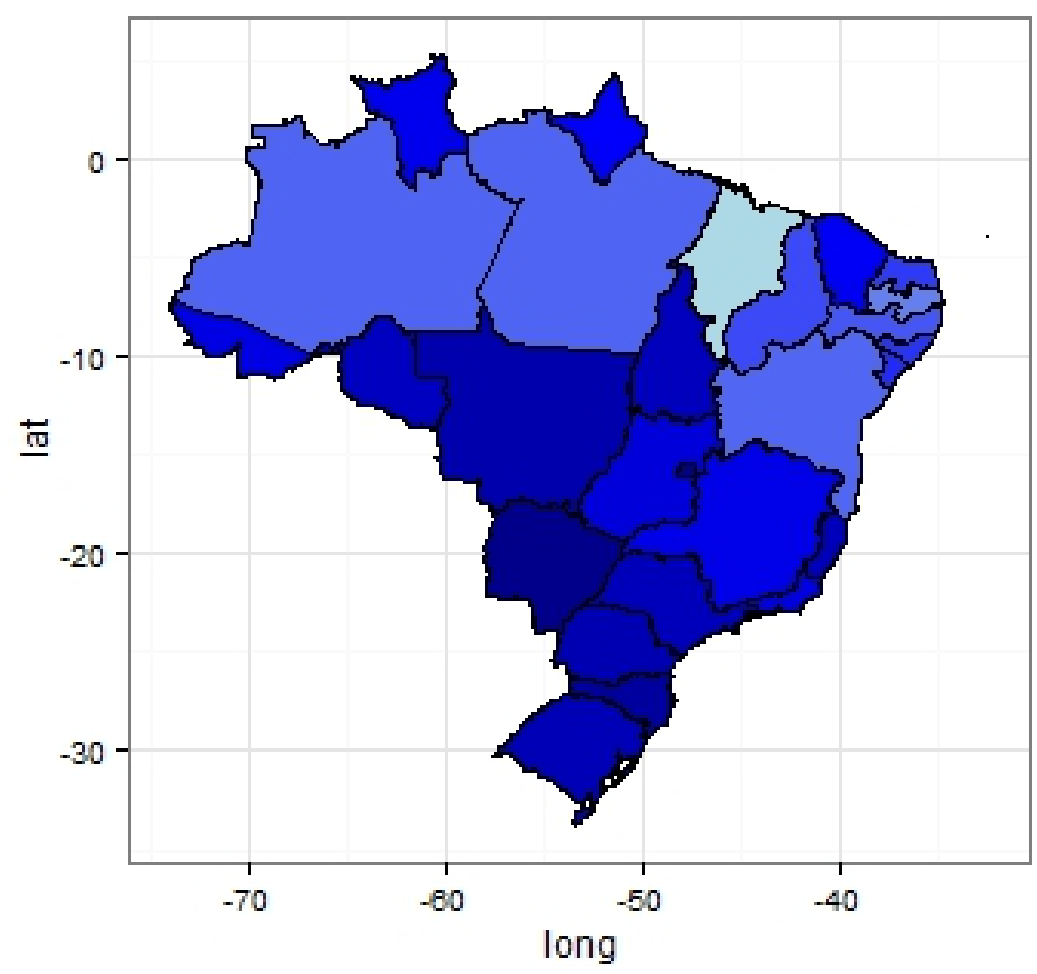

Proporção de escolas modelo misto

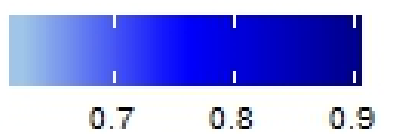

Figura 4.9: Mapa com as estimativas das proporções de escolas em que os professores usam a Internet com os alunos para atividades de ensino-aprendizagem obtidas pelo modelo de efeitos aleatórios

possui a maior estimativa do EQM, assim temos que o valor estimado para a proporção é o que está mais distante do valor real.

Tabela 4.20: Estimativas da proporção de escolas em que os professores usam a Internet com os alunos para atividades de ensino-aprendizagem e do erro quadrático médio, por UF, segundo o modelo de efeitos aleatórios

\begin{tabular}{ccc|ccc|ccc}
\hline UF & Proporção (\%) & EQM & UF & Proporção (\%) & EQM & UF & Proporção (\%) & EQM \\
\hline AC & 79 & 0,0015 & MA & 61 & 0,0055 & RJ & 80 & 0,0011 \\
AL & 72 & 0,0015 & MG & 78 & 0,0010 & RN & 72 & 0,0018 \\
AM & 69 & 0,0015 & MS & 91 & 0,0007 & RO & 84 & 0,0012 \\
AP & 76 & 0,0023 & MT & 86 & 0,0008 & RR & 78 & 0,0019 \\
BA & 69 & 0,0015 & PA & 69 & 0,0016 & RS & 85 & 0,0009 \\
CE & 77 & 0,0014 & PB & 67 & 0,0025 & SC & 88 & 0,0008 \\
DF & 89 & 0,0004 & PE & 70 & 0,0024 & SE & 73 & 0,0021 \\
ES & 84 & 0,0010 & PI & 71 & 0,0020 & SP & 85 & 0,0006 \\
GO & 80 & 0,0009 & PR & 85 & 0,0008 & TO & 84 & 0,0014 \\
\hline
\end{tabular}




\subsection{Modelo com efeitos aleatórios e efeito do plano amostral}

As pesquisas produzidas pelo CGI.br possuem plano amostral complexo, isto é, apresentam probabilidades desiguais, conglomeração das unidades e estratificação. Essas características influenciam a análise dos dados para a realização de inferências, em muitas vezes subestimando a variância dos parâmetros estimados, assim, se faz necessário a inclusão do plano amostral para obtenção dessas estimativas. Uma vez que não encontramos nenhum pacote disponível no software R que realizasse estimação para amostras complexas e modelo de regressão logística no caso de modelos hierárquicos ou multiníveis, utilizamos o software STATA ${ }^{\circledR}$ através do comando svy e da função melogit para obter estimativas utilizando tanto os efeitos aleatórios quanto o plano amostral.

Em todas as abordagens apresentadas neste capítulo, as variáveis incluídas inicialmente no modelo foram: ID_DEPENDENCIA_ADM, ID_LABORATORIO_INFORMATICA, REGIAO, NUM_SALAS_UTILIZADAS, NUM_EQUIP_MULTIMIDIA, MED_IDADE, QT_DOCENTES, ID_PROF_INF, NUM_COMPUTADORES, NUM_COMP_ALUNOS, ID_INTERNET e ID_BANDA_LARGA. Porém, para esta abordagem não utilizamos o método de seleção de variáveis stepwise, sendo apenas utilizado o teste de Wald de múltiplos parâmetros para as variáveis que apresentam valores-p maiores que 0,3 . O modelo final considerou as mesmas variáveis que o modelo de regressão logística com efeitos aleatórios, mas sem levar em consideração o plano amostral, disposto na Seção 4.6. Assim, a equação final do modelo é dada $\operatorname{por}^{5}$ :

$$
\begin{aligned}
\log \left(\frac{\hat{p}_{d j}}{1-\hat{p}_{d j}}\right)= & \left(\hat{\boldsymbol{\beta}}_{0}+\hat{u}_{d}\right)-0,48 \times I D_{-} D E P E N D E N C I A_{-} \text {ADM Municipais } \\
& +1,04 \times I D_{-} \text {DEPENDENCIA_ADMParticulares } \\
& +0,85 \times I D_{-} \text {LABORATORIO_INFORMATICA } \\
& -0,05 \times N M_{-} M_{-} E Q U I P_{-} \text {MULTIMIDIA } \\
& +0,04 \times N U_{-} M_{-} C O M P U T A D O R E S \\
& +1,50 \times I D_{-} \text {INTERNET } \\
& +0,52 \times I D_{-} \text {BANDA_LARGA } \\
& +0,66 \times I D_{-} \text {PROF_INF } \\
& +0,009 \times Q T_{-} \text {DOCENTES } \\
& -0,08 \times M E D_{-} I D A D E,
\end{aligned}
$$

onde $\hat{u}_{d}$ é a predição dos efeitos aleatórios e $\hat{\boldsymbol{\beta}}_{0}$ é a estimativa do intercepto dos efeitos fixos. Dessa forma, cada UF possui um intercepto aleatório que é a soma entre o intercepto dos efeitos fixos e o efeito aleatório, isto é, cada UF possui um intercepto diferente. O valor da predição de cada intercepto aleatório é dado na Tabela 4.21.

Com base nos coeficientes, fixos e aleatórios, encontrados, realizamos a predição para as unidades. Nesta abordagem não utilizamos a validação leave-one-out, mas utilizamos os programas já desenvolvidos no software $\mathrm{R}$ para a obtenção da curva ROC e da matriz de confusão. A Figura 4.10 é a curva ROC obtida através das probabilidades preditas pelo modelo de efeitos aleatórios

\footnotetext{
${ }^{5}$ A tabela contendo as estimativas, os erros-padrão, os valores das estatísticas $t$ e os valores-p está disposta no Apêndice A, Tabela A.15.
} 
Tabela 4.21: Valores dos interceptos obtidos pelo modelo de efeitos aleatórios considerando o plano amostral

\begin{tabular}{cc|cc|cc}
\hline $\mathrm{UF}$ & $\hat{\boldsymbol{\beta}}_{0}+\hat{u}_{d}$ & $\mathrm{UF}$ & $\hat{\boldsymbol{\beta}}_{0}+\hat{u}_{d}$ & $\mathrm{UF}$ & $\hat{\boldsymbol{\beta}}_{0}+\hat{u}_{d}$ \\
\hline $\mathrm{AC}$ & 1,42 & $\mathrm{MA}$ & 1,59 & $\mathrm{RJ}$ & 1,67 \\
$\mathrm{AL}$ & 1,51 & $\mathrm{MG}$ & 1,29 & $\mathrm{RN}$ & 1,32 \\
$\mathrm{AM}$ & 1,54 & $\mathrm{MS}$ & 1,88 & $\mathrm{RO}$ & 1,81 \\
$\mathrm{AP}$ & 1,57 & $\mathrm{MT}$ & 1,71 & $\mathrm{RR}$ & 1,55 \\
$\mathrm{BA}$ & 1,47 & $\mathrm{PA}$ & 1,67 & $\mathrm{RS}$ & 1,89 \\
$\mathrm{CE}$ & 1,55 & $\mathrm{~PB}$ & 1,56 & $\mathrm{SC}$ & 1,84 \\
$\mathrm{DF}$ & 1,36 & $\mathrm{PE}$ & 1,65 & $\mathrm{SE}$ & 1,63 \\
$\mathrm{ES}$ & 1,53 & $\mathrm{PI}$ & 1,66 & $\mathrm{SP}$ & 1,59 \\
$\mathrm{GO}$ & 1,47 & $\mathrm{PR}$ & 1,97 & $\mathrm{TO}$ & 1,84 \\
\hline
\end{tabular}

considerando o plano amostral, de modo a minimizar a sensibilidade e a especificidade conforme definido na Seção 4.2 .

\section{Curva ROC}

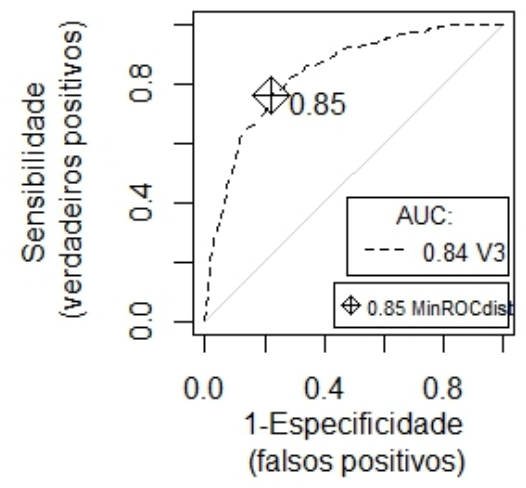

Figura 4.10: Curva ROC para o modelo de efeitos aleatórios considerando o plano amostral

O ponto destacado na Figura 4.10 é o valor do ponto de corte, usado para a classificação, assim, se a probabilidade predita é maior que o valor do ponto de corte, essa escola é classificada como "sim", os professores utilizam Internet, e caso contrário é classificada como "não". Dessa maneira, construímos a matriz de confusão para o modelo, podendo observar a diferença entre os valores preditos pelo modelo e os observados na realização da pesquisa TIC Educação. Esses valores estão dispostos na Tabela 4.22 e através dela encontramos que o modelo prediz corretamente $76 \%$ dos casos. Também observamos que a sensibilidade para este modelo é igual a $76 \%$ e a especificidade é igual a $78 \%$.

Tabela 4.22: Matriz de confusão, segundo o modelo de efeitos aleatórios considerando o plano amostral

\begin{tabular}{c|cc}
\hline $\begin{array}{c}\text { valores preditos } \\
\text { pelo modelo }\end{array}$ & valores observados na pesquisa TIC Educação \\
\hline 0 & 0 & 1 \\
1 & 105 & 188 \\
\hline
\end{tabular}

Como a variável resposta é proveniente da pesquisa amostral TIC Educação, não temos obser- 
vações para as unidades que não compuseram a amostra, assim, é necessário realizar o cálculo da predição dessas unidades de acordo com a Equação (3.4). Cabe ressaltar que nesta abordagem os valores de $\boldsymbol{\beta}$ foram estimados de acordo com a Equação (3.11) e estão dispostos na equação do modelo dada acima. Dessa maneira, obtemos a proporção de escolas em que os professores usam a Internet com os alunos em atividades de ensino-aprendizagem para cada uma das UF, sendo que cada proporção é uma média ponderada entre a soma das respostas fornecidas pelas unidades amostradas e a soma dos valores preditos para as unidades fora da amostra.

Assim como para as demais abordagens, as estimativas das proporções que foram obtidas para cada UF através da construção do modelo, estão dispostas na Figura 4.11, um mapa do Brasil, de modo a facilitar a leitura e compreensão dos resultados. As diferentes tonalidades de azul indicam as diferentes proporções, a escala adotada é intuitiva, pois as tonalidades mais claras indicam as menores proporções e as tonalidades mais escuras, as maiores proporções estimadas. Notamos que o Mato Grosso do Sul possui o azul de cor mais escura, indicando a maior proporção de uso, enquanto o Maranhão é de um azul mais claro, indicando a menor proporção entre as UF. De modo geral, destacamos que a região Centro-Sul do Brasil apresenta uma tonalidade mais escura frente ao Norte-Nordeste, reflexo da concentração de renda e investimentos na área educacional.

Na Tabela 4.23 estão dispostas as estimativas obtidas para a proporção de escolas em que os professores usam a Internet com os alunos para atividades de ensino-aprendizagem, por UF. Uma limitação atribuída a esta abordagem é que não fizemos o cálculo da estimativa do EQM, pois como o STATA ${ }^{\circledR}$ é um software proprietário não conseguimos implementar o algoritmo bootstrap da mesma maneira que o programa foi contruído no software $\mathrm{R}$ e empregado nas demais abordagens.

Tabela 4.23: Estimativas da proporção de escolas em que os professores usam a Internet com os alunos para atividades de ensino-aprendizagem e do erro quadrático médio, por UF, segundo o modelo de efeitos aleatórios e efeito do plano amostral

\begin{tabular}{cc|cc|cc}
\hline UF & Proporção (\%) & UF & Proporção (\%) & UF & Proporção (\%) \\
\hline AC & 78 & MA & 61 & RJ & 80 \\
AL & 71 & MG & 77 & RN & 69 \\
AM & 68 & MS & 92 & RO & 85 \\
AP & 76 & MT & 87 & RR & 78 \\
BA & 68 & PA & 69 & RS & 87 \\
CE & 77 & PB & 67 & SC & 89 \\
DF & 88 & PE & 70 & SE & 73 \\
ES & 84 & PI & 71 & SP & 85 \\
GO & 80 & PR & 87 & TO & 86 \\
\hline
\end{tabular}

Ressaltamos que os coeficientes obtidos por essa abordagem foram iguais ou muito próximos aos encontrados na abordagem modelo misto com efeitos aleatórios, apresentados na Seção 4.5. No entanto, os erros-padrão e, por consequência, os respectivos valores-p eram distintos entre uma abordagem e outra, mas muito próximos de tal forma que nenhuma inferência foi alterada. Note também que as estimativas obtidas para cada UF diferem em, no máximo, 3 pontos percentuais, por exemplo para o estado do Rio Grande do Norte, em relação às estimativas obtidas pelo modelo com efeitos aleatórios que não considerou o plano amostral, ver Tabela 4.20. Assim, optamos por utilizar nas comparações apenas o modelo com efeitos aleatórios sem considerar o efeito do plano 


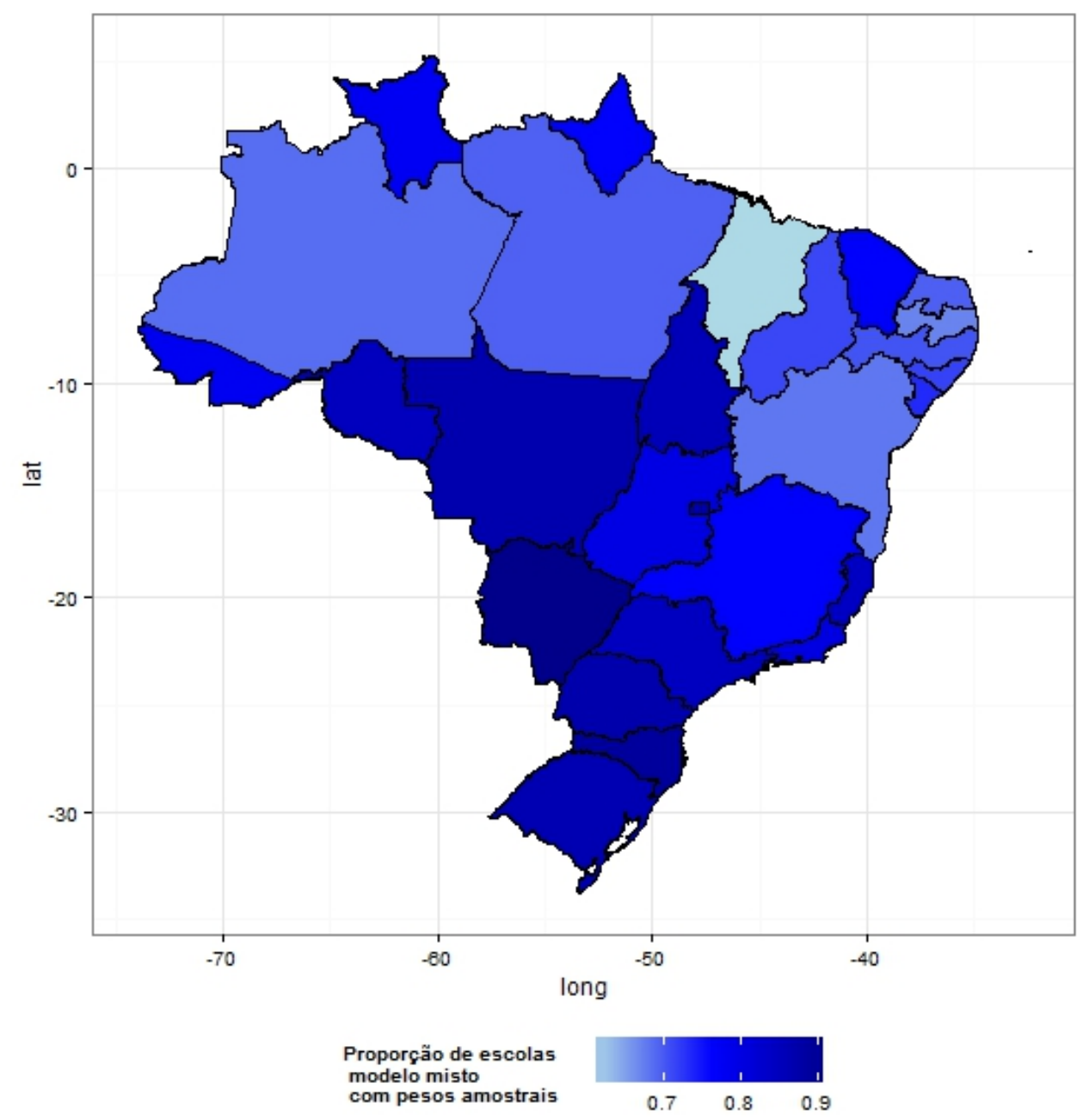

Figura 4.11: Mapa com as estimativas das proporções de escolas em que os professores usam a Internet com os alunos para atividades de ensino-aprendizagem obtidas pelo modelo de efeitos aleatórios considerando o plano amostral

amostral, não estamos afirmando que o plano amostral não teve papel algum na inferência desses parâmetros, só optamos por desconsiderá-lo, inclusive para manter todas as análises baseadas na utilização do software livre R.

\subsection{Comparação das estimativas}

Ao longo deste capítulo, Capítulo 4, foram obtidas as estimativas para a proporção de escolas em que os professores usam a Internet com os alunos em atividade de ensino-aprendizagem para cada UF, por diferentes abordagens para os dados reais provindos do Censo Escolar 2013 e da pesquisa TIC Educação 2013. Dessa forma, se faz necessário comparar essas estimativas e os ajustes a fim de avaliar cada abordagem. De modo geral, as proporções com valores mais altos são obtidas através da estimativa direta da amostra, em $44 \%$ das UF isso ocorre. Em contrapartida, as menores proporções, isto é, os menores valores obtidos para as UF, são provenientes dos modelos geral e por região. Destacamos que na maioria dos casos as estimativas são bem próximas, como por exemplo o estado de Santa Catarina em que as estimativas variam entre 87 e $90 \%$, por outro lado, destacamos 
o estado do Espírito Santo em que a estimativa direta é de $48 \%$ e para os modelos esse valor sobe para a casa dos $80 \%$ e o estado do Paraná em que a estimativa direta é de $98 \%$ e através dos modelos as estimativas são menores em mais de 10 pontos percentuais.

Podemos verificar através dos mapas, Figuras 4.1, 4.3, 4.5, 4.7, 4.9 e 4.11, que as estimativas obtidas pelo estimador direto (Figura 4.1) são maiores, pois o mapa é predominantemente azul escuro se comparado com os demais, inclusive os estados de Tocantins e Mato Grosso do Sul, a estimativa encontrada é de que em 100\% das escolas os professores utilizam a Internet com os alunos para as atividades de ensino-aprendizagem. Destacamos que os dados resultantes do modelo geral (Figura 4.3) tem pontos mais claros na região Nordeste do que os mapas para as outras abordagens, mas de maneira geral, com exceção do estimador direto, as UF das regiões Norte e Nordeste são mais claras que as UF das demais regiões do Centro-Sul do país, refletindo as desigualdades já conhecidas para essas regiões. Para UF específicas, destacamos que o Maranhão possui a menor estimativa para a proporção em todas as abordagens baseadas em modelo, apenas na estimativa direta da amostra os estados do Espírito Santo, Rio Grande do Norte, Paraíba e Sergipe possuem proporções ainda menores, além disso, destacamos que o Distrito Federal possui proporções maiores que o estado de Goiás para todas as abordagens, apesar de aquele ser praticamente um enclave deste.

Tomando como base as matrizes de confusão calculadas para as diferentes abordagens, Tabelas 4.4, 4.6, 4.16, 4.19 e 4.22, podemos observar a proporção de acertos do modelo. Assim, a abordagem do modelo por cluster é o que tem pior desempenho, uma vez que o grupo 1 tem $68 \%$ de acertos, o grupo 2 tem $69 \%$, o grupo 3 tem $63 \%$, o grupo 4 é o que mais acertou, com $73 \%$ e o que apresentou o pior resultado foi o grupo 5 com $59 \%$. O modelo geral tem $72,7 \%$ de acertos, enquanto o modelo por região apresenta um desempenho similar, uma vez que a região Norte tem $73 \%$ de acertos, a região Nordeste $75 \%$, a região Sul tem $85 \%$, mas a região Sudeste tem $67 \%$ e a região Centro-Oeste tem $64 \%$. O modelo misto considerando o plano amostral faz a predição corretamente em $76 \%$ dos casos e o modelo misto sem considerar o efeito do plano amostral acerta em $76,7 \%$ dos casos, sendo o método mais acertivo.

Através das Figuras 4.2, 4.4, 4.6, 4.8, 4.10 podemos avaliar a área sob a curva ROC (AUC), uma medida de acurácia e desempenho do teste. Conforme já introduzido na Seção 4.2, um teste cujo AUC é de 0,5 é um teste totalmente incapaz de discriminar as unidades em usa e não usa, enquanto uma área de 1 representa um teste perfeito, assim, quanto maior a capacidade do teste em classificar as unidades, mais a curva se aproxima do canto superior esquerdo, de tal forma que a área seria o mais próximo de 1 . Assim, temos que a AUC do modelo de efeitos aleatórios é de 0,80 e a do modelo de efeitos aleatórios considerando o plano amostral é de 0,84, definindo uma classificação excelente. A partir do modelo por região, temos que a região Sul possui uma AUC de 0,91, o que caracteriza uma discriminação fora do comum, já as demais regiões possuem uma discriminação boa: para a região Norte o valor obtido é de 0,70 , para a região Nordeste é de 0,79 , para a região Sudeste de 0,74 e para a região Centro-Oeste é de 0,71. O modelo geral possui uma classificação boa, uma vez que a AUC é de 0,78 . O modelo por cluster ao mesmo tempo em que o grupo 3 obteve uma AUC de 0,61 caracterizando uma discriminação regular, o grupo 4 apresentou um poder de discriminação excelente, já que a AUC é de 0,80 , já os grupos 1,2 e 5 são bons classificadores pois ficaram entre 0,71 e 0,78 .

Como medida de qualidade do ajuste obtivemos a estimativa do erro quadrático médio (EQM) para todas as abordagens, com exceção do modelo com efeitos aleatórios e do plano amostral como 
já justificado na Seção 4.6. Através do EQM podemos avaliar o quanto, em média, a estimativa da proporção está distante do valor real, no entanto, o valor real é desconhecido e por isso se faz necessária a construção de um algoritmo bootstrap para a obtenção de sua estimativa. O EQM do estimador direto é obtido através da Equação (3.3), assim não é necessário a utilização desse algoritmo bootstrap para a obtenção de sua estimativa.

Comparando as estimativas do EQM obtidas através dos modelos com a estimativa encontrada com o uso do estimador direto, temos que o modelo por cluster tem melhor desempenho para aproximadamente $93 \%$ das UF, o modelo com efeitos aleatórios para $85 \%$ das UF e o modelo por região em $67 \%$ delas. Não podemos afirmar que os modelos têm melhor desempenho que o estimador direto, pois através da Figura 4.12, notamos que o modelo geral apresentou estimativas mais altas para o EQM em 16 das 27 UF. Assim, consideramos a abordagem de modelo geral com o pior desempenho, pois, também, dentre as abordagens utilizando modelo apresentou as estimativas mais altas para o EQM, com exceção dos estados do Acre, Amazonas, Espírito Santo e Tocantins que têm melhor desempenho segundo o modelo geral do que o modelo por região. Para o conjunto de dados reais utilizado nesta dissertação, o estimador direto apresentou o segundo pior desempenho.

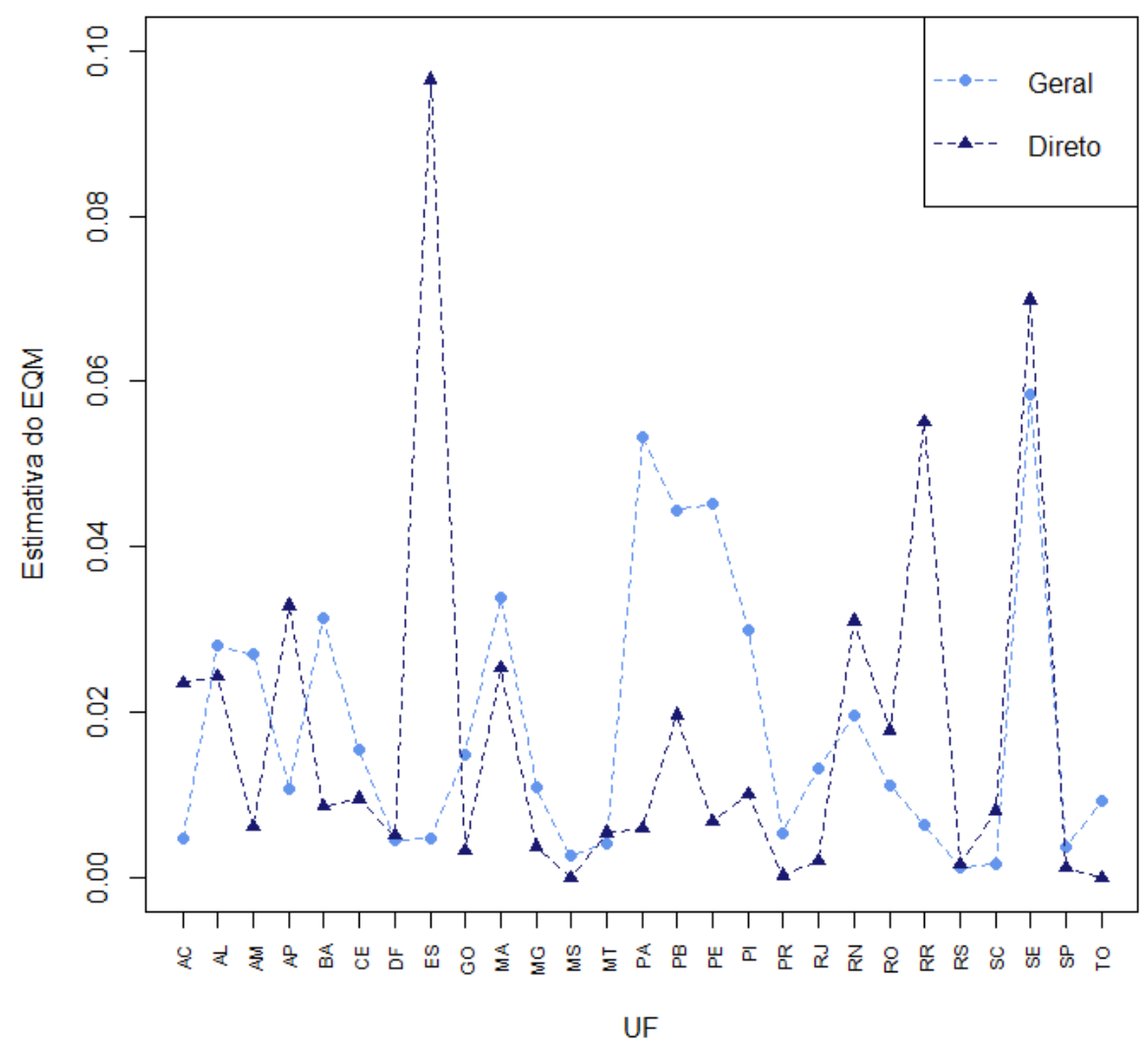

Figura 4.12: Estimativas do EQM sob as abordagens de estimador direto e modelo geral

O modelo por região apresenta um desempenho abaixo dos modelos por cluster e de efeitos aleatórios, como pode ser observado na Figura 4.13. Apesar do eixo vertical variar entre 0 e 0,05 , valores muito pequenos, as estimativas oriundas do modelo por região são maiores que as obtidas segundo as abordagens por cluster e de efeitos aleatórios, ou mistos, exceto para os estados Mara- 
nhão, Sergipe e Pernambuco que são quase coincidentes, pois a maior diferença entre as estimativas obtidas para essas UF, entre o modelo misto e por região, é de $1,6 \times 10^{-5}$. Assim, consideramos que com relação ao EQM, o modelo por região tem o terceiro pior desempenho.

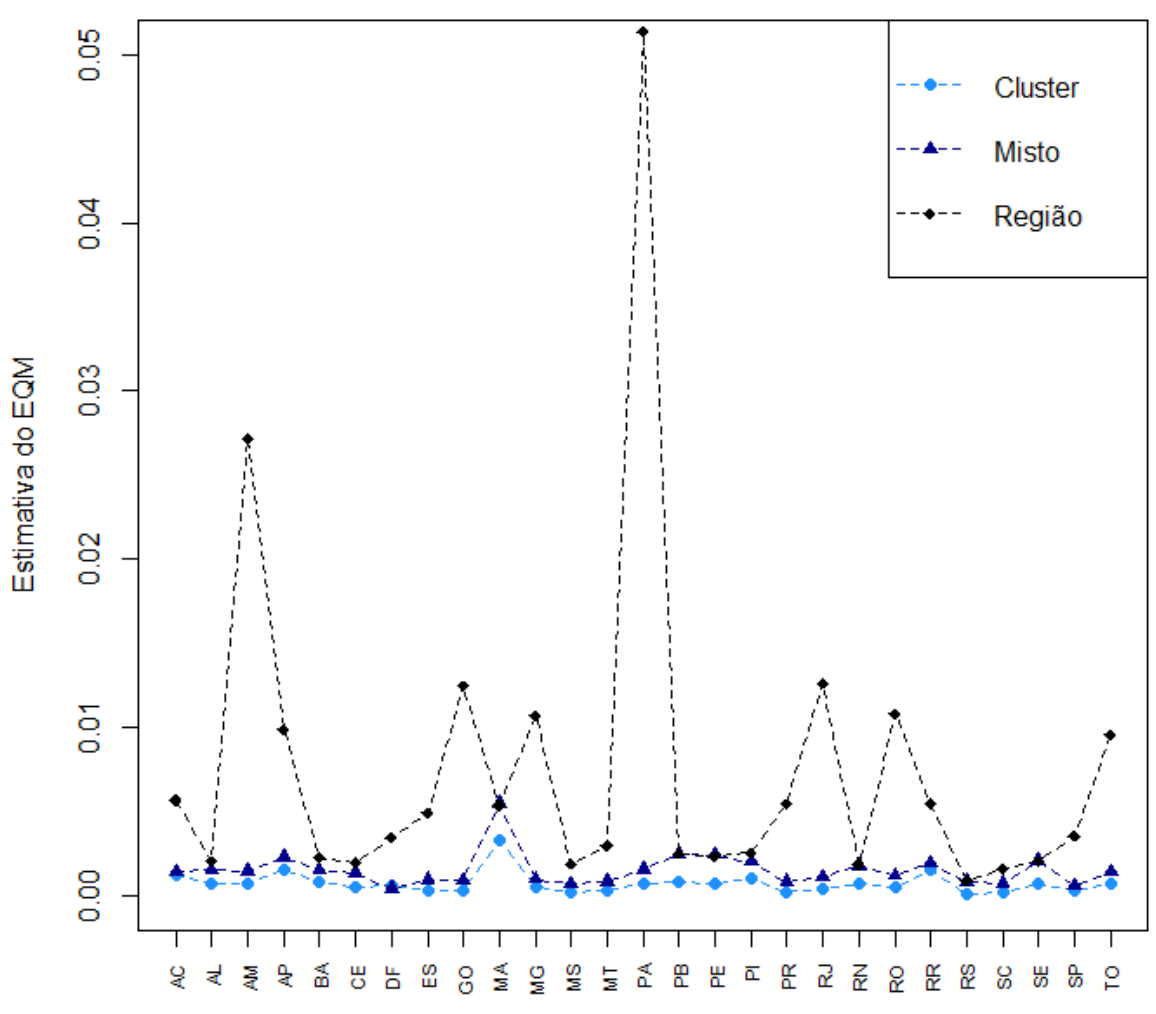

UF

Figura 4.13: Estimativas do EQM sob as abordagens de modelos misto, região e cluster

As duas últimas abordagens a serem comparadas com relação ao EQM são o modelo com efeitos aleatórios e o por cluster. Essas abordagens foram as estimativas baseadas em modelos que apresentaram as estimativas de EQM mais baixas, desse modo, optamos por dispor em um gráfico, Figura 4.14, para podermos compará-las com melhor precisão, pois na Figura 4.14, o eixo vertical varia entre 0 e 0,006, e o da Figura 4.12 tem seu valor máximo em 0,1, que acaba dificultando a comparação entre as duas abordagens. Podemos observar que a magnitude dessas estimativas são muito próximas entre si, mas, apesar de não ser trabalhado extensivamente na literatura de SAE, o modelo por cluster apresentou estimativas do EQM mais baixas que o modelo de efeitos aleatórios, que é o modelo mais utilizado nessa metodologia. Observamos também, que elas possuem o mesmo comportamento, que fica facilmente identificado pelas linhas tracejadas. No entanto, os dois modelos apresentam boas estimativas para o EQM, pois a diferença entre as estimativas para ambos os métodos são próximas a zero e bem menores quando comparadas com as estimativas do EQM obtidas pelas demais abordagens, o que também pode ser verificado na Figura 4.13.

Tomando como base a Figura 4.14, destacamos o Distrito Federal, em que a estimativa do EQM foi a única estimativa menor segundo o modelo misto frente ao modelo por cluster, porém, ainda assim, a diferença entre as estimativas é de $-2 \times 10^{-4}$. Destacamos também que o estado do 
Maranhão é o estado que apresenta a maior diferença entre as estimativas, seguido pelos estados da Paraíba e Pernambuco. Como já mencionado, as estimativas foram obtidas através do algoritmo bootstrap proposto por González-Manteiga et al. (2007) e detalhado na Seção 3.3, dessa forma, disponibilizamos no Apêndice A tabelas contendo as medidas descritivas para as populações obtidas em cada abordagem e que podem facilitar a compreensão dos resultados obtidos para o EQM (Tabelas A.16 a A.19).

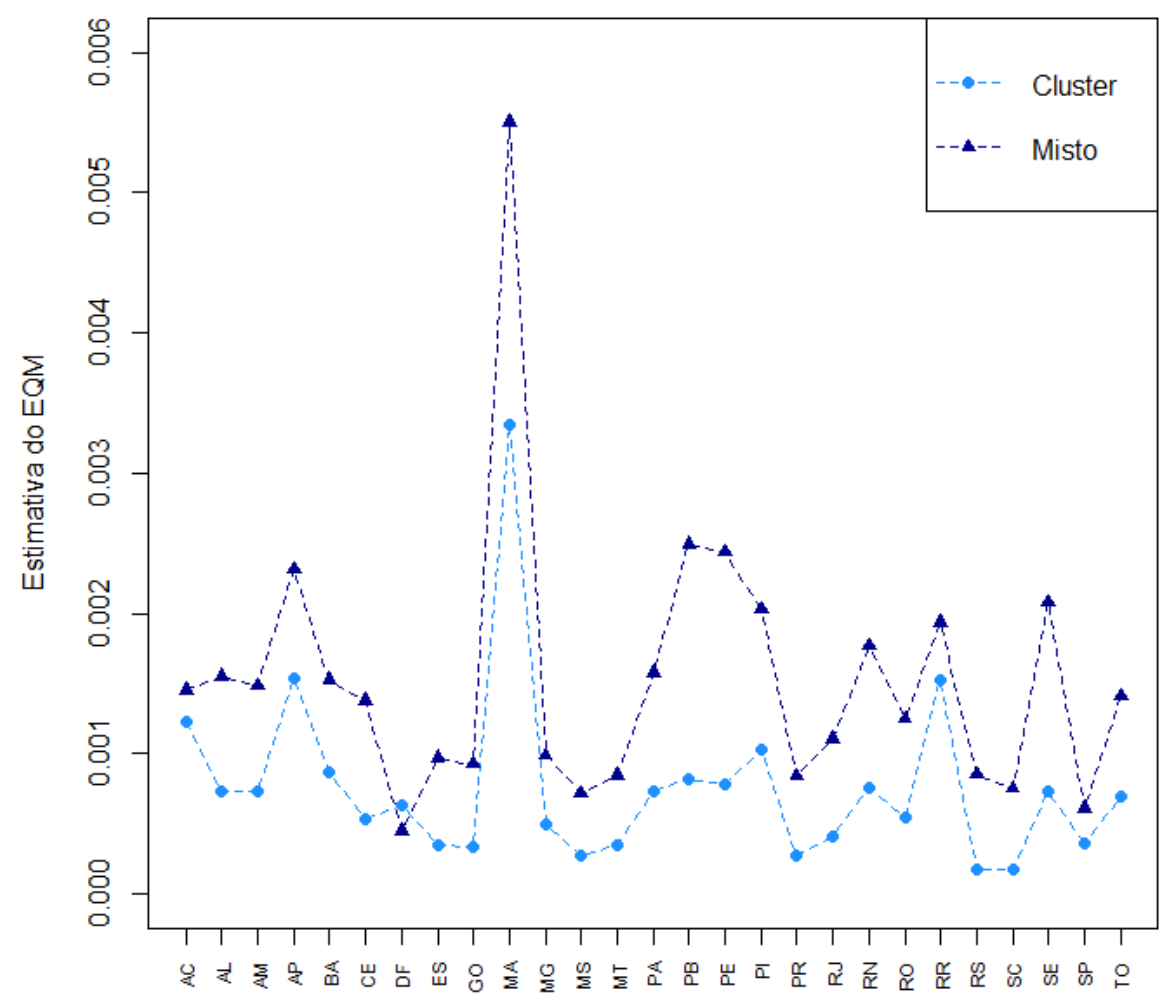

UF

Figura 4.14: Estimativas do EQM sob as abordagens de efeitos aleatórios e por cluster

Para eleger um modelo mais adequado para a utilização neste conjunto de dados, é preciso considerarmos todas as formas de avaliação dos modelos, isto é, a proporção de acertos do modelo, a AUC e a estimativa do EQM. Em suma, temos que o modelo com a maior proporção de acertos foi o modelo de efeitos aleatórios e do plano amostral, seguido pelo modelo que considerou apenas os efeitos mistos, que também foram os modelos com o melhor resultado para a AUC. Já o modelo com a menor proporção de acertos foi o modelo por cluster, que também possuiu a menor AUC. Ao analisarmos apenas o EQM, o modelo por cluster foi o que obteve o melhor desempenho, seguido pelo modelo de efeitos aleatórios. O estimador direto foi comparado apenas com as estimativas do EQM, porém não apresentou um bom desempenho. Dessa maneira, o modelo de efeitos aleatórios foi a abordagem que apresentou o comportamento mais homogêneo, assim, concluímos que foi a abordagem mais adequada para a obtenção de estimativas em pequenas áreas para o problema considerado. Lembrando, também, que o modelo de efeitos aleatórios capta uma variação extra que não é explicada pelos efeitos fixos. 
Como já mencionado ao longo deste trabalho, a metodologia de SAE baseada em modelos utiliza dados de outras fontes, que não a da pesquisa com a característica de interesse, para "emprestar" informações para áreas semelhantes a fim de melhorar a precisão das estimativas. Para nossos dados reais, a partir das observações provenientes do Censo Escolar, temos informações auxiliares para obter a estimativa da proporção de escolas em que os professores utilizam a Internet com os alunos para atividades de ensino-aprendizagem em domínios não garantidos pelo tamanho amostral da pesquisa TIC Educação. No entanto, se não tivéssemos nenhuma fonte externa de dados, só seria possível obter as estimativas diretamente da amostra.

Para o estimador direto podemos calcular a estimativa do coeficiente de variação, pois neste caso a estimativa é não viesada, já para as abordagens baseadas em modelo não podemos assumir que não contenham vício. Dessa forma, utilizamos uma aproximação como medida de precisão para as estimativas obtidas segundo o modelo de efeitos aleatórios, através da razão da raiz quadrada da estimativa do EQM sobre a estimativa da proporção para cada UF. Esses valores estão dispostos na Tabela 4.24.

Tabela 4.24: Razão da raiz quadrada do EQM sobre a estimativa da proporção, segundo o modelo de efeitos aleatórios

\begin{tabular}{cc|cc|cc}
\hline $\mathrm{UF}$ & $\frac{\sqrt{E Q M}}{\widehat{\overline{Y_{d}}}}(\%)$ & $\mathrm{UF}$ & $\frac{\sqrt{E Q M}}{\overline{Y_{d}}}(\%)$ & $\mathrm{UF}$ & $\frac{\sqrt{E Q M}}{\widehat{\overline{Y_{d}}}}(\%)$ \\
\hline $\mathrm{AC}$ & 5 & $\mathrm{MA}$ & 12 & $\mathrm{RJ}$ & 4 \\
$\mathrm{AL}$ & 5 & $\mathrm{MG}$ & 4 & $\mathrm{RN}$ & 6 \\
$\mathrm{AM}$ & 6 & $\mathrm{MS}$ & 3 & $\mathrm{RO}$ & 4 \\
$\mathrm{AP}$ & 6 & $\mathrm{MT}$ & 3 & $\mathrm{RR}$ & 6 \\
$\mathrm{BA}$ & 6 & $\mathrm{PA}$ & 6 & $\mathrm{RS}$ & 3 \\
$\mathrm{CE}$ & 5 & $\mathrm{~PB}$ & 7 & $\mathrm{SC}$ & 3 \\
$\mathrm{DF}$ & 2 & $\mathrm{PE}$ & 7 & $\mathrm{SE}$ & 6 \\
$\mathrm{ES}$ & 4 & $\mathrm{PI}$ & 6 & $\mathrm{SP}$ & 3 \\
$\mathrm{GO}$ & 4 & $\mathrm{PR}$ & 3 & $\mathrm{TO}$ & 4 \\
\hline
\end{tabular}

Através da Figura 4.15 podemos comparar o ganho de precisão das estimativas utilizando o modelo de efeitos aleatórios frente ao estimador direto, pois dispomos no eixo horizontal a razão da raiz quadrada da estimativa do EQM pela estimativa da proporção para cada UF segundo o modelo de efeitos aleatórios e no eixo vertical o coeficiente de variação do estimador direto. Todos os valores que estão acima da linha mostram que a estimativa da proporção é mais precisa utilizando o modelo do que apenas as informações do plano amostral. Os pontos que estão abaixo da linha são os estados de Tocantins, Mato Grosso do Sul e Paraná que, conforme já explicado na Seção 4.1, as estimativas diretas estão superestimadas, pois com auxílio da Tabela A.2 temos que para as duas primeiras UF todas as escolas (presentes na amostra da pesquisa TIC Educação) possuem ao menos um professor utilizando a Internet com os alunos para atividades de ensino-aprendizagem e para a última UF, apenas $1 \%$ das escolas da amostra não possuem professores utilizando a Internet com os alunos para atividades de ensino-aprendizagem.

Comparando o ganho de precisão das estimativas obtidas pelo modelo de efeitos aleatórios frente às estimativas calculadas diretamente da amostra, através das Tabelas 4.2 e 4.24, juntamente com a Figura 4.15, todas as estimativas para a proporção de escolas em que os professores utilizam a Internet com os alunos para atividades de ensino-aprendizagem passaram a ser classificadas como 


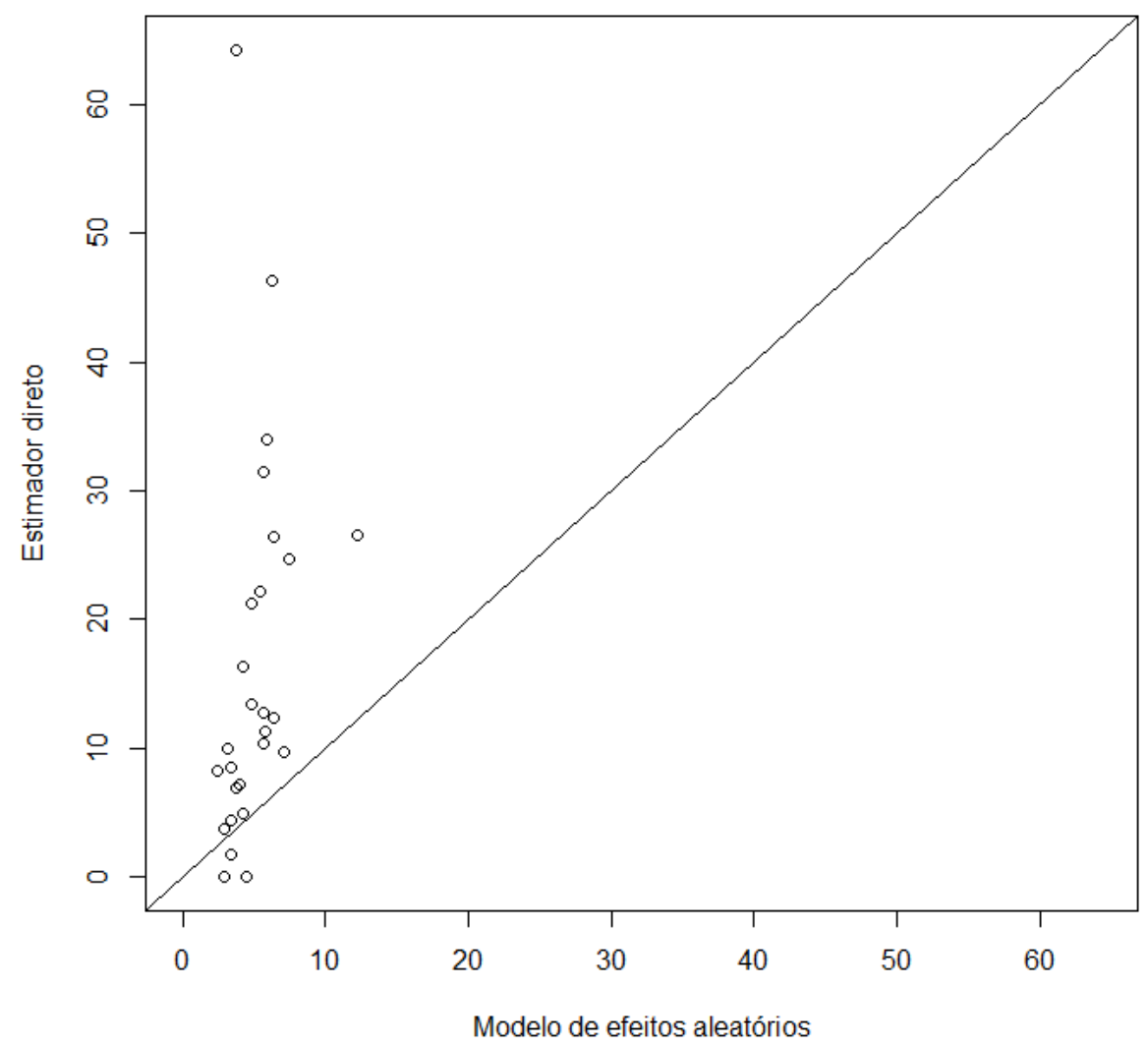

Figura 4.15: Razão da raiz quadrada da estimativa do EQM pela estimativa da proporção, segundo o estimador direto e o modelo de efeitos aleatórios (\%)

ótimas e boas (de acordo com a Tabela 4.1). Destacamos o estado do Espírito Santo, onde o coeficiente de variação da estimativa direta é de $64 \%$ e a razão que estamos utilizando como medida de precisão da estimativa do modelo é de $3 \%$, passando de uma estimativa classificada como imprecisa para uma classificada como ótima. Assumimos que mesmo com o possível vício das estimativas obtidas pelas abordagens baseadas em modelos, as proporções estimadas pelo modelo de efeitos aleatórios para nossa característica de interesse neste conjunto de dados reais se consolida como a melhor abordagem de SAE, e que dado o ganho de qualidade podem ser utilizadas para fins de divulgação para as UF. 


\section{Capítulo 5}

\section{Simulação}

Neste capítulo, os métodos apresentados no Capítulo 3 e utilizados no conjunto de dados reais, Capítulo 4, agora serão aplicados a dados gerados com parâmetros conhecidos. O intuito dessa simulação é analisar qual a melhor abordagem para conjuntos de dados com variáveis binárias visando o cálculo de estimativas para proporções. Para a obtenção da população simulada foram utilizadas três abordagens distintas: a primeira delas seguiu um modelo geral, isto é, sem nenhuma subdivisão; a segunda seguiu um modelo de efeitos aleatórios, ou seja, possui o intercepto aleatório; e a última considerou um modelo de intercepto e inclinação aleatórios.

\subsection{População obtida segundo modelo geral}

Para o estudo de simulação geramos a população como um todo, a fim de conhecer todas as características dessa população. Assumimos que estamos simulando a proporção de escolas em que os professores usam a Internet com os alunos para atividades de ensino-aprendizagem, a variável de interesse deste estudo. Assim, a população foi simulada considerando o modelo de regressão logística apresentado na Seção 3.2.2 com duas variáveis explicativas, $x_{1, d j}$ e $x_{2, d j}$, de tamanho $N=2500$, tal que cada uma das 5 pequenas áreas, $d=1, \cdots, 5$, é de tamanho $N_{d}=500$. As variáveis explicativas $x_{1, d j}$ e $x_{2, d j}$ foram simuladas de acordo com uma distribuição Uniforme em que os parâmetros das distribuições levam em consideração o índice da pequena área $d$ a fim de diferenciar as proporções entre as áreas. Assim, elas seguem a seguinte distribuição:

$$
x_{1, d j} \sim \operatorname{Unif}\left(0, \frac{d}{D}\right) ; \quad x_{2, d j} \sim \operatorname{Unif}\left(0,\left(\frac{d}{D}\right)^{2}\right) ; j=1, \cdots, N_{d}, d=1, \cdots, D .
$$

Para a obtenção do modelo segundo a abordagem do modelo por cluster é preciso realizar a análise de agrupamentos conforme descrita na Seção 4.4.1. Assim, a partir das variáveis explicativas obtidas, realizamos essa análise através do método das k-médias. Para o método das k-médias é preciso determinar a priori o número $k$ de grupos formados, neste caso, consideramos a formação de 3 agrupamentos homogêneos. Para a aplicação do método, utilizamos a variável $x_{1, d j}$ conforme foi gerada e a variável $x_{2, d j}$ padronizada, isto é, dividimos cada valor pelo valor máximo obtido.

Para gerar os dados simulados para a variável resposta $y_{d j}$ binária, com valores 0 ou 1 , primeiro encontramos a probabilidade de sucesso para cada elemento da população, $p_{d j}$, através do modelo de regressão logística e a consideramos na distribuição de Bernoulli, isto é, $y_{d j} \sim \operatorname{Bernoulli}\left(p_{d j}\right)$, 
tal que,

$$
p_{d j}=\frac{\exp \left\{\beta_{0}+\beta_{1} x_{1, d j}+\beta_{2} x_{2, d j}\right\}}{1+\exp \left\{\beta_{0}+\beta_{1} x_{1, d j}+\beta_{2} x_{2, d j}\right\}}, j=1, \cdots, N_{d}, d=1, \cdots, D
$$

Para este caso, foram escolhidos os seguintes valores para $\boldsymbol{\beta}^{\prime}=\left(\beta_{0}, \beta_{1}, \beta_{2}\right)=(0,5 ; 1,5 ; 0,5)$.

A amostra é obtida através da amostragem aleatória estratificada simples, tal que cada área $d$ foi considerada um estrato e dentro de cada área foi extraída uma amostra de tamanho $n_{d}=30$ sem reposição. Logo, o tamanho final da amostra $s$ é $n=\sum_{d=1}^{5} n_{d}=150$. Dessa forma, com base nessa amostra são ajustados os modelos para cada abordagem, também se obtém a estimativa direta da amostra e é realizada a predição para as unidades não amostradas da população. Assim, é possível calcular a estimativa da proporção para cada área $d, \widehat{\overline{Y_{d}}}$, conforme a Equação (3.10).

Cabe relembrar que para a abordagem segundo o modelo por área, são construídos cinco modelos, um para cada área, e a partir desses modelos é realizada a predição para os elementos não amostrados, pois, neste caso, supomos que para as unidades não amostradas as observações da variável resposta são desconhecidas e, assim, se faz necessária a predição dessas observações. Com todos os elementos conhecidos, isto é, preditos e observados, é possível calcular a estimativa da proporção para cada área $d$. Para a abordagem segundo o modelo por cluster a ideia é a mesma, a construção de um modelo para cada agrupamento, posteriormente é realizada a predição das observações não amostradas e, então, obtém-se a estimativa da proporção para cada área, uma vez que todas as unidades da população passam a ter uma resposta conhecida. O modelo com efeitos aleatórios considera o índice da área como efeito aleatório e segue a mesma etapa das abordagens anteriores. A abordagem do modelo geral considera todas as informações da amostra de uma só vez, sem nenhuma subdivisão, mas segue a mesma ideia que as demais abordagens.

A simulação pode ser sumarizada no seguinte algoritmo:

a. Repita $g=1, \cdots, G$ vezes:

1. Obtenha a população simulada, $P$ :

i. Defina o índice da pequena área $d, d=1, \cdots, D$;

ii. Gere $\boldsymbol{x}_{d j}^{\prime}=\left(1, x_{1, d j}, x_{2, d j}\right)$ com as variáveis explicativas, tal que:

$$
x_{1, d j} \sim \operatorname{Unif}\left(0, \frac{d}{D}\right) ; \quad x_{2, d j} \sim \operatorname{Unif}\left(0,\left(\frac{d}{D}\right)^{2}\right) ; j=1, \cdots, N_{d}, d=1, \cdots, D
$$

iii. Faça a análise de agrupamentos através do método de k-médias formando $k$ grupos. As variáveis utilizadas são $x_{1 d}$ e $\frac{x_{2 d}}{\max \left(x_{2 d}\right)}$;

iv. A partir dos valores fixados de $\beta$, determine

$$
p_{d j}=\frac{\exp \left\{\boldsymbol{x}_{d j}^{\prime} \boldsymbol{\beta}\right\}}{1+\exp \left\{\boldsymbol{x}_{d j}^{\prime} \boldsymbol{\beta}\right\}}, j=1, \cdots, N_{d}, d=1, \cdots, D
$$

v. Obtenha $y_{d j} \sim \operatorname{Bernoulli}\left(p_{d j}\right) j=1, \cdots, N_{d}, d=1, \cdots, D$;

vi. Calcule a média por área ${\overline{Y_{d}}}^{(g)}$;

2. Selecione a amostra $s$ por amostragem aleatória estratificada simples de tamanho $n_{d}$ sem reposição. 
3. Obtenha as estimativas da média para cada área $d=1, \cdots, D$ pelas diferentes abordagens:

i. Estimador direto: $\widehat{\bar{Y}}_{d}^{D I R^{(g)}}$;

ii. Modelo geral: ${\widehat{\overline{Y_{d}}}}^{G E R^{(g)}}$;

iii. Modelo por cluster: $\widehat{\bar{Y}}^{C L U^{(g)}}$;

iv. Modelo por área: ${\widehat{\overline{Y_{d}}}}^{A R^{(g)}}$;

v. Modelo com efeitos aleatórios: ${\widehat{\bar{Y}_{d}}}^{M I S^{(g)}}$.

b. Calcule para $d=1, \cdots, D$ :

$$
\begin{aligned}
& \overline{Y_{d}}=\frac{1}{G} \sum_{g=1}^{G}{\overline{Y_{d}}}^{(g)} ; \\
{\widehat{\bar{Y}_{d}}}^{D I R}=\frac{1}{G} \sum_{g=1}^{G}{\widehat{\bar{Y}_{d}}}^{D I R^{(g)}} ; & E Q M_{d}^{D I R}=\frac{1}{G} \sum_{g=1}^{G}\left({\widehat{\overline{Y_{d}}}}^{D I R^{(g)}}-{\overline{Y_{d}}}^{(g)}\right)^{2} ; \\
{\widehat{\overline{Y_{d}}}}^{G E R}=\frac{1}{G} \sum_{g=1}^{G}{\widehat{\overline{Y_{d}}}}^{G E R^{(g)}} ; & E Q M_{d}^{G E R}=\frac{1}{G} \sum_{g=1}^{G}\left({\widehat{\overline{Y_{d}}}}^{G E R^{(g)}}-{\overline{Y_{d}}}^{(g)}\right)^{2} ; \\
{\widehat{\overline{Y_{d}}}}^{C L U}=\frac{1}{G} \sum_{g=1}^{G}{\widehat{\widehat{Y_{d}}}}^{C L U^{(g)}} ; & E Q M_{d}^{C L U}=\frac{1}{G} \sum_{g=1}^{G}\left({\widehat{\overline{Y_{d}}}}^{C L U^{(g)}}-{\overline{\overline{Y_{d}}}}^{(g)}\right)^{2} ; \\
\widehat{\bar{Y}}_{d}^{A R}=\frac{1}{G} \sum_{g=1}^{G}{\widehat{\overline{Y_{d}}}}^{A R^{(g)}} ; & E Q M_{d}^{A R}=\frac{1}{G} \sum_{g=1}^{G}\left({\widehat{\overline{Y_{d}}}}^{A R^{(g)}}-{\overline{Y_{d}}}^{(g)}\right)^{2} ; \\
\widehat{\bar{Y}}^{M I S}=\frac{1}{G} \sum_{g=1}^{G}{\widehat{\overline{Y_{d}}}}^{M I S^{(g)}} ; & E Q M_{d}^{M I S}=\frac{1}{G} \sum_{g=1}^{G}\left({\widehat{\overline{Y_{d}}}}^{M I S^{(g)}}-{\overline{Y_{d}}}^{(g)}\right)^{2} .
\end{aligned}
$$

Para este trabalho utilizamos $G=10^{4}$ repetições. Dessa maneira, temos que a "verdadeira" proporção por área está disposta na Tabela 5.1, isto é, assumimos que para a pequena área 1, em 65,9\% das escolas os professores usam a Internet com os alunos para atividades de ensinoaprendizagem, para a área 2 esse valor é de $69,7 \%$, para a área 3 é de $73,6 \%$, a área 4 de $77,3 \%$ e a área 5 a proporção é de $80,8 \%$.

As estimativas das proporções quanto os erros quadráticos médios teóricos obtidos através das diferentes abordagens na simulação estão dispostos na Tabela 5.2. Podemos observar que as proporções obtidas segundo todas as abordagens são bem próximas ao verdadeiro valor, portanto, temos uma evidência que com um grande número de simulações as estimativas se aproximam desse verdadeiro valor da proporção para cada área na população. Com o intuito de analisar a precisão dessas estimativas, a fazemos através dos valores obtidos no EQM. Destarte, notamos que o modelo geral 
Tabela 5.1: Verdadeira proporção das pequenas áreas, por área, segundo a simulação pelo modelo geral

\begin{tabular}{c|c}
\hline Área & $\overline{Y_{d}}$ \\
\hline 1 & $65,9 \%$ \\
2 & $69,7 \%$ \\
3 & $73,6 \%$ \\
4 & $77,3 \%$ \\
5 & $80,8 \%$ \\
\hline
\end{tabular}

foi aquele que obteve melhor desempenho, no entanto, isso já era esperado visto que a população é gerada também pelo modelo geral. O modelo por área apresenta o pior desempenho, inclusive quando comparado com o estimador direto, com exceção das áreas 4 e 5 . O estimador direto, como esperado, apresenta um desempenho pior que o modelo por cluster, modelo geral e modelo com efeitos aleatórios. Entre o modelo de efeitos aleatórios e o modelo por cluster o que apresenta o melhor desempenho é o de efeitos aleatórios. Essas comparações também podem ser vistas pela Figura 5.1, em que temos os EQM das estimativas diretas e do modelo por área acima dos demais, e o modelo geral como o valor mais baixo, seguido pelo modelo misto.

Tabela 5.2: Estimativas da proporção e erro quadrático médio, por área, segundo cada abordagem a partir da população gerada através do modelo geral

\begin{tabular}{|c|c|c|c|c|c|c|}
\hline Área & ${\widehat{\bar{Y}_{d}}}^{D I R}$ & $E Q M_{d}^{D I R}$ & ${\widehat{\widehat{Y_{d}}}}^{M I S}$ & $E Q M_{d}^{M I S}$ & ${\widehat{\overline{Y_{d}}}}_{G E R}$ & $E Q M_{d}^{G E R}$ \\
\hline 1 & $65,9 \%$ & 0,0070 & $65,7 \%$ & 0,0037 & $65,7 \%$ & 0,0034 \\
\hline 2 & $69,7 \%$ & 0,0066 & $69,7 \%$ & 0,0025 & $69,7 \%$ & 0,0022 \\
\hline 3 & $73,5 \%$ & 0,0061 & $73,7 \%$ & 0,0019 & $73,8 \%$ & 0,0016 \\
\hline 4 & $77,3 \%$ & 0,0055 & $77,4 \%$ & 0,0019 & $77,5 \%$ & 0,0017 \\
\hline 5 & $80,8 \%$ & 0,0048 & $80,6 \%$ & 0,0024 & $80,6 \%$ & 0,0023 \\
\hline & Área & ${\widehat{\bar{Y}_{d}}}^{C L U}$ & $E Q M_{d}^{C L U}$ & ${\widehat{\overline{Y_{d}}}}^{A R}$ & \multicolumn{2}{|l|}{$E Q M_{d}^{A R}$} \\
\hline & 1 & $65,8 \%$ & 0,0047 & $65,7 \%$ & \multicolumn{2}{|l|}{0,0074} \\
\hline & 2 & $69,7 \%$ & 0,0026 & $69,6 \%$ & \multicolumn{2}{|l|}{0,0069} \\
\hline & 3 & $73,5 \%$ & 0,0026 & $73,2 \%$ & \multicolumn{2}{|l|}{0,0063} \\
\hline & 4 & $76,4 \%$ & 0,0024 & $76,9 \%$ & \multicolumn{2}{|l|}{0,0054} \\
\hline & 5 & $79,2 \%$ & 0,0027 & $79,9 \%$ & \multicolumn{2}{|l|}{0,0044} \\
\hline
\end{tabular}

\subsection{População obtida segundo modelo de intercepto aleatório}

Do mesmo modo que apresentado na seção anterior, no estudo de simulação determinamos os parâmetros a serem estudados, de tal forma que conhecemos todas as características da população. Dessa forma, podemos dizer que conhecemos o "verdadeiro valor" da proporção de escolas em que os professores usam a Internet com os alunos para atividades de ensino-aprendizagem, assim, podemos avaliar a preditividade dos estimadores pelas diferentes abordagens a fim de verificar qual delas possui um desempenho melhor, isto é, que mais se aproxima do "verdadeiro valor" conhecido.

A população simulada, neste caso, considerou o modelo de regressão logística com efeitos aleatórios, conforme Seção 3.2.1. As duas variáveis explicativas foram geradas da mesma maneira, ou 


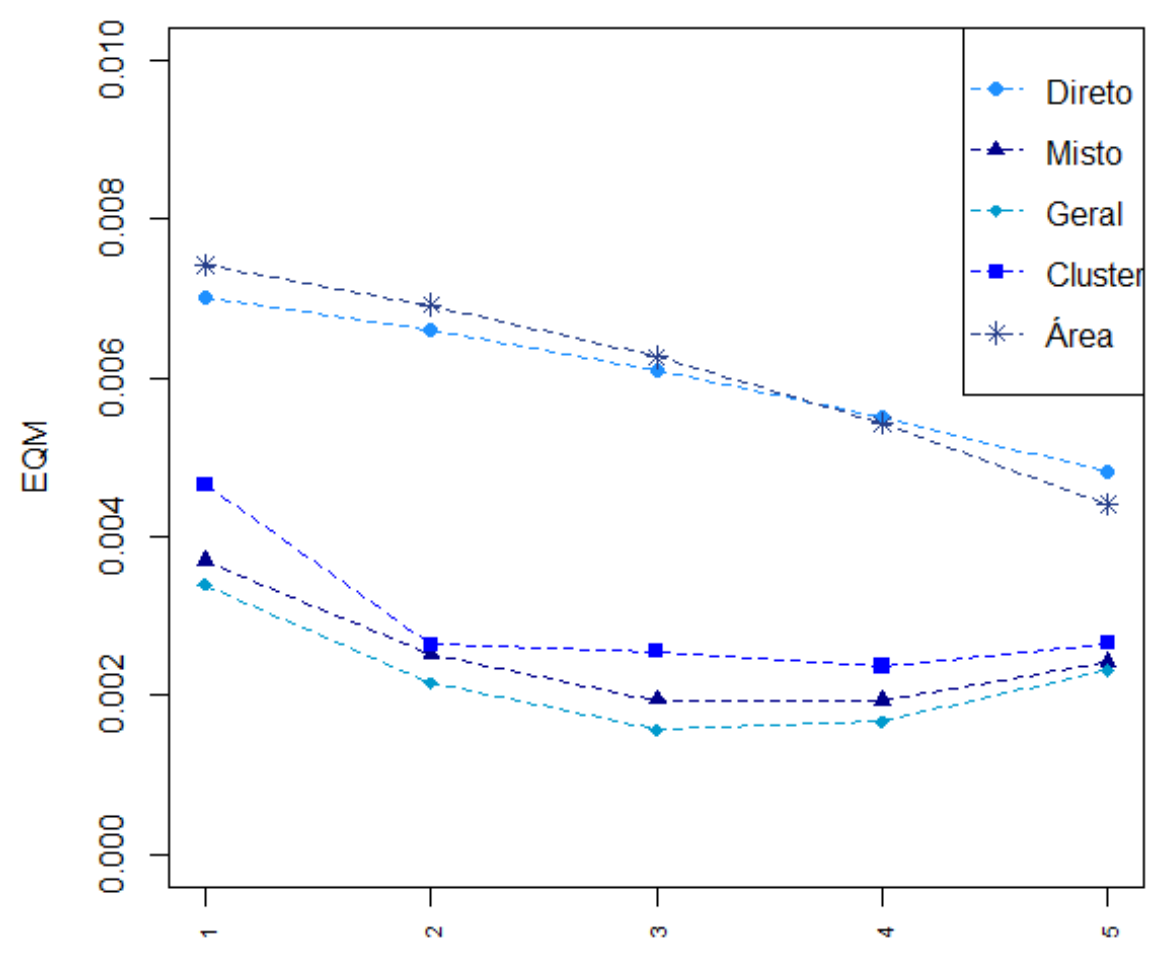

Área

Figura 5.1: EQM obtidos na simulação com a população determinada pelo modelo geral

seja, $x_{1, d j}$ e $x_{2, d j}$ seguem uma distribuição Uniforme que leva em consideração o índice da pequena área $d$ a fim de ter diferentes proporções entre as áreas. De outra maneira, temos que:

$$
x_{1, d j} \sim \operatorname{Unif}\left(0, \frac{d}{D}\right) ; \quad x_{2, d j} \sim \operatorname{Unif}\left(0,\left(\frac{d}{D}\right)^{2}\right) ; j=1, \cdots, N_{d}, d=1, \cdots, D .
$$

O tamanho da população e o número de pequenas áreas se manteve o mesmo, a saber: $N=2500$, onde cada pequena área $d=1, \cdots, 5$ é de tamanho $N_{d}=500$. Os valores de $\beta$ foram mantidos os mesmos, $\boldsymbol{\beta}^{\prime}=\left(\beta_{0}, \beta_{1}, \beta_{2}\right)=(0,5 ; 1,5 ; 0,5)$. No entanto, se faz necessário gerar os efeitos aleatórios que são normalmente distribuídos com média 0 e variância $\varphi=0,4$. Dessa forma, para a obtenção de escolas com a presença de professores que utilizam a Internet com os alunos para atividades de ensino-aprendizagem, $y_{d j}$, passamos a considerar a probabilidade de sucesso a ser considerada na distribuição de Bernoulli como:

$$
p_{d j}=\frac{\exp \left\{\beta_{0}+\beta_{1} x_{1, d j}+\beta_{2} x_{2, d j}+u_{d}\right\}}{1+\exp \left\{\beta_{0}+\beta_{1} x_{1, d j}+\beta_{2} x_{2, d j}+u_{d}\right\}}, j=1, \cdots, N_{d}, d=1, \cdots, D .
$$

Dessa população simulada é extraída uma amostra aleatória estratificada simples sem reposição de tamanho $n_{d}=30, d=1, \cdots, 5$, pois considera que cada pequena área $d$ é um estrato. Assim, fazemos a suposição que apenas os elementos amostrados têm respostas conhecidas, de tal modo que, ajustamos um modelo com essas observações e realizamos a predição para os elementos não 
amostrados. Uma vez que toda a população passa a ter uma resposta conhecida, é possível obter a proporção de escolas em que os professores usam a Internet com os alunos para atividades de ensino-aprendizagem, $\widehat{\overline{Y_{d}}}$, conforme a Equação (3.7).

As abordagens segundo o modelo geral, o modelo de efeitos aleatórios e o estimador direto seguem a mesma estrutura que já foi apresentada nos capítulos anteriores: o modelo geral considera todas as informações sem qualquer subdivisão, o modelo de efeitos aleatórios utiliza o índice da área como efeito aleatório e o estimador direto só utiliza as informações da amostra para fazer inferência sobre o total populacional. Assim como também já utilizado, na abordagem segundo o modelo por área, são construídos cinco modelos, um para cada área, e a partir desses modelos é realizada a predição para os elementos não amostrados e do mesmo modo na abordagem por cluster, tal que é construído um modelo para cada um dos $k$ agrupamentos. Neste caso, os agrupamentos foram realizados através do método das k-médias, com $k=3$ grupos homogêneos formados. As variáveis utilizadas para a análise de agrupamentos foram $x_{1, d j}$ e a variável $x_{2, d j}$ padronizada, isto é, dividimos cada valor pelo valor máximo obtido.

O passo-a-passo da simulação para a população obtida segundo modelo de intercepto aleatório pode ser definido pelo seguinte algoritmo:

a. Repita $g=1, \cdots, G$ vezes:

1. Obtenha a população simulada, $P$ :

i. Defina o índice da pequena área $d, d=1, \cdots, D$;

ii. Gere $\boldsymbol{x}_{d j}^{\prime}=\left(1, x_{1, d j}, x_{2, d j}\right)$ com as variáveis explicativas, tal que:

$$
x_{1, d j} \sim \operatorname{Unif}\left(0, \frac{d}{D}\right) ; \quad x_{2, d j} \sim \operatorname{Unif}\left(0,\left(\frac{d}{D}\right)^{2}\right) ; j=1, \cdots, N_{d}, d=1, \cdots, D
$$

iii. Faça a análise de agrupamentos através do método de k-médias formando $k$ grupos. As variáveis utilizadas são $x_{1 d}$ e $\frac{x_{2 d}}{\max \left(x_{2 d}\right)}$;

iv. Gere o vetor $\mathbf{T}_{\mathbf{1}}$ de tamanho $D$, com variáveis independentes tal que $E\left[T_{1}\right]=0 \mathrm{e}$ $\operatorname{Var}\left[T_{1}\right]=1$

v. Construa o vetor $u=\left(u_{1}, \cdots, u_{D}\right)=\varphi \mathbf{T}_{\mathbf{1}}$;

vi. A partir dos valores fixados de $\beta$, determine

$$
p_{d j}=\frac{\exp \left\{\boldsymbol{x}_{d j}^{\prime} \boldsymbol{\beta}+u_{d}\right\}}{1+\exp \left\{\boldsymbol{x}_{d j}^{\prime} \boldsymbol{\beta}+u_{d}\right\}}, j=1, \cdots, N_{d}, d=1, \cdots, D
$$

vii. Obtenha $y_{d j} \sim \operatorname{Bernoulli}\left(p_{d j}\right) j=1, \cdots, N_{d}, d=1, \cdots, D$;

viii. Calcule a média por área ${\overline{Y_{d}}}^{(g)}$;

2. Selecione a amostra $s$ por amostragem aleatória estratificada simples de tamanho $n_{d}$ sem reposição.

3. Obtenha as estimativas da média para cada área $d=1, \cdots, D$ pelas diferentes abordagens:

i. Estimador direto: ${\widehat{\overline{Y_{d}}}}^{D I R^{(g)}}$;

ii. Modelo geral: $\widehat{\bar{Y}}^{G E R^{(g)}}$; 
iii. Modelo por cluster: ${\widehat{\bar{Y}_{d}}}^{C L U^{(g)}}$;

iv. Modelo por área: $\widehat{\widehat{Y}}^{A R^{(g)}}$;

v. Modelo com efeitos aleatórios: $\widehat{\bar{Y}}_{d}^{M I S^{(g)}}$.

b. Calcule para $d=1, \cdots, D$ :

$$
\begin{aligned}
& \overline{Y_{d}}=\frac{1}{G} \sum_{g=1}^{G}{\overline{Y_{d}}}^{(g)} \\
& {\widehat{\bar{Y}_{d}}}^{D I R}=\frac{1}{G} \sum_{g=1}^{G}{\widehat{\bar{Y}_{d}}}^{D I R^{(g)}} ; \quad E Q M_{d}^{D I R}=\frac{1}{G} \sum_{g=1}^{G}\left({\widehat{\bar{Y}_{d}}}^{D I R^{(g)}}-{\overline{Y_{d}}}^{(g)}\right)^{2} ; \\
& {\widehat{\overline{Y_{d}}}}^{G E R}=\frac{1}{G} \sum_{g=1}^{G}{\widehat{\bar{Y}_{d}}}^{G E R^{(g)}} ; \quad E Q M_{d}^{G E R}=\frac{1}{G} \sum_{g=1}^{G}\left({\widehat{\bar{Y}_{d}}}^{G E R^{(g)}}-{\overline{Y_{d}}}^{(g)}\right)^{2} ; \\
& {\widehat{\bar{Y}_{d}}}^{C L U}=\frac{1}{G} \sum_{g=1}^{G}{\widehat{\bar{Y}_{d}}}^{C L U^{(g)}} ; \quad E Q M_{d}^{C L U}=\frac{1}{G} \sum_{g=1}^{G}\left({\widehat{\bar{Y}_{d}}}^{C L U^{(g)}}-{\overline{Y_{d}}}^{(g)}\right)^{2} ; \\
& {\widehat{\bar{Y}_{d}}}^{A R}=\frac{1}{G} \sum_{g=1}^{G}{\widehat{\bar{Y}_{d}}}^{A R^{(g)}} ; \quad E Q M_{d}^{A R}=\frac{1}{G} \sum_{g=1}^{G}\left({\widehat{\bar{Y}_{d}}}^{A R^{(g)}}-{\overline{Y_{d}}}^{(g)}\right)^{2} ; \\
& {\widehat{\bar{Y}_{d}}}^{M I S}=\frac{1}{G} \sum_{g=1}^{G}{\widehat{\bar{Y}_{d}}}^{M I S^{(g)}} ; \quad E Q M_{d}^{M I S}=\frac{1}{G} \sum_{g=1}^{G}\left({\widehat{\bar{Y}_{d}}}^{M I S^{(g)}}-{\overline{Y_{d}}}^{(g)}\right)^{2} .
\end{aligned}
$$

Também foram utilizadas $G=10^{4}$ repetições para esta simulação e os resultados obtidos ao final estão dispostos nas Tabelas 5.3 e 5.4. Na Tabela 5.3 temos os valores considerados como a verdadeira proporção de escolas em que os professores usam a Internet com os alunos para atividades de ensino-

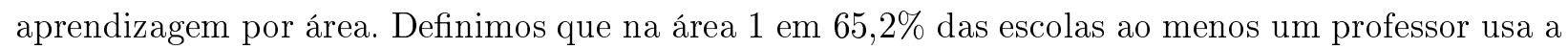
Internet nas atividades de ensino-aprendizagem com os alunos. Essa proporção é de $69,1 \%$ na área 2, $72,7 \%$ na área $3,76,6 \%$ na área 4 e de $80,1 \%$ na área 5.

Para avaliar o quanto os modelos produziram estimativas precisas, na Tabela 5.4 são apresentadas as estimativas das proporções para cada área obtida por cada uma das abordagens enunciadas no Capítulo 3 e os respectivos EQM. Notamos que independentemente da área analisada, as estimativas das proporções são muito próximas ao valor de referência, $\overline{Y_{d}}$, para todas as abordagens. Dessa forma, analisando o EQM verificamos a precisão dessas estimativas. Com auxílio da Figura 5.2 notamos que o modelo misto foi o que apresentou os menores valores dos EQM, porém, tal como o modelo geral na Seção 5.1, a forma de obtenção desse modelo é a mesma utilizada para a construção da população simulada, o que pode favorecer a qualidade desse ajuste. Assim, observamos 
Tabela 5.3: Verdadeira proporção das pequenas áreas, por área, segundo a simulação pelo modelo de efeitos aleatórios

\begin{tabular}{c|c}
\hline Área & $\overline{Y_{d}}$ \\
\hline 1 & $65,2 \%$ \\
2 & $69,1 \%$ \\
3 & $72,7 \%$ \\
4 & $76,6 \%$ \\
5 & $80,1 \%$ \\
\hline
\end{tabular}

que os modelos por cluster e geral apresentam os EQM bem próximos, o primeiro apresenta valores menores para as áreas 1, 2 e 3, enquanto o segundo é melhor para as áreas 4 e 5. Os EQM para o estimador direto e o modelo por área são as mais elevados, sendo que o estimador direto é inferior ao modelo por área apenas na área de índice 5.

Tabela 5.4: Estimativas da proporção e erro quadrático médio, por área, segundo cada abordagem a partir da população gerada através do modelo de efeitos aleatórios

\begin{tabular}{|c|c|c|c|c|c|c|}
\hline Área & ${\widehat{\bar{Y}_{d}}}^{D I R}$ & $E Q M_{d}^{D I R}$ & ${\widehat{\bar{Y}_{d}}}^{M I S}$ & $E Q M_{d}^{M I S}$ & ${\widehat{\widehat{Y_{d}}}}^{G E R}$ & $E Q M_{d}^{G E R}$ \\
\hline 1 & $65,2 \%$ & 0,0070 & $65,1 \%$ & 0,0054 & $64,9 \%$ & 0,0064 \\
\hline 2 & $69,1 \%$ & 0,0066 & $69,0 \%$ & 0,0049 & $69,0 \%$ & 0,0063 \\
\hline 3 & $72,7 \%$ & 0,0061 & $72,9 \%$ & 0,0044 & $73,1 \%$ & 0,0056 \\
\hline 4 & $76,6 \%$ & 0,0054 & $76,7 \%$ & 0,0039 & $76,8 \%$ & 0,0046 \\
\hline 5 & $80,1 \%$ & 0,0049 & $80,0 \%$ & 0,0035 & $79,9 \%$ & 0,0038 \\
\hline & Área & ${\widehat{\widehat{Y_{d}}}}^{C L U}$ & $E Q M_{d}^{C L U}$ & ${\widehat{Y_{d}}}^{A R}$ & $E Q M_{d}^{A R}$ & \\
\hline & 1 & $65,1 \%$ & 0,0062 & $64,9 \%$ & 0,0074 & \\
\hline & 2 & $68,8 \%$ & 0,0061 & $68,7 \%$ & 0,0068 & \\
\hline & 3 & $72,4 \%$ & 0,0054 & $72,0 \%$ & 0,0062 & \\
\hline & 4 & $75,2 \%$ & 0,0047 & $75,5 \%$ & 0,0055 & \\
\hline & 5 & $78,0 \%$ & 0,0040 & $78,3 \%$ & 0,0048 & \\
\hline
\end{tabular}

\subsection{População obtida segundo modelo de intercepto e inclinação aleatórios}

Nesta seção, para a obtenção da população simulada seguimos o que já foi desenvolvido nas seções anteriores. Mantemos o efeito aleatório já mencionado no intercepto e passamos a incluir efeitos aleatórios na inclinação, ou seja, adicionamos um efeito aleatório para cada variável explicativa. Como trata-se de um estudo de simulação dos dados, fixamos os parâmetros e, consequentemente, conhecemos todas as características da população. Logo, também temos o "verdadeiro valor" da proporção de escolas em que os professores usam a Internet com os alunos para atividades de ensino-aprendizagem e, assim, podemos avaliar a preditividade dos estimadores pelas diferentes abordagens a fim de verificar qual delas possui um desempenho melhor. Cabe dizer que a inclusão de efeitos aleatórios na inclinação não é modelada em nenhuma das abordagens, pois comparamos as predições através dos modelos geral, por área, por cluster e de efeitos aleatórios (somente no 


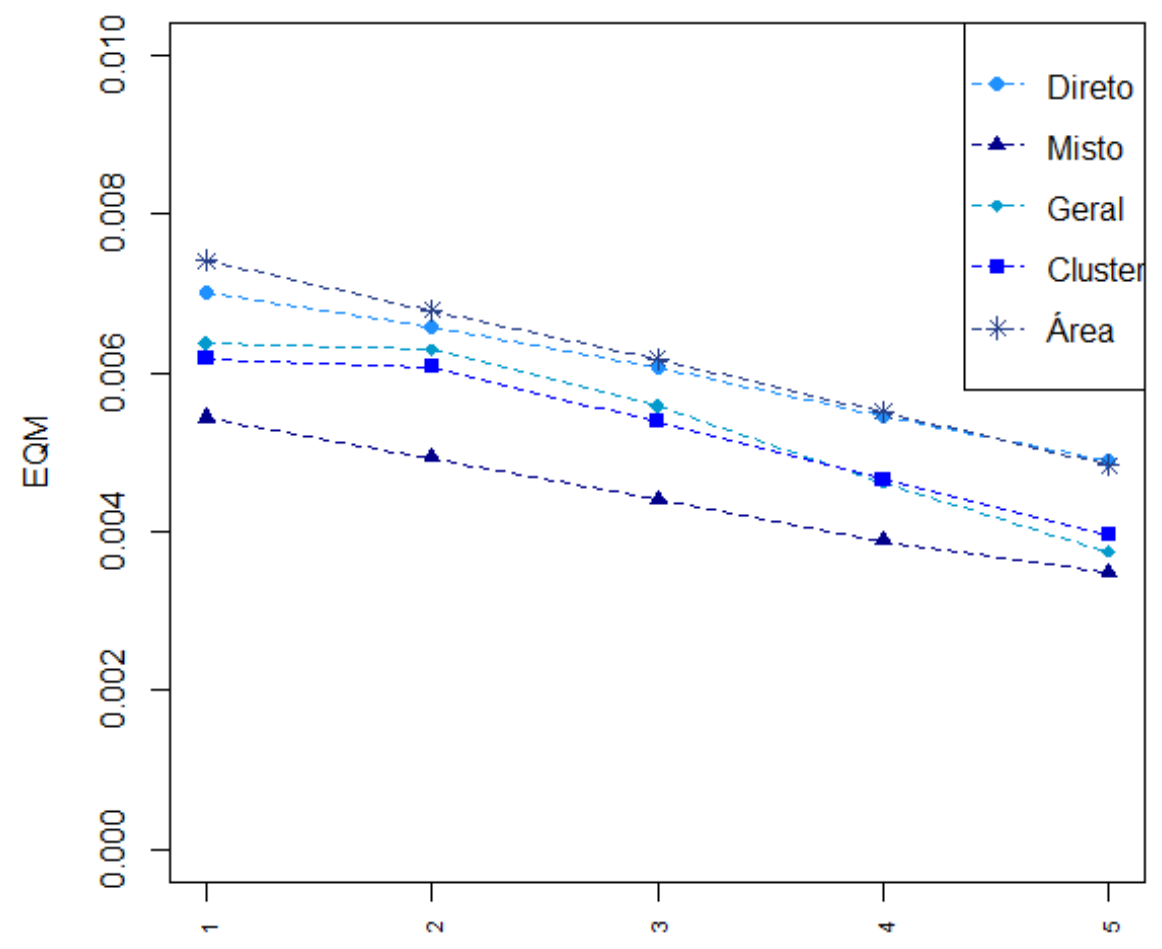

Área

Figura 5.2: EQM obtidos na simulação com a população determinada pelo modelo de efeitos aleatórios

intercepto).

Consideramos, novamente, duas variáveis explicativas, $x_{1, d j}$ e $x_{2, d j}$ em que

$$
x_{1, d j} \sim \operatorname{Unif}\left(0, \frac{d}{D}\right) ; \quad x_{2, d j} \sim \operatorname{Unif}\left(0,\left(\frac{d}{D}\right)^{2}\right) ; j=1, \cdots, N_{d}, d=1, \cdots, D .
$$

O tamanho da população e o número de pequenas áreas se manteve o mesmo: $N=2500$ e $N_{d}=$ $500, d=1, \cdots, 5$. Os valores de $\beta$ também permaneceram iguais: $\boldsymbol{\beta}^{\prime}=\left(\beta_{0}, \beta_{1}, \beta_{2}\right)=(0,5 ; 1,5 ; 0,5)$. Além de incluir os efeitos aleatórios (no intercepto) para cada pequena área, $u_{d}$, como na seção anterior, com média 0 e variância $\varphi=0,4$, incluímos efeitos aleatórios nas inclinações, ou seja, em $x_{1, d j}$ e $x_{2, d j}$. Desse modo, os efeitos das variáveis explicativas serão as somas dos efeitos fixos (respectivamente $\beta_{1}$ e $\beta_{2}$ ) e dos efeitos aleatórios para cada área, que podem ser vistos como ruídos (que não serão modelados). Denotamos por $\alpha_{1 d}$ e $\alpha_{2 d}$ tais efeitos para, respectivamente, $x_{1, d j} \mathrm{e}$ $x_{2, d j}, d=1, \cdots, 5$ e geramos, para cada área, de uma distribuição Uniforme $(0,1)$. Portanto, para a obtenção de escolas com a presença de professores que utilizam a Internet com os alunos para atividades de ensino-aprendizagem, $y_{d j}$, passamos a considerar a probabilidade de sucesso a ser considerada na distribuição de Bernoulli como:

$$
p_{d j}=\frac{\exp \left\{\beta_{0}+\left(\beta_{1}+\alpha_{1 d}\right) x_{1, d j}+\left(\beta_{2}+\alpha_{2 d}\right) x_{2, d j}+u_{d}\right\}}{1+\exp \left\{\beta_{0}+\left(\beta_{1}+\alpha_{1 d}\right) x_{1, d j}+\left(\beta_{2}+\alpha_{2 d}\right) x_{2, d j}+u_{d}\right\}}, \quad j=1, \cdots, N_{d}, d=1, \cdots, D .
$$


Seguindo a mesma ideia das seções anteriores, a partir de tal população simulada é extraída uma amostra aleatória estratificada simples sem reposição de tamanho $n_{d}=30, d=1, \cdots, 5$, por considerar cada pequena área $d$ como um estrato. Assim, fazemos a suposição que apenas os elementos amostrados têm respostas conhecidas, de tal modo que, ajustamos um modelo com essas observações e realizamos a predição para os elementos não amostrados. Tendo, com auxílio do modelo, conhecida as respostas das unidades da população inteira, é possível obter a proporção de escolas em que os professores usam a Internet com os alunos para atividades de ensino-aprendizagem, $\widehat{\overline{Y_{d}}}$, conforme a Equação (3.7).

As abordagens segundo o modelo geral, o modelo de efeitos aleatórios, modelo por área, modelo por cluster e o estimador direto seguem a mesma estrutura que já foi apresentada nos capítulos anteriores. Cabe ressaltar novamente que as variáveis explicativas utilizadas para a análise de agrupamentos para o modelo por cluster foram $x_{1, d j}$ e $x_{2, d j}$ padronizada, isto é, dividimos cada valor pelo valor máximo obtido.

O algoritmo de simulação para este caso é dado abaixo:

a. Repita $g=1, \cdots, G$ vezes:

1. Obtenha a população simulada, $P$ :

i. Defina o índice da pequena área $d, d=1, \cdots, D$;

ii. Gere $\boldsymbol{x}_{d j}^{\prime}=\left(1, x_{1, d j}, x_{2, d j}\right)$ com as variáveis explicativas, tal que:

$$
x_{1, d j} \sim \operatorname{Unif}\left(0, \frac{d}{D}\right) ; \quad x_{2, d j} \sim \operatorname{Unif}\left(0,\left(\frac{d}{D}\right)^{2}\right) ; j=1, \cdots, N_{d}, d=1, \cdots, D
$$

iii. Faça a análise de agrupamentos através do método de k-médias formando $k$ grupos. As variáveis utilizadas são $x_{1 d}$ e $\frac{x_{2 d}}{\max \left(x_{2 d}\right)}$;

iv. Gere o vetor $\mathbf{T}_{\mathbf{1}}$ de tamanho $D$, com variáveis independentes tal que $E\left[T_{1}\right]=0 \mathrm{e}$ $\operatorname{Var}\left[T_{1}\right]=1$

v. Construa o vetor $u=\left(u_{1}, \cdots, u_{D}\right)=\varphi \mathbf{T}_{\mathbf{1}}$;

vi. Gere os efeitos aleatórios das inclinações para cada pequena área $\alpha_{1 d} \sim \operatorname{Unif}(0,1)$ e $\alpha_{2 d} \sim \operatorname{Unif}(0,1), d=1, \cdots, D$

vii. A partir dos valores fixados de $\beta$, determine

$$
p_{d j}=\frac{\exp \left\{\beta_{0}+\left(\beta_{1}+\alpha_{1 d}\right) x_{1, d j}+\left(\beta_{2}+\alpha_{2 d}\right) x_{2, d j}+u_{d}\right\}}{1+\exp \left\{\beta_{0}+\left(\beta_{1}+\alpha_{1 d}\right) x_{1, d j}+\left(\beta_{2}+\alpha_{2 d}\right) x_{2, d j}+u_{d}\right\}}, j=1, \cdots, N_{d}, d=1, \cdots, D .
$$

viii. Obtenha $y_{d j} \sim \operatorname{Bernoulli}\left(p_{d j}\right) j=1, \cdots, N_{d}, d=1, \cdots, D$;

ix. Calcule a média por área ${\overline{Y_{d}}}^{(g)}$;

2. Selecione a amostra $s$ por amostragem aleatória estratificada simples de tamanho $n_{d}$ sem reposição.

3. Obtenha as estimativas da média para cada área $d=1, \cdots, D$ pelas diferentes abordagens:

i. Estimador direto: ${\widehat{\overline{Y_{d}}}}^{D I R^{(g)}}$;

ii. Modelo geral: $\widehat{\bar{Y}}^{G E R^{(g)}}$;

iii. Modelo por cluster: ${\widehat{\widehat{Y_{d}}}}^{C L U^{(g)}}$; 
iv. Modelo por área: ${\widehat{\overline{Y_{d}}}}^{A R^{(g)}}$;

v. Modelo com efeitos aleatórios: $\widehat{\bar{Y}}^{M I S^{(g)}}$.

b. Calcule para $d=1, \cdots, D$ :

$$
\begin{aligned}
& \overline{Y_{d}}=\frac{1}{G} \sum_{g=1}^{G}{\overline{Y_{d}}}^{(g)} \\
& {\widehat{\bar{Y}_{d}}}^{D I R}=\frac{1}{G} \sum_{g=1}^{G}{\widehat{\bar{Y}_{d}}}^{D I R^{(g)}} ; \quad E Q M_{d}^{D I R}=\frac{1}{G} \sum_{g=1}^{G}\left({\widehat{\bar{Y}_{d}}}^{D I R^{(g)}}-{\overline{Y_{d}}}^{(g)}\right)^{2} ; \\
& {\widehat{\overline{Y_{d}}}}^{G E R}=\frac{1}{G} \sum_{g=1}^{G}{\widehat{\bar{Y}_{d}}}^{G E R^{(g)}} ; \quad E Q M_{d}^{G E R}=\frac{1}{G} \sum_{g=1}^{G}\left({\widehat{\bar{Y}_{d}}}^{G E R^{(g)}}-{\overline{Y_{d}}}^{(g)}\right)^{2} ; \\
& {\widehat{\bar{Y}_{d}}}^{C L U}=\frac{1}{G} \sum_{g=1}^{G}{\widehat{\bar{Y}_{d}}}^{C L U^{(g)}} ; \quad E Q M_{d}^{C L U}=\frac{1}{G} \sum_{g=1}^{G}\left({\widehat{\bar{Y}_{d}}}^{C L U^{(g)}}-{\overline{Y_{d}}}^{(g)}\right)^{2} ; \\
& {\widehat{\bar{Y}_{d}}}^{A R}=\frac{1}{G} \sum_{g=1}^{G}{\widehat{\bar{Y}_{d}}}^{A R^{(g)}} ; \quad E Q M_{d}^{A R}=\frac{1}{G} \sum_{g=1}^{G}\left({\widehat{\bar{Y}_{d}}}^{A R^{(g)}}-{\overline{Y_{d}}}^{(g)}\right)^{2} ; \\
& {\widehat{\bar{Y}_{d}}}^{M I S}=\frac{1}{G} \sum_{g=1}^{G}{\widehat{\bar{Y}_{d}}}^{M I S^{(g)}} ; \quad E Q M_{d}^{M I S}=\frac{1}{G} \sum_{g=1}^{G}\left({\widehat{\bar{Y}_{d}}}^{M I S^{(g)}}-{\overline{Y_{d}}}^{(g)}\right)^{2} .
\end{aligned}
$$

Como anteriormente, fixamos $G=10^{4}$ repetições. Assim, temos os resultados ao final das simulações dispostos nas Tabelas 5.5 e 5.6. Tal como já mencionado, como trata-se de um estudo de simulação dos dados, temos a "verdadeira" proporção de escolas em que os professores usam a Internet com os alunos para atividades de ensino-aprendizagem e para este estudo esses valores estão na Tabela 5.5. Logo, notamos que a "verdadeira" proporção para a área 1 é de 66,5\%, para a área 2 é de $71,8 \%$, para a área 3 é de $76,9 \%$, para a área 4 é de $81,5 \%$ e para a área 5 é de $85,6 \%$.

Tabela 5.5: Verdadeira proporção das pequenas áreas, por área, segundo a simulação pelo modelo de intercepto e inclinação aleatórios

\begin{tabular}{c|c}
\hline Área & $\overline{Y_{d}}$ \\
\hline 1 & $66,5 \%$ \\
2 & $71,8 \%$ \\
3 & $76,9 \%$ \\
4 & $81,5 \%$ \\
5 & $85,6 \%$ \\
\hline
\end{tabular}

A Tabela 5.6 traz as estimativas das proporções obtidas ao final das $G=10^{4}$ repetições para 
todas as abordagens para cada área $d$, e os respectivos EQM. Notamos que o estimador direto e o modelo por área apresentam os piores desempenhos, pois possuem os maiores EQM, o que também pode ser verificado na Figura 5.3. Os modelos geral e por cluster apresentaram um comportamento semelhante, enquanto o modelo de efeito aleatórios, ressaltando que considera o efeito apenas no intercepto, teve o melhor desempenho, uma vez que os resultados do EQM ficaram menores.

Tabela 5.6: Estimativas da proporção e erro quadrático médio, por área, segundo cada abordagem a partir da população gerada através do modelo de intercepto e inclinação aleatórios

\begin{tabular}{|c|c|c|c|c|c|c|}
\hline Área & ${\widehat{\bar{Y}_{d}}}^{D I R}$ & $E Q M_{d}^{D I R}$ & ${\widehat{\bar{Y}_{d}}}^{M I S}$ & $E Q M_{d}^{M I S}$ & ${\widehat{\widehat{Y_{d}}}}^{G E R}$ & $E Q M_{d}^{G E R}$ \\
\hline 1 & $66,5 \%$ & 0,0067 & $66,4 \%$ & 0,0053 & $66,2 \%$ & 0,0061 \\
\hline 2 & $71,9 \%$ & 0,0061 & $71,8 \%$ & 0,0046 & $71,8 \%$ & 0,0059 \\
\hline 3 & $76,9 \%$ & 0,0053 & $77,0 \%$ & 0,0038 & $77,2 \%$ & 0,0047 \\
\hline 4 & $81,6 \%$ & 0,0046 & $81,7 \%$ & 0,0031 & $81,8 \%$ & 0,0037 \\
\hline 5 & $85,6 \%$ & 0,0038 & $85,6 \%$ & 0,0026 & $85,5 \%$ & 0,0028 \\
\hline & Área & ${\widehat{\bar{Y}_{d}}}^{C L U}$ & $E Q M_{d}^{C L U}$ & ${\widehat{\widehat{Y}_{d}}}^{A R}$ & \multicolumn{2}{|l|}{$E Q M_{d}^{A R}$} \\
\hline & 1 & $66,3 \%$ & 0,0058 & $66,2 \%$ & \multicolumn{2}{|l|}{0,0068} \\
\hline & 2 & $71,4 \%$ & 0,0056 & $71,1 \%$ & \multicolumn{2}{|l|}{0,0063} \\
\hline & 3 & $75,9 \%$ & 0,0045 & $75,6 \%$ & \multicolumn{2}{|l|}{0,0052} \\
\hline & 4 & $78,9 \%$ & 0,0041 & $79,5 \%$ & \multicolumn{2}{|l|}{0,0045} \\
\hline & 5 & $82,2 \%$ & 0,0035 & $82,4 \%$ & \multicolumn{2}{|l|}{0,0038} \\
\hline
\end{tabular}

\subsection{Comparação das estimativas}

Ao longo das seções anteriores deste capítulo apresentamos nosso estudo de simulação de dados diferenciando a forma de obtenção da variável resposta $y_{d j}, d=1, \cdots, 5$, pois o cálculo da probabilidade de sucesso, da escola ter professores que utilizam a Internet com os alunos para atividades de ensino-aprendizagem, $p_{d j}$, levou em consideração a presença de efeitos aleatórios apenas no intercepto, no intercepto e na inclinação e sem efeitos aleatórios. Uma limitação conhecida deste estudo é que para o caso da Seção 5.1, o modelo geral apresenta os melhores resultados por ser o modelo mais parecido com a forma de obtenção da população, assim como na Seção 5.2, o modelo de intercepto aleatório tem esse favorecimento. O intuito da Seção 5.3 é acrescentar uma aleatoridade que não será modelada em nenhuma das abordagens, não favorecendo nenhuma delas.

Independentemente da forma de obtenção da população simulada, o estimador direto e o modelo por área não apresentaram um bom desempenho, sendo as abordagens com os maiores EQM. Dessa maneira, essas abordagens não são recomendadas para a obtenção de estimativas confiáveis para a proporção de escolas em que os professores usam a Internet com os alunos para atividades de ensino-aprendizagem.

O modelo por cluster apresentou um desempenho mediano, pois o EQM para as áreas 1, 2 e 3 são melhores, pois são menores, que o modelo geral quando a população considera efeitos aleatórios na sua obtenção. Dessa maneira, acreditamos que é preciso acrescentar novas variáveis para a análise de agrupamentos e também rever o número de grupos a serem formados, para que os modelos possam captar melhor a homogeneidade dos agrupamentos e, assim, aumentar o poder de preditividade.

A existência de informações para todas as unidades da população é extremamente útil, pois 


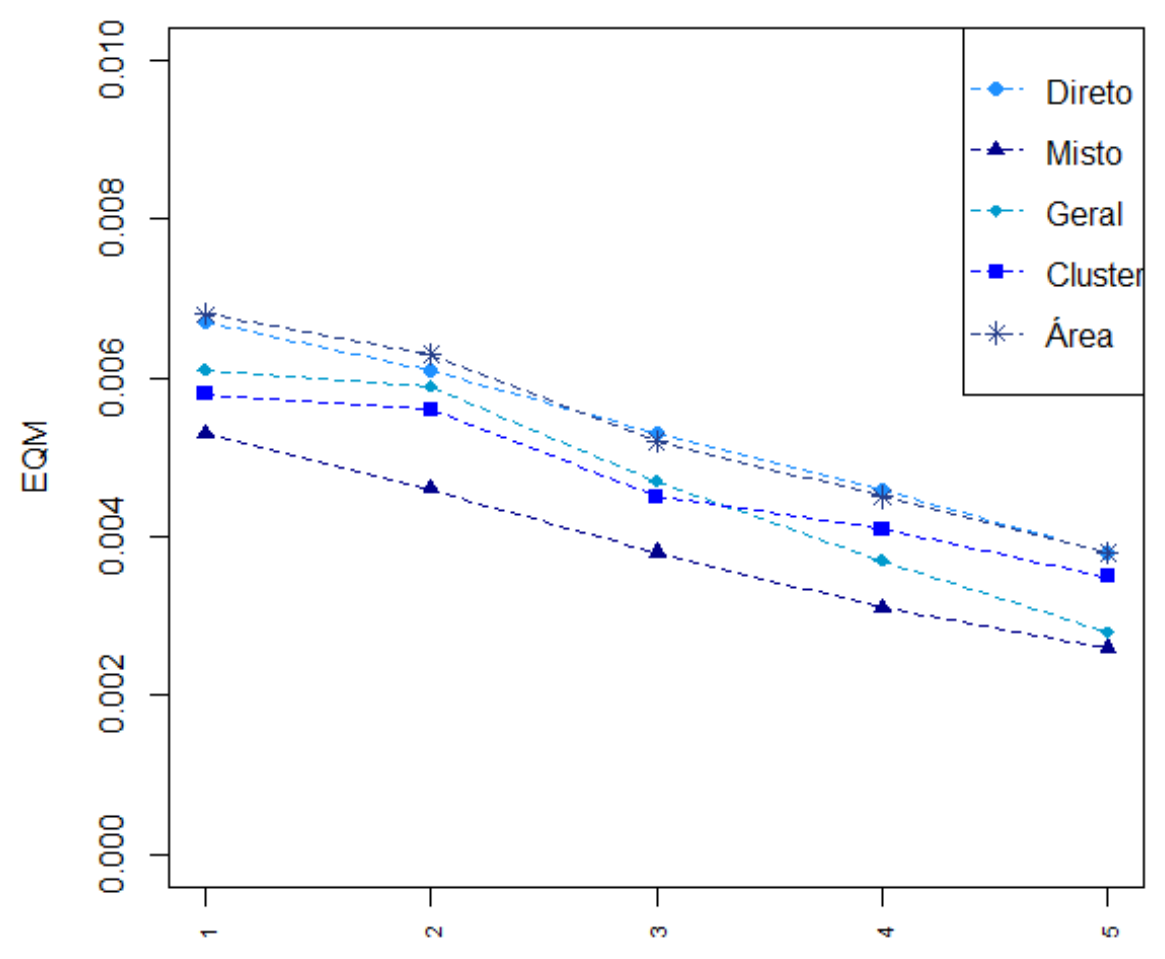

Área

Figura 5.3: EQM obtidos na simulação com a população determinada pelo modelo de intercepto e inclinação aleatórios

o ganho na qualidade das estimativas é notório quando comparando as estimativas provenientes do estimador direto, que utiliza apenas as informações das unidades amostradas, e as obtidas pelo modelo geral, que é considerado o modelo mais simples dentre todas as abordagens utilizadas nesta dissertação, mas que considera as informações de toda a população na predição. Ao compararmos as abordagens do modelo geral e do modelo de efeitos aleatórios, notamos que o segundo apresenta um comportamento mais homogêneo nas diferentes simulações, pois mesmo acrescentando um ruído na população que não é modelado, ele obteve valores pequenos para o EQM, que representa o quanto, em média, a estimativa obtida, $\widehat{\overline{Y_{d}}}$, está distante do verdadeiro valor, $\overline{Y_{d}}$. Assim, consideramos que o modelo de efeitos aleatórios é o modelo mais adequado à necessidade de obter estimativas confiáveis para a proporção de escolas em que os professores utilizam a Internet com os alunos para atividade de ensino-aprendizagem em pequenas áreas. 


\section{Capítulo 6}

\section{Conclusões}

Neste capítulo apresentamos as conclusões finais desta dissertação. Comparamos as estimativas obtidas pelos diferentes métodos no conjunto de dados reais e a partir dos dados simulados, indicando o método mais vantajoso. Apresentamos também uma seção com os trabalhos a serem desenvolvidos no futuro, para que cada vez mais os indicadores possam ser aprimorados e assim gerar estimativas mais precisas e confiáveis que servirão de insumos para o fomento de políticas públicas, principalmente, na área de tecnologia educacional.

\subsection{Considerações finais}

Ao longo desta dissertação foram enunciadas diversas abordagens com o intuito de comparar as estimativas da proporção de escolas em que os professores usam a Internet para atividades de ensino-aprendizagem com os alunos para pequenas áreas. A metodologia de SAE vem avançando muito rapidamente, pois o interesse na obtenção de resultados confiáveis para domínios com uma amostra pequena é extremamente importante e necessária quando os recursos estão se tornando escassos. Pesquisas que tenham informações disponíveis no nível de unidade devem ser exaustivamente utilizadas para servirem como insumos para a construção dos modelos, pois acabam "emprestando" informações para áreas semelhantes e com isso aprimorando a precisão das estimativas. O que pode ser notado com o ganho de precisão quando comparamos as estimativas provenientes do estimador direto com o modelo de efeitos aleatórios, que é o modelo mais utilizado na literatura.

Ao longo do Capítulo 4 aplicamos as abordagens enunciadas no Capítulo 3 a um conjunto de dados reais, o caso da TIC Educação, tal que o modelo de efeitos aleatórios é a abordagem que apresenta os resultados mais homogêneos e é considerada superior às demais abordagens. Resultado esse corroborado pelos dados simulados apresentados no Capítulo 5, que confirmam o que já está presente nas principais referências da metodologia de SAE: o modelo que considera o efeito das pequenas áreas como efeito aleatório é o que produz resultados mais precisos para a estimação de proporções para pequenas áreas. Dessa forma, para o conjunto de dados reais utilizados, o modelo que deve ser utilizado para estimar proporções para pequenas áreas é o modelo de efeitos aleatórios. Recomendamos que para o cálculo de proporções para outros conjuntos de dados, sejam consideradas as mesmas abordagens e a que apresentar o menor EQM seja utilizada para fins de divulgação das estimativas.

Nesta dissertação também abarcamos duas abordagens que não são encontradas facilmente na literatura: o modelo por cluster e o modelo de efeitos aleatórios e efeito do plano amostral. A pri- 
meira apresentou bons resultados, próximos aos obtidos pela modelagem com efeito aleatório. A segunda além de considerar o efeito aleatório da pequena área considerou o efeito do plano amostral complexo, porém por uma limitação do software utilizado não foi possível avançar no desenvolvimento dos modelos sob essa metodologia, mas julgamos que estudos futuros nessa abordagem devem ser realizados.

\subsection{Trabalhos futuros}

Para atingir o objetivo principal desta dissertação que é a obtenção de estimativas confiáveis para a proporção de escolas em que os professores usam a Internet com os alunos em atividades de ensinoaprendizagem, podemos considerar outras técnicas estatísticas para a construção de modelos e comparar com as estimativas já alcançadas, visando eleger o método mais eficiente. Alguns métodos que podem ser utilizados são a construção de modelos não paramétricos; modelos de acordo com a abordagem Bayesiana; inclusão de estruturas de correlação temporal e/ou espacial também podem ser introduzidas, uma vez que a pesquisa TIC Educação e o Censo Escolar são coletados anualmente e possuem as informações necessárias para o georreferenciamento. Além disso, esses resultados podem ser expandidos para outras variáveis de interesse, bem como para domínios ou áreas ainda menores, por exemplo para as capitais e regiões metropolitanas das UF.

Os livros e demais referências sobre estimação em pequenas áreas não são extensivos e aprofundados na teoria e aplicação de modelos logísticos, há pouca coisa na área desenvolvida utilizando pesos amostrais. Assim, essa também é uma frente que pode ser melhor explorada.

Como o uso das tecnologias não depende exclusivamente da gestão escolar e dos recursos disponíveis, também é importante avaliar o conhecimento e habilidade de alunos e professores. Em geral, as pesquisas educacionais são realizadas com diferentes atores escolares, como é o caso da pesquisa TIC Educação, tal que após a seleção das escolas, são selecionadas turmas e posteriormente, alunos e professores. Uma teoria já desenvolvida e aceita pela comunidade científica é o uso de estruturas hierárquicas na construção de modelos, assim pode-se adicionar, também, efeitos aleatórios para desenhos amostrais de múltiplos estágios. Com isso, é possível utilizar as informações declaradas por alunos e professores para compreender o uso dessas tecnologias no processo de ensino-aprendizagem visando uma melhoria na educação básica no Brasil. 


\section{Apêndice A}

\section{Tabelas adicionais}

Tabela A.1: Tamanho da população e tamanho da amostra, por UF

\begin{tabular}{c|c|c}
\hline $\mathrm{UF}$ & $N_{d}$ & $n_{d}$ \\
\hline $\mathrm{AC}$ & 273 & 13 \\
$\mathrm{AL}$ & 1161 & 11 \\
$\mathrm{AM}$ & 1142 & 42 \\
$\mathrm{AP}$ & 248 & 10 \\
$\mathrm{BA}$ & 5932 & 46 \\
$\mathrm{CE}$ & 3377 & 29 \\
$\mathrm{DF}$ & 742 & 40 \\
$\mathrm{ES}$ & 1234 & 3 \\
$\mathrm{GO}$ & 2862 & 62 \\
$\mathrm{MA}$ & 2505 & 14 \\
$\mathrm{MG}$ & 7092 & 52 \\
$\mathrm{MS}$ & 841 & 33 \\
$\mathrm{MT}$ & 1095 & 31 \\
$\mathrm{PA}$ & 2596 & 79 \\
$\mathrm{~PB}$ & 2081 & 25 \\
$\mathrm{PE}$ & 3981 & 39 \\
$\mathrm{PI}$ & 1630 & 16 \\
$\mathrm{PR}$ & 4621 & 72 \\
$\mathrm{RJ}$ & 6748 & 30 \\
$\mathrm{RN}$ & 1520 & 12 \\
$\mathrm{RO}$ & 492 & 18 \\
$\mathrm{RR}$ & 150 & 3 \\
$\mathrm{RS}$ & 3955 & 78 \\
$\mathrm{SC}$ & 2299 & 42 \\
$\mathrm{SE}$ & 856 & 8 \\
$\mathrm{SP}$ & 13396 & 107 \\
$\mathrm{TO}$ & 735 & 12 \\
\hline
\end{tabular}


Tabela A.2: Proporção da variável de interesse P44_TOTAL, por UF, para as observações da amostra da pesquisa TIC Educação

\begin{tabular}{c|c|c}
\hline UF & Não (\%) & Sim (\%) \\
\hline AC & 23 & 77 \\
AL & 27 & 73 \\
AM & 24 & 76 \\
AP & 20 & 80 \\
BA & 22 & 78 \\
CE & 24 & 76 \\
DF & 15 & 85 \\
ES & 33 & 67 \\
GO & 16 & 84 \\
MA & 29 & 71 \\
MG & 23 & 77 \\
MS & 0 & 100 \\
MT & 10 & 90 \\
PA & 22 & 78 \\
PB & 32 & 68 \\
PE & 15 & 85 \\
PI & 25 & 75 \\
PR & 1 & 99 \\
RJ & 10 & 90 \\
RN & 33 & 67 \\
RO & 11 & 89 \\
RR & 33 & 67 \\
RS & 6 & 94 \\
SC & 2 & 98 \\
SE & 13 & 88 \\
SP & 10 & 90 \\
TO & 0 & 100 \\
\hline & &
\end{tabular}


Tabela A.3: Estimativas, erros-padrão, estatísticas t e valores-p do modelo geral

\begin{tabular}{ccccc}
\hline & Estimativa & Erro-padrão & valor $t$ & valor $-p$ \\
\hline INTERCEPTO & 4,16 & 2,14 & 1,94 & 0,05 \\
ID_DEPENDENCIA_ADM Municipais & $-1,13$ & 0,35 & $-3,28$ & 0,001 \\
ID_DEPENDENCIA_ADMParticulares & 0,33 & 0,78 & 0,43 & 0,67 \\
NUM_EQUIP_MULTIMIDIA & $-0,06$ & 0,03 & $-1,85$ & 0,06 \\
NUM_COMP_ALUNOS & 0,05 & 0,03 & 2,04 & 0,04 \\
ID_INTERNET & 1,74 & 0,64 & 2,73 & 0,01 \\
ID_BANDA_LARGA & 0,66 & 0,36 & 1,82 & 0,07 \\
MED_IDADE & $-0,11$ & 0,05 & $-2,32$ & 0,02 \\
ID_PROF_INF & 1,84 & 0,61 & 3,03 & 0,002 \\
REGIAOSordeste & $-0,80$ & 0,43 & $-1,85$ & 0,06 \\
REGIAOSudeste & $-0,46$ & 0,47 & $-1,00$ & 0,32 \\
REGIAOSul & 0,24 & 0,62 & 0,39 & 0,70 \\
REGIAOCentro-Oeste & $-0,44$ & 0,52 & $-0,85$ & 0,40 \\
\hline
\end{tabular}

Tabela A.4: Estimativas, erros-padrão, estatísticas t e valores-p do modelo para a região Norte

\begin{tabular}{ccccc}
\hline & Estimativa & Erro-padrão & valor $t$ & valor $-p$ \\
\hline INTERCEPTO & $-0,40$ & 1,12 & $-0,36$ & 0,71 \\
NUM_SALAS_UTILIZADAS & $-0,06$ & 0,05 & $-1,23$ & 0,21 \\
ID_INTERNET & 1,71 & 0,81 & 2,10 & 0,03 \\
NUM_COMPUTADORES & 0,21 & 0,15 & 1,44 & 0,15 \\
NUM_COMP_ALUNOS & $-0,21$ & 0,14 & $-1,55$ & 0,12 \\
QT__DOCENTES & 0,01 & 0,01 & 1,23 & 0,22 \\
\hline
\end{tabular}

Tabela A.5: Estimativas, erros-padrão, estatísticas $t$ e valores-p do modelo para a região Nordeste

\begin{tabular}{ccccc}
\hline & Estimativa & Erro-padrão & valor $t$ & valor $-p$ \\
\hline INTERCEPTO & $-1,77$ & 0,92 & $-1,94$ & 0,05 \\
ID_DEPENDENCIA_ADM Municipais & $-0,20$ & 0,56 & $-0,36$ & 0,72 \\
ID_DEPENDENCIA_ADM $M_{\text {Particulares }}$ & 1,83 & 0,70 & 2,63 & 0,01 \\
NUM_COMPUTADORES & 0,07 & 0,03 & 2,37 & 0,02 \\
ID_INTERNET & 1,44 & 0,71 & 2,03 & 0,04 \\
\hline
\end{tabular}


Tabela A.6: Estimativas, erros-padrão, estatísticas t e valores-p do modelo para a região Sudeste

\begin{tabular}{ccccc}
\hline & Estimativa & Erro-padrão & valor $t$ & valor $-p$ \\
\hline INTERCEPTO & 12,88 & 3,49 & 3,69 & 0,0002 \\
ID_DEPENDENCIA_ADM Municipais & $-1,26$ & 0,63 & $-2,01$ & 0,05 \\
ID_DEPENDENCIA_ADM & 0,24 & 1,07 & 0,23 & 0,82 \\
ID_LABORATORIO_ulares & $-2,19$ & 1,49 & $-1,47$ & 0,14 \\
NUM_EQUIP_MULORMATICA & $-0,19$ & 0,15 & $-1,37$ & 0,17 \\
NUM_COMPUTADORES & $-0,05$ & 0,03 & $-1,47$ & 0,14 \\
NUM_COMP_ALUNOS & 0,12 & 0,06 & 2,00 & 0,05 \\
MED_IDADE & $-0,21$ & 0,07 & $-3,29$ & 0,001 \\
ID_PROF_INF & 19,21 & 3,43 & 5,61 & 0,0008 \\
\hline
\end{tabular}

Tabela A.7: Estimativas, erros-padrão, estatísticas t e valores-p do modelo para a região Sul

\begin{tabular}{ccccc}
\hline & Estimativa & Erro-padrão & valor $t$ & valor $-p$ \\
\hline INTERCEPTO & 0,19 & 1,42 & 0,14 & 0,89 \\
NUM_SALAS_UTILIZADAS & $-0,28$ & 0,10 & $-3,02$ & 0,002 \\
NUM_COMPUTADORES & 1,31 & 0,47 & 2,77 & 0,01 \\
NUM_COMP_ALUNOS & $-1,22$ & 0,45 & $-2,72$ & 0,01 \\
ID_PROF_INF & 18,37 & 1,21 & 15,22 & 0,000 \\
\hline
\end{tabular}

Tabela A.8: Estimativas, erros-padrão, estatísticas $t$ e valores- $p$ do modelo para a região Centro-Oeste

\begin{tabular}{ccccc}
\hline & Estimativa & Erro-padrão & valor $t$ & valor $-p$ \\
\hline INTERCEPTO & $-7,23$ & 3,57 & $-2,03$ & 0,04 \\
ID_LABORATORIO_INFORMATICA & 2,13 & 1,76 & 1,21 & 0,23 \\
NUM_EQUIP_MULTIMIDIA & $-0,28$ & 0,16 & $-1,73$ & 0,09 \\
NUM_COMPUTADORES & 0,39 & 0,22 & 1,77 & 0,08 \\
NUM_COMP_ALUNOS & $-0,42$ & 0,24 & $-1,79$ & 0,08 \\
ID_INTERNET & 20,84 & 1,50 & 13,87 & 0,000 \\
ID_BANDA_LARGA & $-1,47$ & 1,13 & $-1,31$ & 0,19 \\
MED_IDADE & $-0,32$ & 0,11 & $-3,00$ & 0,003 \\
QT_DOCENTES & 0,01 & 0,01 & 1,50 & 0,14 \\
ID_PROF_INF & $-1,59$ & 1,35 & $-1,18$ & 0,24 \\
\hline
\end{tabular}


Tabela A.9: Estimativas, erros-padrão, estatísticas $t$ e valores-p do modelo para o grupo 1

\begin{tabular}{ccccc}
\hline & Estimativa & Erro-padrão & valor $t$ & valor $-p$ \\
\hline INTERCEPTO & 4,75 & 1,98 & 2,41 & 0,02 \\
ID_INTERNET & 2,75 & 0,94 & 2,93 & 0,003 \\
MED_IDADE & $-0,14$ & 0,05 & $-3,14$ & 0,001 \\
QT_DOCENTES & 0,008 & 0,004 & 1,97 & 0,05 \\
REGIAONordeste & $-0,02$ & 0,56 & $-0,04$ & 0,97 \\
REGIAOSudeste & $-0,20$ & 0,51 & $-0,40$ & 0,69 \\
REGIAOSul & 2,69 & 1,08 & 2,49 & 0,01 \\
REGIAO Centro-Oeste & 0,31 & 0,55 & 0,57 & 0,57 \\
\hline
\end{tabular}

Tabela A.10: Estimativas, erros-padrão, estatísticas $t$ e valores-p do modelo para o grupo 2

\begin{tabular}{ccccc}
\hline & Estimativa & Erro-padrão & valor $t$ & valor $-p$ \\
\hline INTERCEPTO & 2,46 & 2,64 & 0,93 & 0,35 \\
ID_DEPENDENCIA_ADM & 1,41 & 0,77 & 1,83 & 0,07 \\
NUarticulares & 0,36 & 0,14 & 2,64 & 0,01 \\
MEOMPUTADORES & $-0,11$ & 0,07 & $-1,58$ & 0,11 \\
\hline
\end{tabular}

Tabela A.11: Estimativas, erros-padrão, estatísticas $t$ e valores-p do modelo para o grupo 3

\begin{tabular}{ccccc}
\hline & Estimativa & Erro-padrão & valor $t$ & valor $-p$ \\
\hline INTERCEPTO & $-2,08$ & 1,06 & $-1,96$ & 0,04 \\
ID_INTERNET & 2,16 & 1,14 & 1,90 & 0,05 \\
\hline
\end{tabular}


Tabela A.12: Estimativas, erros-padrão, estatísticas $t$ e valores-p do modelo para o grupo 4

\begin{tabular}{ccccc}
\hline & Estimativa & Erro-padrão & valor $t$ & valor $-p$ \\
\hline INTERCEPTO & $-1,39$ & 0,59 & $-2,37$ & 0,02 \\
NUM_SALAS_UTILIZADAS & $-0,09$ & 0,03 & $-2,69$ & 0,01 \\
NUM_COMPUTADORES & 0,33 & 0,09 & 3,56 & 0,0003 \\
NUM_COMP_ALUNOS & $-0,28$ & 0,10 & $-2,82$ & 0,004 \\
ID_BANDA_LARGA & 1,80 & 0,39 & 4,63 & 0,0000 \\
QT_DOCENTES & 0,01 & 0,01 & 1,49 & 0,14 \\
ID_PROF_INF & 1,53 & 0,89 & 1,72 & 0,08 \\
\hline
\end{tabular}

Tabela A.13: Estimativas, erros-padrão, estatísticas $t$ e valores-p do modelo para o grupo 5

\begin{tabular}{ccccc}
\hline & Estimativa & Erro-padrão & valor $t$ & valor $-p$ \\
\hline INTERCEPTO & 10,74 & 4,18 & 2,57 & 0,01 \\
MED_IDADE & $-0,21$ & 0,10 & $-2,12$ & 0,03 \\
$Q T \_D O C E N T E S$ & 0,03 & 0,02 & 1,64 & 0,10 \\
\hline
\end{tabular}

Tabela A.14: Estimativas, erros-padrão, estatísticas t e valores-p do modelo de efeitos aleatórios

\begin{tabular}{|c|c|c|c|c|}
\hline & Estimativa & Erro-padrão & valor $t$ & valor $-p$ \\
\hline INTERCEPTO_FIXO $\left(\hat{\beta_{0}}\right)$ & 1,52 & 1,11 & 1,36 & 0,17 \\
\hline$I D \_D E P E N D E N C I \bar{A} \_A D M_{M u n i c i p a i s}$ & $-0,46$ & 0,26 & $-1,73$ & 0.08 \\
\hline ID_DEPENDENCIA_ADM Particulares & 1,04 & 0,42 & 2,48 & 0,01 \\
\hline ID_LABORATORIO_INFORMATICA & 0,84 & 0,36 & 2,32 & 0,02 \\
\hline $\bar{N}_{\text {NU_EQUIP_}} \bar{M} U L T I M I D I A$ & $-0,05$ & 0,03 & $-1,43$ & 0,15 \\
\hline NUT_COMPUTADORES & 0,04 & 0,01 & 3,06 & 0,002 \\
\hline ID_INTERNET & 1,48 & 0,46 & 3,19 & 0,001 \\
\hline$I D \_B A N D A \_L A R G A$ & 0,53 & 0,29 & 1,83 & 0,06 \\
\hline $\bar{I} D_{-} P R O F_{-} I N F$ & 0,66 & 0,49 & 1,31 & 0,18 \\
\hline$Q T \_D O C E N T E S$ & 0,009 & 0,003 & 2,18 & 0,03 \\
\hline$\overline{M E} D_{-} I D A D E$ & $-0,08$ & 0,02 & $-3,22$ & 0,001 \\
\hline
\end{tabular}

Tabela A.15: Estimativas, erros-padrão, estatísticas $t$ e valores-p do modelo de efeitos aleatórios e efeito do plano amostral

\begin{tabular}{|c|c|c|c|c|}
\hline & Estimativa & Erro-padrão & valor $t$ & valor $-p$ \\
\hline INTERCEPTO_FIXO $\left(\hat{\beta_{0}}\right)$ & 1,61 & 1,40 & 1,15 & 0,25 \\
\hline$I D \_D E P E N D E N C I \bar{A}_{-} A D M_{M u n i c i p a i s}$ & $-0,48$ & 0,15 & $-3,16$ & 0.002 \\
\hline ID_DEPENDENCIA_ADM Particulares & 1,04 & 0,51 & 2,02 & 0,04 \\
\hline ID_LABORATORIO_INFORMATICA & 0,85 & 0,35 & 2,44 & 0,01 \\
\hline $\bar{N}^{-} M_{-} E Q U I P \_\bar{M} U L T I M I D I A$ & $-0,05$ & 0,02 & $-2,25$ & 0,025 \\
\hline NU $\bar{M} \_C O M P U T A D O R E S$ & 0,04 & 0,01 & 2,51 & 0,01 \\
\hline ID_INTERNET & 1,50 & 0,36 & 4,09 & 0,000 \\
\hline$I D \_\overline{B A N D A} L A R G A$ & 0,52 & 0,27 & 1,88 & 0,06 \\
\hline$\overline{I D}{ }_{-} P R O F-I N F$ & 0,66 & 0,45 & 1,46 & 0,15 \\
\hline$Q T_{-}{ }^{-} D O C E \bar{N} T E S$ & 0,009 & 0,004 & 2,18 & 0,03 \\
\hline$\overline{M E} D_{-} I D A D E$ & $-0,08$ & 0,03 & $-2,84$ & 0,005 \\
\hline
\end{tabular}


Tabela A.16: Medidas descritivas para as populações bootstrap, segundo o modelo geral

\begin{tabular}{c|c|c|c|c|c}
\hline UF & EQM & Desvio Padrão & $1^{\circ}$ Quartil & Mediana & $3^{\circ}$ Quartil \\
\hline AC & 0,0047 & 0,0043 & 0,0016 & 0,0036 & 0,0069 \\
AL & 0,0280 & 0,0109 & 0,0202 & 0,0270 & 0,0348 \\
AM & 0,0272 & 0,0115 & 0,0190 & 0,0259 & 0,0336 \\
AP & 0,0107 & 0,0082 & 0,0049 & 0,0092 & 0,0143 \\
BA & 0,0314 & 0,0126 & 0,0224 & 0,0297 & 0,0385 \\
CE & 0,0156 & 0,0087 & 0,0090 & 0,0144 & 0,0201 \\
DF & 0,0045 & 0,0032 & 0,0022 & 0,0038 & 0,0060 \\
ES & 0,0048 & 0,0055 & 0,0008 & 0,0029 & 0,0067 \\
GO & 0,0149 & 0,0085 & 0,0085 & 0,0135 & 0,0195 \\
MA & 0,0338 & 0,0130 & 0,0250 & 0,0324 & 0,0413 \\
MG & 0,0110 & 0,0070 & 0,0059 & 0,0093 & 0,0151 \\
MS & 0,0027 & 0,0035 & 0,0003 & 0,0014 & 0,0038 \\
MT & 0,0042 & 0,0043 & 0,0009 & 0,0029 & 0,0058 \\
PA & 0,0533 & 0,0137 & 0,0438 & 0,0523 & 0,0616 \\
PB & 0,0444 & 0,0134 & 0,0345 & 0,0435 & 0,0525 \\
PE & 0,0453 & 0,0133 & 0,0360 & 0,0441 & 0,0540 \\
PI & 0,0299 & 0,0113 & 0,0220 & 0,0285 & 0,0364 \\
PR & 0,0055 & 0,0043 & 0,0024 & 0,0043 & 0,0074 \\
RJ & 0,0133 & 0,0080 & 0,0072 & 0,0119 & 0,0180 \\
RN & 0,0196 & 0,0098 & 0,0124 & 0,0180 & 0,0252 \\
RO & 0,0112 & 0,0065 & 0,0065 & 0,0100 & 0,0145 \\
RR & 0,0064 & 0,0064 & 0,0014 & 0,0046 & 0,0096 \\
RS & 0,0013 & 0,0022 & 0,0001 & 0,0005 & 0,0017 \\
SC & 0,0018 & 0,0023 & 0,0003 & 0,0009 & 0,0024 \\
SE & 0,0584 & 0,0149 & 0,0482 & 0,0569 & 0,0675 \\
SP & 0,0038 & 0,0037 & 0,0010 & 0,0028 & 0,0055 \\
TO & 0,0093 & 0,0062 & 0,0047 & 0,0080 & 0,0127 \\
\hline & & & & &
\end{tabular}


Tabela A.17: Medidas descritivas para as populações bootstrap, segundo o modelo por região

\begin{tabular}{c|c|c|c|c|c}
\hline UF & EQM & Desvio Padrão & $1^{\circ}$ Quartil & Mediana & $3^{\circ}$ Quartil \\
\hline AC & 0,0057 & 0,0066 & 0,0009 & 0,0035 & 0,0081 \\
AL & 0,0021 & 0,0029 & 0,0002 & 0,0010 & 0,0027 \\
AM & 0,0272 & 0,0122 & 0,0184 & 0,0257 & 0,0343 \\
AP & 0,0099 & 0,0095 & 0,0029 & 0,0073 & 0,0143 \\
BA & 0,0023 & 0,0033 & 0,0002 & 0,0010 & 0,0032 \\
CE & 0,0020 & 0,0029 & 0,0002 & 0,0009 & 0,0027 \\
DF & 0,0034 & 0,0035 & 0,0009 & 0,0024 & 0,0049 \\
ES & 0,0049 & 0,0068 & 0,0009 & 0,0028 & 0,0066 \\
GO & 0,0125 & 0,0079 & 0,0066 & 0,0110 & 0,0167 \\
MA & 0,0054 & 0,0062 & 0,0009 & 0,0031 & 0,0079 \\
MG & 0,0107 & 0,0069 & 0,0061 & 0,0094 & 0,0138 \\
MS & 0,0019 & 0,0024 & 0,0003 & 0,0010 & 0,0027 \\
MT & 0,0030 & 0,0030 & 0,0007 & 0,0021 & 0,0043 \\
PA & 0,0513 & 0,0162 & 0,0400 & 0,0501 & 0,0611 \\
PB & 0,0025 & 0,0035 & 0,0003 & 0,0011 & 0,0034 \\
PE & 0,0023 & 0,0033 & 0,0003 & 0,0011 & 0,0031 \\
PI & 0,0026 & 0,0036 & 0,0002 & 0,0011 & 0,0036 \\
PR & 0,0054 & 0,0032 & 0,0032 & 0,0048 & 0,0070 \\
RJ & 0,0126 & 0,0075 & 0,0072 & 0,0115 & 0,0166 \\
RN & 0,0019 & 0,0026 & 0,0002 & 0,0009 & 0,0024 \\
RO & 0,0108 & 0,0066 & 0,0061 & 0,0094 & 0,0142 \\
RR & 0,0055 & 0,0063 & 0,0009 & 0,0032 & 0,0078 \\
RS & 0,0009 & 0,0014 & 0,0001 & 0,0004 & 0,0011 \\
SC & 0,0016 & 0,0019 & 0,0002 & 0,0010 & 0,0023 \\
SE & 0,0021 & 0,0029 & 0,0002 & 0,0009 & 0,0027 \\
SP & 0,0035 & 0,0038 & 0,0012 & 0,0028 & 0,0049 \\
TO & 0,0096 & 0,0072 & 0,0044 & 0,0081 & 0,0127 \\
\hline & & & & & \\
\hline & & &
\end{tabular}


Tabela A.18: Medidas descritivas para as populações bootstrap, segundo o modelo por cluster

\begin{tabular}{c|c|c|c|c|c}
\hline UF & EQM & Desvio Padrão & $1^{\circ}$ Quartil & Mediana & $3^{\circ}$ Quartil \\
\hline AC & 0,0012 & 0,00173 & 0,00011 & 0,00166 & 0,00052 \\
AL & 0,0007 & 0,00100 & 0,00006 & 0,00101 & 0,00034 \\
AM & 0,0007 & 0,00102 & 0,00008 & 0,00098 & 0,00037 \\
AP & 0,0015 & 0,00218 & 0,00015 & 0,00206 & 0,00072 \\
BA & 0,0009 & 0,00113 & 0,00011 & 0,00121 & 0,00044 \\
CE & 0,0005 & 0,00068 & 0,00006 & 0,00078 & 0,00025 \\
DF & 0,0006 & 0,00089 & 0,00007 & 0,00088 & 0,00027 \\
ES & 0,0004 & 0,00049 & 0,00004 & 0,00046 & 0,00018 \\
GO & 0,0003 & 0,00047 & 0,00003 & 0,00044 & 0,00014 \\
MA & 0,0033 & 0,00269 & 0,00123 & 0,00476 & 0,00286 \\
MG & 0,0005 & 0,00066 & 0,00006 & 0,00069 & 0,00024 \\
MS & 0,0003 & 0,00041 & 0,00003 & 0,00036 & 0,00011 \\
MT & 0,0004 & 0,00049 & 0,00004 & 0,00048 & 0,00016 \\
PA & 0,0007 & 0,00102 & 0,00009 & 0,00097 & 0,00035 \\
PB & 0,0008 & 0,00109 & 0,00009 & 0,00113 & 0,00039 \\
PE & 0,0008 & 0,00106 & 0,00007 & 0,00110 & 0,00036 \\
PI & 0,0010 & 0,00127 & 0,00011 & 0,00156 & 0,00051 \\
PR & 0,0003 & 0,00041 & 0,00003 & 0,00034 & 0,00012 \\
RJ & 0,0004 & 0,00056 & 0,00004 & 0,00051 & 0,00019 \\
RN & 0,0008 & 0,00113 & 0,00007 & 0,00098 & 0,00035 \\
RO & 0,0005 & 0,00075 & 0,00006 & 0,00074 & 0,00027 \\
RR & 0,0015 & 0,00213 & 0,00016 & 0,00203 & 0,00070 \\
RS & 0,0002 & 0,00024 & 0,00002 & 0,00023 & 0,00008 \\
SC & 0,0002 & 0,00025 & 0,00002 & 0,00023 & 0,00009 \\
SE & 0,0007 & 0,00105 & 0,00008 & 0,00094 & 0,00035 \\
SP & 0,0004 & 0,00048 & 0,00004 & 0,00049 & 0,00018 \\
TO & 0,0007 & 0,00108 & 0,00006 & 0,00089 & 0,00026 \\
\hline & & & & & \\
& & &
\end{tabular}


Tabela A.19: Medidas descritivas para as populações bootstrap, segundo o modelo de efeitos aleatórios

\begin{tabular}{c|c|c|c|c|c}
\hline UF & EQM & Desvio Padrão & $1^{\circ}$ Quartil & Mediana & $3^{\circ}$ Quartil \\
\hline AC & 0,0015 & 0,0002 & 0,0007 & 0,0020 & 0,0021 \\
AL & 0,0015 & 0,0001 & 0,0006 & 0,0020 & 0,0022 \\
AM & 0,0015 & 0,0002 & 0,0006 & 0,0020 & 0,0023 \\
AP & 0,0023 & 0,0003 & 0,0011 & 0,0030 & 0,0035 \\
BA & 0,0015 & 0,0001 & 0,0007 & 0,0020 & 0,0021 \\
CE & 0,0014 & 0,0001 & 0,0006 & 0,0017 & 0,0020 \\
DF & 0,0004 & 0,0000 & 0,0002 & 0,0006 & 0,0007 \\
ES & 0,0010 & 0,0001 & 0,0005 & 0,0012 & 0,0018 \\
GO & 0,0009 & 0,0001 & 0,0005 & 0,0013 & 0,0012 \\
MA & 0,0055 & 0,0013 & 0,0040 & 0,0080 & 0,0055 \\
MG & 0,0010 & 0,0001 & 0,0004 & 0,0013 & 0,0015 \\
MS & 0,0007 & 0,0001 & 0,0003 & 0,0009 & 0,0011 \\
MT & 0,0008 & 0,0001 & 0,0003 & 0,0010 & 0,0014 \\
PA & 0,0016 & 0,0002 & 0,0006 & 0,0022 & 0,0022 \\
PB & 0,0025 & 0,0003 & 0,0013 & 0,0035 & 0,0033 \\
PE & 0,0024 & 0,0003 & 0,0013 & 0,0034 & 0,0032 \\
PI & 0,0020 & 0,0002 & 0,0010 & 0,0028 & 0,0027 \\
PR & 0,0008 & 0,0001 & 0,0004 & 0,0011 & 0,0012 \\
RJ & 0,0011 & 0,0001 & 0,0005 & 0,0015 & 0,0017 \\
RN & 0,0018 & 0,0002 & 0,0008 & 0,0023 & 0,0027 \\
RO & 0,0012 & 0,0001 & 0,0006 & 0,0016 & 0,0019 \\
RR & 0,0019 & 0,0002 & 0,0009 & 0,0024 & 0,0028 \\
RS & 0,0009 & 0,0001 & 0,0004 & 0,0011 & 0,0013 \\
SC & 0,0008 & 0,0001 & 0,0003 & 0,0009 & 0,0013 \\
SE & 0,0021 & 0,0002 & 0,0010 & 0,0029 & 0,0029 \\
SP & 0,0006 & 0,0001 & 0,0003 & 0,0007 & 0,0009 \\
TO & 0,0014 & 0,0001 & 0,0006 & 0,0019 & 0,0022 \\
\hline
\end{tabular}




\section{Referências Bibliográficas}

Albieri (2006) ALBIERI, S. Pesquisas por amostragem: política de divulgação de estimativas com baixa precisão amostral. Em II encontro nacional de produtores e usuários de informações sociais, econômicas e territoriais. V Conferência Nacional de Estatística. URL http://www.ibge. gov.br/confest_e_confege/pesquisa_trabalhos/CD/mesas_redondas/294-3.pdf. Acesso em: 16/05/2016. Citado na pág. 27,28

Albino (2015) ALBINO, R. D. Uma visão integrada sobre o nível de uso das tecnologias da informação e comunicação em escolas brasileiras. Dissertação de Mestrado, Faculdade de Economia, Administração e Contabilidade, Universidade de São Paulo, Brasil. Citado na pág. 1, 2, 4

Barbosa et al. (2004) BARBOSA, E. F., MOURA, D. G. e BARBOSA, A. F. Inclusão das tecnologias de informação e comunicação na educação através de projetos. Em Congresso anual de tecnologia de informação - CATI. Citado na pág. 1

Barroso e Artes (2003) BARROSO, L. P. e ARTES, R. Análise multivariada. Em Minicurso do $10^{\circ}$ simpósio de estatística aplicada à experimentação agronômica. Universidade Federal de Lavras. Citado na pág. 38

Battese et al. (1988) BATTESE, G. E., HARTER, R. M. e FULLER, W. A. An error-components model for prediction of county crop areas using survey and satellite data. Journal of the American Statistical Association, 83(401):28-36. Citado na pág. 16

Belloni (2001) BELLONI, M. L. O que é mídia-educação, volume 78. Autores Associados. Citado na pág. 1

Binder (1983) BINDER, D. A. On the variances of asymptotically normal estimators from complex surveys. International Statistical Review/Revue Internationale de Statistique, páginas 279-292. Citado na pág. 21

Bolfarine e Bussab (2005) BOLFARINE, H. e BUSSAB, W. O. Elementos de amostragem, volume 1. Edgard Blücher São Paulo. Citado na pág. 25

Casella e Berger (2002) CASELLA, G. e BERGER, R. L. Statistical inference, volume 2. Duxbury Pacific Grove, CA. Citado na pág. 22

CGI.br (2014) COMITÊ GESTOR DA INTERNET NO BRASIL. Pesquisa sobre o uso das tecnologias de informação e comunicação nas escolas brasileiras: TIC Educação 2013. Comitê Gestor da Internet no Brasil. URL http://cetic.br/media/docs/publicacoes/2/tic-educacao- 2013. pdf. Último acesso em 06/09/2015. Citado na pág. 2, 4, 5, 7, 9, 13, 33

Cochran (1977) COCHRAN, W. G. Sampling techniques. John Wiley \& Sons. Citado na pág. 17, 25

Fawcett (2006) FAWCETT, T. An introduction to roc analysis. Pattern recognition letters, 27 (8):861-874. Citado na pág. 29 
Fay e Herriot (1979) FAY, R. E. e HERRIOT, R. A. Estimates of income for small places: an application of James-Stein procedures to census data. Journal of the American Statistical Association, 74(366):269-277. Citado na pág. 15

Fu (2013) FU, J. S. Ict in education: A critical literature review and its implications. International Journal of Education and Development using Information and Communication Technology, 9(1): 112. Citado na pág. 2

González-Manteiga et al. (2007) GONZÁLEZ-MANTEIGA, W., LOMBARDÍA, M. J., MOLINA, I., MORALES, D. e SANTAMARÍA, L. Estimation of the mean squared error of predictors of small area linear parameters under a logistic mixed model. Computational statistics 6 data analysis, 51(5):2720-2733. Citado na pág. 13, 16, 22, 32, 57

Heeringa et al. (2010) HEERINGA, S. G., WEST, B. T. e BERGLUND, P. A. Applied survey data analysis. CRC Press. Citado na pág. 21, 22

INEP (2014a) INSTITUTO NACIONAL DE ESTUDOS E PESQUISAS EDUCACIONAIS ANÍSIO TEIXEIRA, MINISTÉRIO DA EDUCAÇÃO, BRASIL. Censo escolar 2013, 2014a. URL http://portal.inep.gov.br/basica-levantamentos-acessar. Acesso em: 13/10/2014. Citado na pág. 4, $5,7,9$

INEP (2014b) INSTITUTO NACIONAL DE ESTUDOS E PESQUISAS EDUCACIONAIS ANÍSIO TEIXEIRA, MINISTÉRIO DA EDUCAÇÃO, BRASIL. Censo escolar da educação básica 2013 - resumo técnico, 2014b. URL http://download.inep.gov.br/educacao_basica/ censo_escolar/resumos_tecnicos/resumo_tecnico_censo_educacao_basica_2013.pdf. Acesso em: $1 \overline{3} / 11 / 2014$. Citado na pág. 7

Jiang (1998) JIANG, J. Consistent estimators in generalized linear mixed models. Journal of the American Statistical Association, 93(442):720-729. Citado na pág. 18

Jiang (2007) JIANG, J. Linear and generalized linear mixed models and their applications. Springer Science \& Business Media. Citado na pág. 18

Liu (2009) LIU, B. Hierarchical Bayes estimation and empirical best prediction of small-area proportions. Tese de Doutorado, University of Maryland, College Park. Citado na pág. 18

Lopes et al. (2010) LOPES, R. L., FICHEMAN, I. K. , MARTINZAZZO, A. A. G., CORREA, A. G. D., VENÂNCIO, V., YIN, H. T. e BIAZON, L. C. O uso dos computadores e da internet em escolas públicas de capitais brasileiras. Estudos $\mathcal{E}$ Pesquisas Educacionais, 1:275-336. Citado na pág. 2

Lumley (2011) LUMLEY, T. Complex surveys: a guide to analysis using $R$, volume 565. John Wiley \& Sons. Citado na pág. 22

Martinez et al. (2003) MARTINEZ, E. Z., LOUZADA-NETO, F. e PEREIRA, B. B. A curva roc para testes diagnósticos. Cad Saúde Coletiva, 11(1):7-31. Citado na pág. 31

McCullagh e Nelder (1989) MCCULLAGH, P. e NELDER, J. A. Generalized linear models, volume 37. CRC press. Citado na pág. 18

Molina e Marhuenda (2015) MOLINA, I. e MARHUENDA, Y. Basic direct and indirect estimators in sae package. Citado na pág. 17

Moura (2008) MOURA, F. A. S. Estimação em pequenos domínios. Em Minicurso do $18^{\circ}$ Simpósio Nacional de Probabilidade e Estatística. Associação Brasileira de Estatística. Citado na pág. 16 
Ohlsson (1998) OHLSSON, E. Sequential Poisson sampling. Journal of official Statistics, 14(2): 149. Citado na pág. $14,23,24$

Pessoa e Silva (1998) PESSOA, D. G. C. e SILVA, P. L. N. Análise de dados amostrais complexos. São Paulo: Associação Brasileira de Estatística, 1. Citado na pág. 21

Pfeffermann (2013) PFEFFERMANN, D. New important developments in small area estimation. Statistical Science, 28(1):40-68. Citado na pág. 16

Rahman et al. (2010) RAHMAN, N., CLARKE, P., MCGRATH, K. e SILVA, D. B. N. Small area estimates of households in poverty for England and Wales. Citado na pág. 18

Rao (2003) RAO, J. N. K. Small area estimation. Wiley Online Library. Citado na pág. 15, 16

Rao e Molina (2015) RAO, J. N. K. e MOLINA, I. Small area estimation, volume 2. Wiley Online Library. Citado na pág. 16

UIS (2009) UNESCO INSTITUTE FOR STATISTICS, UNITED NATIONS EDUCATIONAL, SCIENTIFIC AND CULTURAL ORGANIZATION. Global education digest 2009: Comparing education statistics across the world, 2009. Citado na pág. 1

Unesco Brasil (2008a) UNESCO BRASIL. Computador na escola-o futuro anunciado. Revista TIC nas Escolas, 3(1). Citado na pág. 4

Unesco Brasil (2008b) UNESCO BRASIL. Computador na escola-tecnologia e aprendizagem. Revista TIC nas Escolas, 3(3). Citado na pág. 4

Wu (1986) WU, C. F. J. Jackknife, bootstrap and other resampling methods in regression analysis. the Annals of Statistics, páginas 1261-1295. Citado na pág. 22 